Prepared in cooperation with the U.S. Army Corps of Engineers

\title{
Channel Change and Bed-Material Transport in the Lower Chetco River, Oregon
}

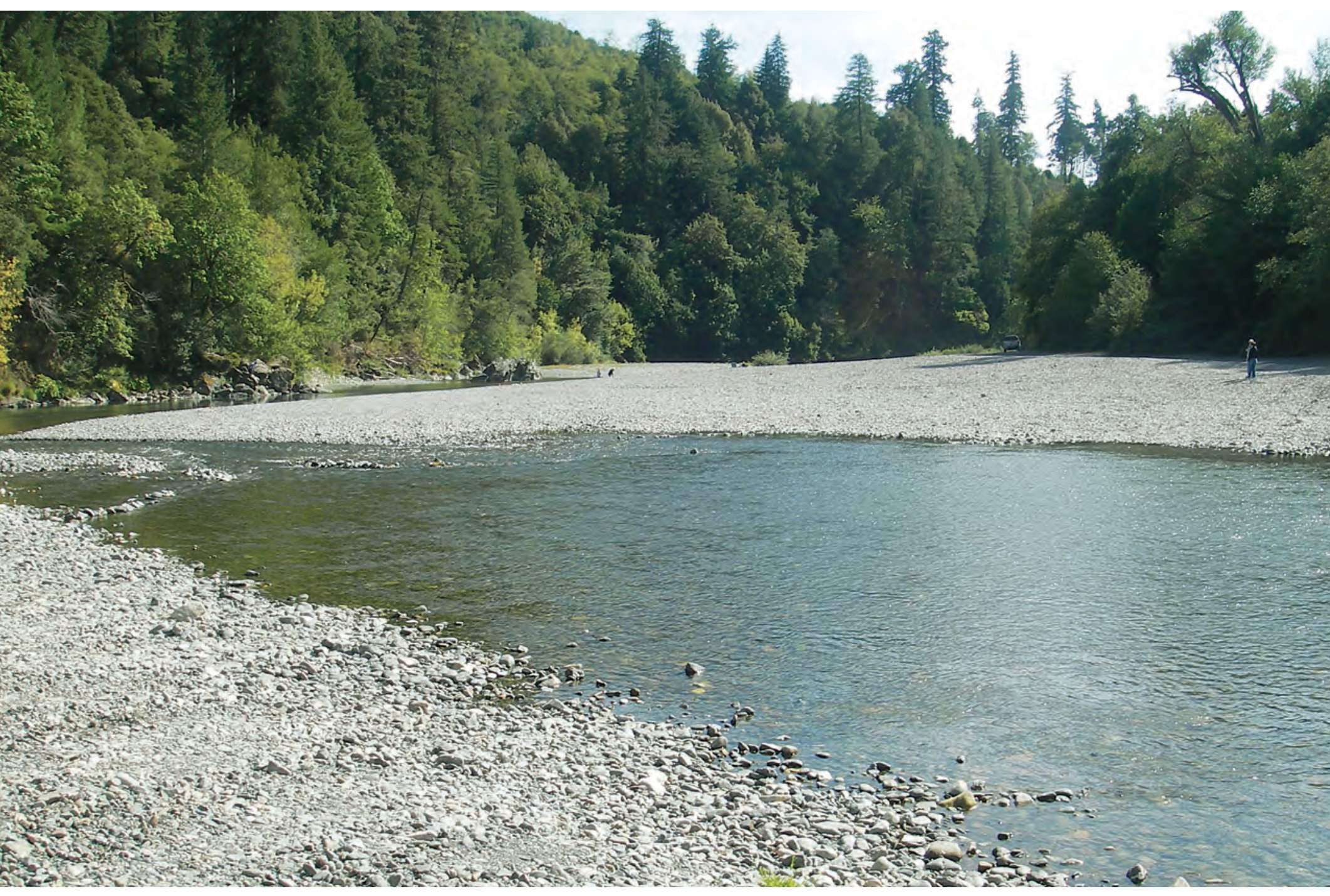

Scientific Investigations Report 2010-5065 Version 2.0, July 2012

U.S. Department of the Interior U.S. Geological Survey 
Cover: Chetco River near Alfred A. Loeb State Park. (Photograph by Jim 0'Connor, U.S. Geological Survey, September 2008. 


\section{Channel Change and Bed-Material Transport in the Lower Chetco River, Oregon}

By J. Rose Wallick, Scott W. Anderson, Charles Cannon, and Jim E. O'Connor

Prepared in cooperation with the U.S. Army Corps of Engineers

Scientific Investigations Report 2010-5065

Version 2.0, July 2012 


\title{
U.S. Department of the Interior \\ KEN SALAZAR, Secretary \\ U.S. Geological Survey \\ Marcia K. McNutt, Director
}

\author{
U.S. Geological Survey, Reston, Virginia: 2010 \\ Revised: 2012
}

\begin{abstract}
For more information on the USGS - the Federal source for science about the Earth, its natural and living resources, natural hazards, and the environment, visit http://www.usgs.gov or call 1-888-ASK-USGS

For an overview of USGS information products, including maps, imagery, and publications, visit http://www.usgs.gov/pubprod

To order this and other USGS information products, visit http://store.usgs.gov
\end{abstract}

Any use of trade, product, or firm names is for descriptive purposes only and does not imply endorsement by the U.S. Government.

Although this report is in the public domain, permission must be secured from the individual copyright owners to reproduce any copyrighted materials contained within this report.

Suggested citation:

Wallick, J.R., Anderson, S.W., Cannon, Charles, and O'Connor, J.E., 2010, Channel change and bed-material transport in the lower Chetco River, Oregon: U.S. Geological Survey Scientific Investigations Report 2010-5065, 68 p. 


\section{Contents}

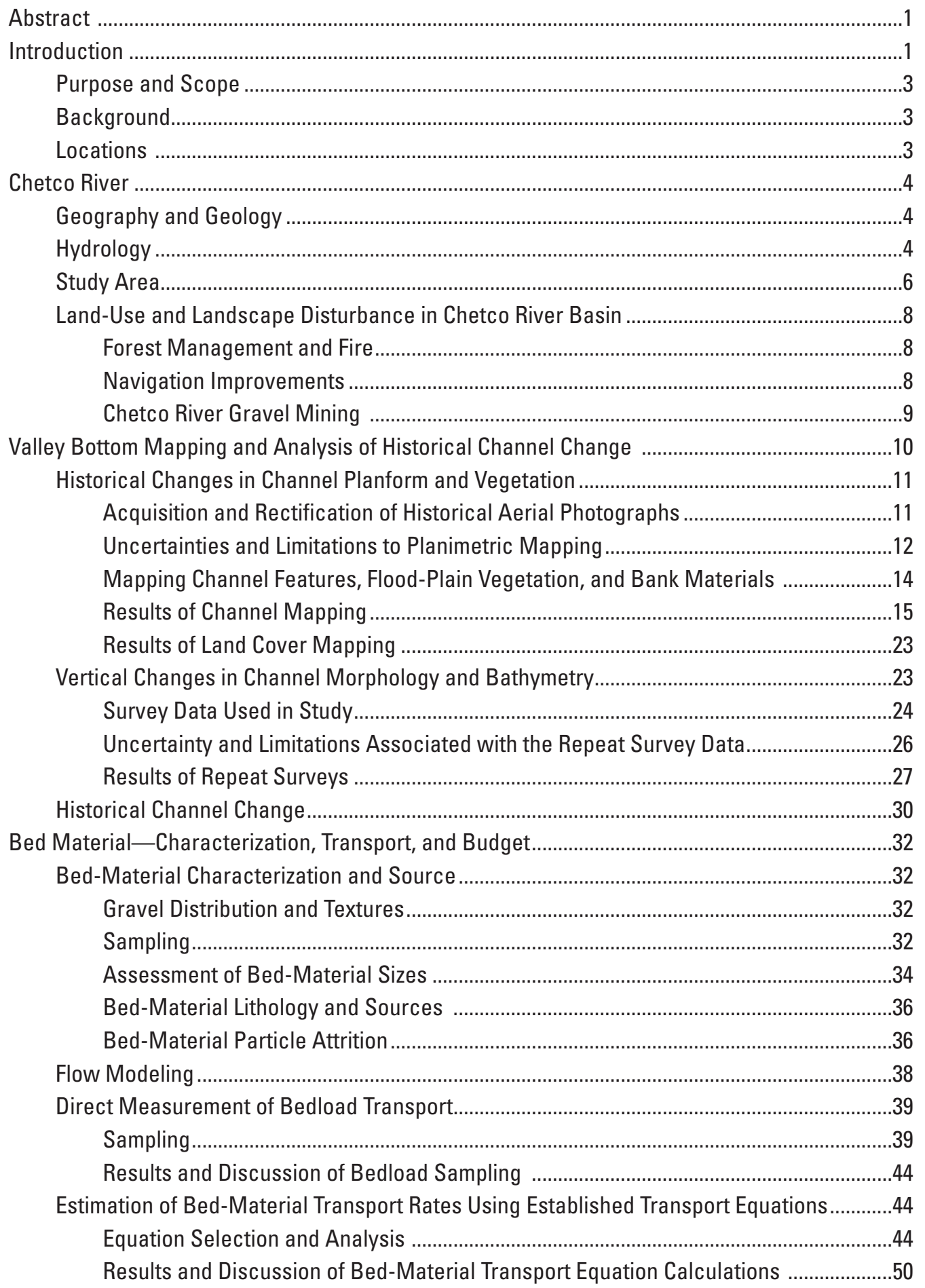




\section{Contents-Continued}

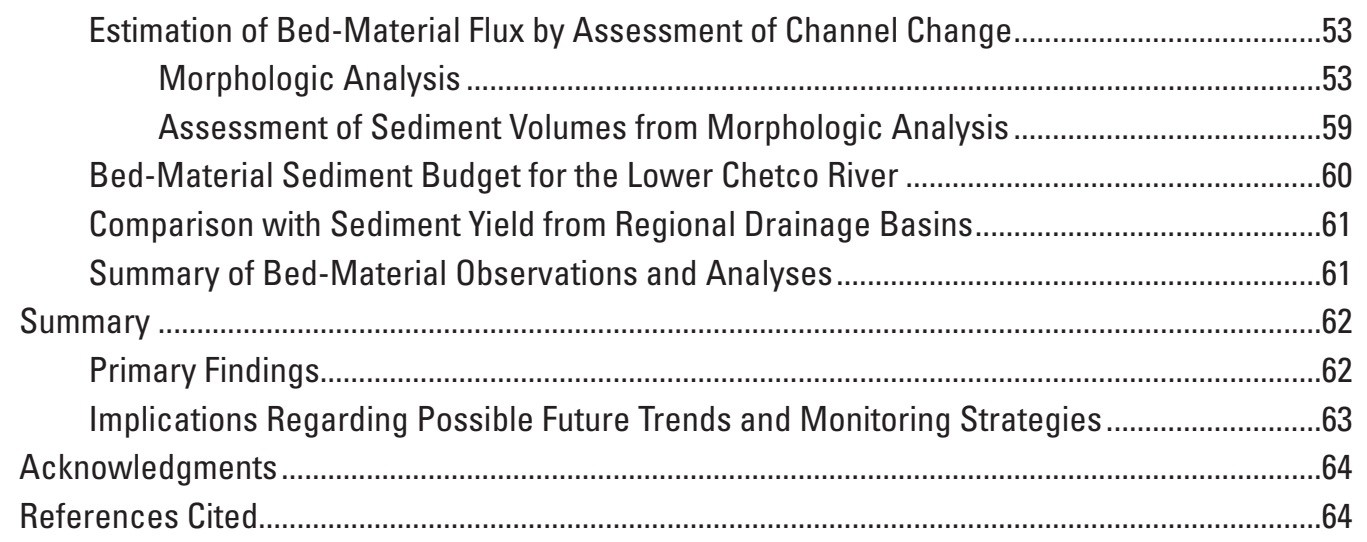

\section{Figures}

Figure 1. Map showing drainage basin and study area, Chetco River, Oregon

Figure 2. Graphs showing flow records for USGS streamflow-gaging station 14400000 ,

Chetco River near Brookings, Oregon

Figure 3. Map and orthophotograph showing example of alternate bar sequence near flood-plain kilometer 11, Chetco River, Oregon

Figure 4. Graph showing channel bed and water-surface elevations along study area, Chetco River, Oregon

Figure 5. Graph showing annual and cumulative navigational dredging volumes, 1962-2008, Chetco River, Oregon

Figure 6. Graph showing annual and cumulative extraction volume for instream commercial gravel mining, Chetco River, Oregon, 1993-2008

Figure 7. Graph showing bar area inundation compared with discharge, Chetco River, Oregon

Figure 8. Oblique photographs showing examples of landcover mapping categories, as depicted in an orthophotograph from 2005 near flood-plain kilometer 9 of the Chetco River, Oregon

Figure 9. Graphs showing summary of channel change in the study area, Chetco River, Oregon, 1939-2008.

Figure 10. Graph showing spatial and temporal variation in gravel bar area for eight time periods, Chetco River, Oregon, 1939-2008...

Figure 11. Graph showing reach-segregated distribution of bank material and revetment, Chetco River, Oregon

Figure 12. Map showing channel changes between flood-plain kilometers 0 and 4.5 encompassing the Estuary Reach, Chetco River, Oregon, 1939-2008 19

Figure 13. Map showing channel changes between flood-plain kilometers 4.5 and 8.4 encompassing the North Fork Reach, Chetco River, Oregon, 1939-2008 20

Figure 14. Map showing channel changes between flood-plain kilometers 7.5 and 11.5 encompassing the Mill Creek Reach, Chetco River, Oregon, 1939-2008 


\section{Figures-Continued}

Figure 15. Map showing channel changes between flood-plain kilometers 10.6 and 15.2 along the Emily Creek and Upper reaches, Chetco River, Oregon, 1939-2008 ..... 22

Figure 16. Graphs showing changes in flood-plain land cover by reach, Chetco River,

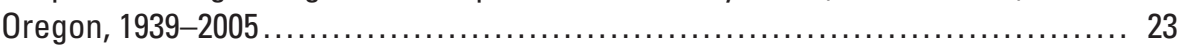

Figure 17. Map showing bathymetry for 1939 and 2008 between flood-plain kilometer 0.6

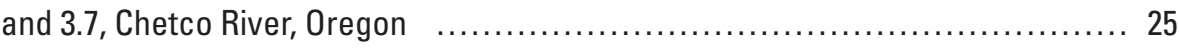

Figure 18. Graphs showing channel thalweg profiles downstream of river kilometer 18, Chetco River, Oregon .................................................. 26

Figure 19. Graphs showing cross sections from the flood study survey in 1977, digitized from Soil Conservation Service, and approximately relocated during the U.S. Geological Survey resurveys in September 2008, Chetco River, Oregon ........... 28

Figure 20. Graphs showing specific gage analysis and discharge-measurement cross sections for the USGS streamflow-gaging station, Chetco River near Brookings, Oregon.

Figure 21. Photographs showing examples of bar evolution to flood-plain and developed

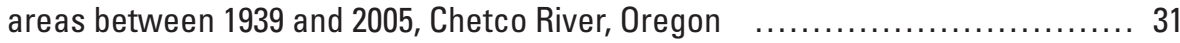

Figure 22. Graph showing longitudinal variation in surface-particle size for bar apices along the study area, Chetco River, Oregon

Figure 23. Graphs showing particle size distributions for surface and subsurface samples at Fitzhugh Bar, Chetco River, Oregon, Social Security Bar, and Tidewater Estuary Bar

Figure 24. Graphs showing variation in clast lithology and size ratio of sandstone and quartzite clasts for sites along the study area, Chetco River, Oregon

Figure 25. Graph showing surveyed channel thalweg in 2008, water-surface, bar surfaces, and water-surface profiles as calculated from HEC-RAS for flows between 50 and 2,000 cubic meters per second for the lower Chetco River, Oregon

Figure 26. Photographs showing bedload sampling at USGS streamflow-gaging station, Chetco River near Brookings, Oregon, December 28, 2008

Figure 27. Graphs showing discharge and sampling periods for bedload measurements on the Chetco River, Oregon ............................................. 42

Figure 28. Graphs showing summary flow and bedload transport data for December 28-30, 2008, and February 24-25, 2009, measurements, Chetco River, Oregon ..... 43

Figure 29. Graph showing particle size distributions for sampled bedload and Fitzhugh Bar surface and subsurface measurement, Chetco River, Oregon

Figure 30. Graphs and map showing streamflow hydraulics, calculated and measured bed-material transport, and location map for vicinity of measurement site near flood-plain kilometer 15.3 on Chetco River, Oregon

Figure 31. Graph showing mean annual calculated bed-material transport capacity for seven cross sections along the lower Chetco River, Oregon, for water years 1970-2008

Figure 32. Graph showing annual transport capacity and mean annual discharge at USGS streamflow-gaging station, Chetco River near Brookings, Oregon ....

Figure 33. Graphs showing discharge and calculated bed-material transport for water year 2002 at reference cross section at flood-plain kilometer 15.3, Chetco River, Oregon 


\section{Figures-Continued}

Figure 34. Photographs and map showing example of erosion and deposition classification for morphologic analysis near flood-plain kilometer 7, Chetco

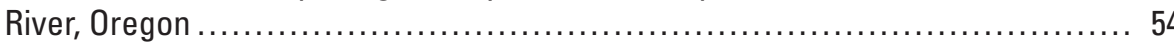

Figure 35. Graphs showing areas of bed-material deposition and erosion volumes for selected periods in the Chetco River, Oregon 55

Figure 36. Graph showing bar thickness values used to calculate erosion and deposition volumes from changes in bar area in the Chetco River, Oregon ................ 58

Figure 37. Schematic diagram of sediment budget for the lower Chetco River, Oregon $\ldots \ldots 60$

\section{Tables}

Table 1. Summary of reach attributes for the study area, Chetco River, Oregon

Table 2. Aerial photographs and orthophotographs used in the sediment transport study, Chetco River, Oregon

Table 3. Map and survey data reviewed in the sediment transport study, Chetco River, Oregon

Table 4. Sediment sampling locations used in the sediment transport study, Chetco River, Oregon

Table 5. Summary of bedload measurements for winter 2008-09, Chetco River, Oregon ... 41

Table 6. Summary of calculated transport rates for the Chetco River, Oregon 49

Table 7. Summary of morphology-based sediment-transport-volume estimates, Chetco River, Oregon .....

Table 8. Sources for estimates of bedload production rates for coastal drainage basins in northern California and southern Oregon 


\title{
Conversion Factors, Datums, and Abbreviations and Acronyms
}

\author{
Conversion Factors
}

\begin{tabular}{|c|c|c|}
\hline Multiply & By & To obtain \\
\hline \multicolumn{3}{|c|}{ Length } \\
\hline centimeter (cm) & 0.3937 & inch (in.) \\
\hline millimeter (mm) & 0.03937 & inch (in.) \\
\hline meter (m) & 3.281 & foot (ft) \\
\hline kilometer (km) & 0.6214 & mile (mi) \\
\hline \multicolumn{3}{|c|}{ Area } \\
\hline square meter $\left(\mathrm{m}^{2}\right)$ & 10.76 & square foot $\left(\mathrm{ft}^{2}\right)$ \\
\hline square kilometer $\left(\mathrm{km}^{2}\right)$ & 0.3861 & square mile $\left(\mathrm{mi}^{2}\right)$ \\
\hline \multicolumn{3}{|c|}{ Volume } \\
\hline cubic meter $\left(\mathrm{m}^{3}\right)$ & 0.0008107 & acre-foot (acre-ft) \\
\hline cubic meter $\left(\mathrm{m}^{3}\right)$ & 35.31 & cubic foot $\left(\mathrm{ft}^{3}\right)$ \\
\hline cubic meter $\left(\mathrm{m}^{3}\right)$ & 1.308 & cubic yard $\left(\mathrm{yd}^{3}\right)$ \\
\hline liter (L) & 0.03531 & cubic foot $\left(\mathrm{ft}^{3}\right)$ \\
\hline \multicolumn{3}{|c|}{ Flow rate } \\
\hline cubic meter per second $\left(\mathrm{m}^{3} / \mathrm{s}\right)$ & 35.31 & cubic foot per second $\left(\mathrm{ft}^{3} / \mathrm{s}\right)$ \\
\hline cubic meter per year (m³/yr) & 1.308 & cubic yard per year (yd³/yr) \\
\hline meter per second (m/s) & 3.281 & foot per second (ft/s) \\
\hline meter per year (m/yr) & 3.281 & foot per year (ft/yr) \\
\hline millimeter per year (mm/yr) & 0.0397 & inch per year (in/yr) \\
\hline kilogram per second (kg/s) & 2.205 & pound per second (lb/s) \\
\hline $\begin{array}{l}\text { kilogram per meter per second } \\
{[(\mathrm{kg} / \mathrm{m}) / \mathrm{s}]}\end{array}$ & 4.486 & $\begin{array}{l}\text { pound avoirdupois per foot per } \\
\text { second }[(\mathrm{lb} / \mathrm{ft}) / \mathrm{s}]\end{array}$ \\
\hline \multicolumn{3}{|c|}{ Mass } \\
\hline kilogram (kg) & 2.205 & pound avoirdupois (lb) \\
\hline
\end{tabular}

\section{Datums}

Vertical coordinate information is referenced to the North American Vertical Datum of 1988 (NAVD 88).

Horizontal coordinate information is referenced to the North American Datum of 1983 (NAD 83).

Elevation, as used in this report, refers to the distance above the vertical datum.

Abbreviations and Acronyms 


\section{Conversion Factors, Datums, and Abbreviations and Acronyms-Continued}

$\begin{array}{ll}\text { BAGS } & \text { Bedload Assessment in Gravel-bedded Streams } \\ \text { BLM } & \text { Bureau of Land Management } \\ \text { FPkm } & \text { flood-plain kilometer } \\ \text { GIS } & \text { geographic information system } \\ \text { GPS } & \text { global positioning system } \\ \text { HEC-RAS } & \text { Hydrologic Engineering Center's River Analysis System } \\ \text { ka } & \text { kiloannum, a unit of time equal to one thousand years } \\ \text { LIDAR } & \text { Light Detection and Ranging } \\ \text { MLLW } & \text { mean lower low water } \\ \text { NAIP } & \text { National Agriculture Imagery Program } \\ \text { Rkm } & \text { river kilometer } \\ \text { RMSE } & \text { root mean square error } \\ \text { RTK } & \text { real-time kinematic } \\ \text { USFS } & \text { U.S. Forest Service } \\ \text { USGS } & \text { U.S. Geological Survey } \\ \text { UTM } & \text { Universal Transverse Mercator }\end{array}$




\title{
Channel Change and Bed-Material Transport in the Lower Chetco River, Oregon
}

\author{
By J. Rose Wallick, Scott W. Anderson, Charles Cannon, and Jim E. O'Connor
}

\section{Abstract}

The lower Chetco River is a wandering gravel-bed river flanked by abundant and large gravel bars formed of coarse bed-material sediment. Since the early twentieth century, the large gravel bars have been a source of commercial aggregate for which ongoing permitting and aquatic habitat concerns have motivated this assessment of historical channel change and sediment transport rates. Analysis of historical channel change and bed-material transport rates for the lower 18 kilometers shows that the upper reaches of the study area are primarily transport zones, with bar positions fixed by valley geometry and active bars mainly providing transient storage of bed material. Downstream reaches, especially near the confluence of the North Fork Chetco River, are zones of active sedimentation and channel migration.

Multiple analyses, supported by direct measurements of bedload during winter 2008-09, indicate that since 1970 the mean annual flux of bed material into the study reach has been about 40,000-100,000 cubic meters per year. Downstream tributary input of bed-material sediment, probably averaging 5-30 percent of the influx coming into the study reach from upstream, is approximately balanced by bed-material attrition by abrasion. Probably little bed material leaves the lower river under natural conditions, with most net influx historically accumulating in wider and more dynamic reaches, especially near the North Fork Chetco River confluence, 8 kilometers upstream from the Pacific Ocean.

The year-to-year flux, however, varies tremendously. Some years may have less than 3,000 cubic meters of bed material entering the study area; by contrast, some highflow years, such as 1982 and 1997, likely have more than 150,000 cubic meters entering the reach. For comparison, the estimated annual volume of gravel extracted from the lower Chetco River for commercial aggregate during 2000-2008 has ranged from 32,000 to 90,000 cubic meters and averaged about 59,000 cubic meters per year. Mined volumes probably exceeded 140,000 cubic meters per year for several years in the late 1970 s.
Repeat surveys and map analyses indicate a reduction in bar area and sinuosity between 1939 and 2008, chiefly in the period 1965-95. Repeat topographic and bathymetric surveys show channel incision for substantial portions of the study reach, with local areas of bed lowering by as much as 2 meters. A specific gage analysis at the upstream end of the study reach indicates that incision and narrowing followed aggradation culminating in the late 1970s. These observations are all consistent with a reduction of sediment supply relative to transport capacity since channel surveys in the late 1970s, probably owing to a combination of (1) bed-sediment removal and (2) transient river adjustments to large sediment volumes brought by floods such as those in 1964 and, to a lesser extent, 1996.

\section{Introduction}

The Chetco River is a steep gravel-bed river in southwestern Oregon draining $914 \mathrm{~km}^{2}$ of the rugged Klamath Mountains before entering the Pacific Ocean $5 \mathrm{~km}$ north of the California-Oregon State line (fig 1). Downstream of the confluence of the South Fork Chetco River at river kilometer (Rkm) 29, the Chetco River is flanked by varying widths and areas of gravel bars and flood plains. Downstream of Rkm 18, several of these gravel bars have been mined as a source of aggregate during the last century. Ongoing permitting actions have instigated questions of possible effects from such mining on physical channel conditions (for example, Kondolf, 1994, 1997), prompting the U.S. Army Corps of Engineers, in conjunction with regulatory agencies and stakeholder groups, to request from the U.S. Geological Survey (USGS) a measurement and analysis program to evaluate transport rates of bed material and to assess changes in channels and flood plains for the lower $18 \mathrm{~km}$ of the Chetco River. 


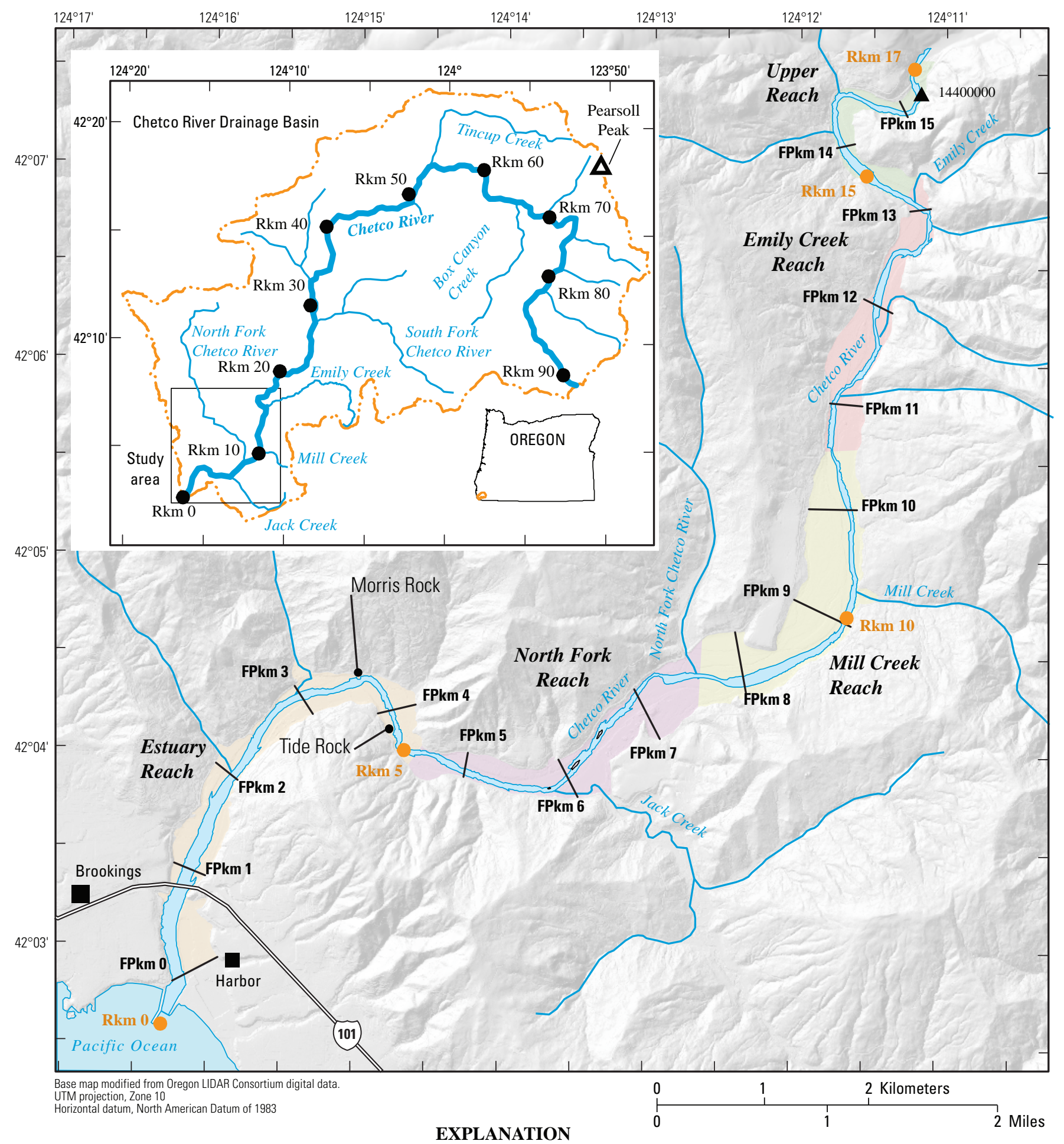

\section{A USGS streamflow-gaging station \\ R km 50 River kilometer \\ FPkm 1 Flood-plain kilometer}

Figure 1. Drainage basin and study area, Chetco River, Oregon. Reaches analyzed are defined by valley geomorphology and tributary junctions. Morris Rock and Tide Rock are informal names for prominent local landmarks. Topography based on U.S. Geological Survey 10-m digital elevation data and Light Detection and Ranging (LIDAR) topography acquired in 2008. 


\section{Purpose and Scope}

This report summarizes analyses of temporal trends in channel width and gravel bar area, and bed-material transport measurements and calculations, with the goal to estimate temporal and spatial trends in bedload transport, deposition, and erosion within the lowermost $18 \mathrm{~km}$ of the Chetco River, and further to assess historical changes to the channel and flood plain. These analyses were supported by systematic mapping of channels and flood plains from historical and current aerial photographs, sampling of bed-material size distributions, bedload transport measurements, and hydraulic modeling. Additionally, the channel mapping in conjunction with new surveys allows for assessment of planform and vertical changes in channels, possibly attributable to changes in sediment balances and transport. The datasets developed in this study also will form a basis for ongoing monitoring programs to evaluate future changes in channel and bar morphology along the Chetco River. The scope of the study follows a process established in the State of Oregon to address permitting issues for inchannel gravel extraction.

\section{Background}

The Chetco River is like many rivers in the western United States for which issues of fish habitat, water quality, climate change, and changing land use have motivated new efforts to manage rivers and flood plains for multiple resources. In Oregon, rivers potentially subject to inchannel gravel extraction undergo a two-phase process of review and assessment by an interagency team co-chaired by the U.S. Army Corps of Engineers and the Oregon Department of State Lands. This team is subdivided into an executive team of policy managers and a technical team of supporting resource experts. The first phase is a preliminary assessment of "vertical stability" based primarily on available information. If the Phase I analysis shows no clear evidence of adverse channel or flood-plain conditions, a Phase II analysis may be initiated to provide more information relevant to permitting decisions. For the Chetco River, the Phase I assessment was completed in May 2007 (Janine Castro, U.S. Fish and Wildlife Service, written commun., 2007). This assessment of maps and surveys concluded that although the lowermost $2 \mathrm{~km}$ of the river "appears to have deepened slightly over the past 20 years," there was no evidence of systematic channel incision for the balance of the lower $18 \mathrm{~km}$ of the Chetco River. These findings prompted the executive team to consider permitting of future instream gravel extraction upon completion of a more extensive Phase II analysis consisting of data acquisition and analysis aimed at:
1. Determining spatial and temporal rates of bed-material transport.

2. Assessing planform and vertical changes to the river channel.

In addition to these specific Phase II analysis components, the USGS was requested to provide broadscale maps of flood-plain geomorphology and general vegetation along the flood plain flanking the lower $18 \mathrm{~km}$ of the river corridor. The lower $18 \mathrm{~km}$ forms a convenient analysis segment because the upstream end approximately corresponds to the location of the USGS streamflow-gaging station for the Chetco River, which is $16.9 \mathrm{~km}$ upstream from the mouth and encompasses the extent of commercial gravel extraction. These findings and maps will be used by the regulatory agencies as supporting information for future permitting decisions for instream gravel extraction along the Chetco River.

Our approaches for assessing channel changes, as well as mapping current and historical channels and vegetation, followed established procedures of aerial photograph analysis, and channel and flood-plain surveys. Our analysis period extends back to include aerial photographs and bathymetric surveys from 1939. Assessing sediment transport rates and budgets is more difficult (Reid and Dunne, 1996, 2003), particularly for bed material (Edwards and Glysson, 1999; Hicks and Gomez, 2003; Reid and Dunne, 2003). Because of the challenges in assessing bed-material transport rates, we have adopted several measurement, modeling, and analysis approaches to ensure the greatest likelihood of meaningful results and to provide qualitative assessment of their accuracy.

\section{Locations}

All analyses and results are presented in metric units. Conversions to English units are provided in the report front matter. Locations along the channel alignment in summer 2008 are referenced to river kilometers ( $\mathrm{Rkm}$ ) measured from the mouth of the Chetco River (ig. 1) along the channel centerline mapped from Light Detection and Ranging (LIDAR) topography acquired in 2008. Ambiguity because of channel shifting was avoided by referencing locations and analyses for the lowermost $18 \mathrm{~km}$ to a flood-plain kilometer (FPkm) centerline, measured from the river mouth along the centerline of the Holocene flood plain. In 2008, approximately $18 \mathrm{~km}$ of channel were within the 16 -km-long length of flood plain composing the study reach. Prominent landmarks and locations include the Highway 101 bridge at FPkm 0.9 (Rkm 1.4), Tide Rock at FPkm 4.2 (Rkm 4.9), North Fork Chetco River confluence at FPkm 7.6 (Rkm 8.3), and the USGS streamflow-gaging station (at Second Bridge) at FPkm 15.2 (Rkm 16.9). 


\section{Chetco River}

The Chetco River drains $914 \mathrm{~km}^{2}$ of southwestern Oregon and empties into the Pacific Ocean $5 \mathrm{~km}$ north of the California-Oregon border (fig. 1). Major tributaries are Tincup Creek (Rkm 54), South Fork Chetco River (Rkm 29), and North Fork Chetco River (Rkm 8.3; FPkm 7.6). In 1988, the Chetco River between Rkms 16 and 88 was designated as "Wild and Scenic" as part of the National Wild and Scenic River program. The eastern half of the drainage basin is within the Kalmiopsis Wilderness Area, established in 1964. At its entrance to the Pacific Ocean, the river separates the coastal communities of Brookings and Harbor. The drainage basin is entirely within Curry County, Oregon.

\section{Geography and Geology}

The drainage basin is steep and rugged. The highest point is Pearsoll Peak at $1,554 \mathrm{~m}$, and the lowest elevation is sea level at the river mouth. The average basin slope is $0.42 \mathrm{~m} / \mathrm{m}$ as measured from 10-m resolution digital elevation data. Drainage density, as measured from the 1:24,000 National Hydrologic Data set is $1.4 \mathrm{~km} / \mathrm{km}^{2}$. The Chetco River is $88 \mathrm{~km}$ long, heading at an elevation of $540 \mathrm{~m}$ and descending to sea level at an average gradient of $0.006 \mathrm{~m} / \mathrm{m}$, but most elevation loss is in the upper part of the drainage basin, leaving the lowermost $38 \mathrm{~km}$ with a gradient of $0.0013 \mathrm{~m} / \mathrm{m}$.

The drainage basin is in the Klamath Mountains physiographic province, an amalgamation of several geologic terranes affixed to western North America during the late Mesozoic Era and early Tertiary Period in a progression of eastward dipping underthrusts. During accretion and subsequently, the rocks have been metamorphosed and intruded by igneous plutons, dikes, and sills, chiefly of Cretaceous and Tertiary age. The degree of metamorphism and igneous intrusive activity decreases westward, with most highly deformed metamorphic rock and intrusive igneous rocks forming the steeper and higher eastern part of the drainage basin, mainly upstream of $\mathrm{Rkm} 70$. The western half of the basin is dominated by the Dothan Formation, which consists mainly of slightly metamorphosed greywacke sandstone and siltstone with minor amounts of volcanic rocks and chert (Ramp, 1975; Orr and others, 1992).

The steep slopes, high drainage density, and high gravel transport rates result from the combined effects of geologically recent uplift and erodible rock types. Analysis of uplifted 80-120 kiloannum (ka) shore platforms indicate late Quaternary uplift rates as high as $1 \mathrm{~mm} / \mathrm{yr}$ (Kelsey and others, 1994), whereas geodetic and tidal observations suggest even higher historical rates of 2.5-3.5 mm/yr (Burgette and others, 2009). The rapid uplift has facilitated river incision and landsliding, especially in the upper drainage basin (Ramp, 1975).
The lower river valley, particularly along the lowermost $18 \mathrm{Rkm}$, has been strongly affected by the $130 \mathrm{~m}$ of sea-level rise after the culmination of the last maximum glacial period 18,000 years ago. Along the Oregon coast, rising sea levels have drowned river valleys incised during low stands of sea level, creating estuaries now extending inland from the coast. With the onset of sea-level rise, and especially during the last 2000 years of relatively stable sea level, these drowned river valleys have been filling with fluvial sediment (Komar, 1997, p. 30-32). For the Chetco River, the wide valley bottom of the lowermost $10 \mathrm{~km}$ is the result of this valley filling. Tidal effects extend $5 \mathrm{~km}$ inland, evidence that filling of the lower river valley has not yet matched Holocene sea level rise, and that the river has not yet attained a graded profile to the coast.

\section{Hydrology}

As described by early U.S. Army Corps of Engineers (1893, p. 3,431) navigation engineers, "Above the head of tide the [Chetco] river runs nearly dry in the summer, and is at all times but a small mountain stream, which becomes a torrent from the winter storms.” The combination of rugged physiography, high drainage density, and high rainfall associated with a Pacific marine climate results in high annual runoff values and flashy short-duration peak flows, but very low summer flows. Average annual rainfall in the drainage basin is about $2.4 \mathrm{~m}$ (Soil Conservation Service, 1979), ranging from about $2 \mathrm{~m} / \mathrm{yr}$ at Brookings and increasing with elevation to nearly $4 \mathrm{~m} / \mathrm{yr}$ in the basin headwaters (Maguire, 2001). Eighty percent of the precipitation falls during October through March, mostly resulting from 2- to 4-day Pacific frontal systems from the southwest.

Flow has been measured at the USGS streamflow-gaging station (14400000; Chetco River near Brookings) at FPkm 15.24 since October 1, 1969. For water years (October 1September 30) 1970 through 2008, mean annual flow has been $64 \mathrm{~m}^{3} / \mathrm{s}$, equating to $0.75 \mathrm{~m}$ of runoff from the contributing area above the measurement station. Measured annual peak flows have ranged from $280 \mathrm{~m}^{3} / \mathrm{s}$ in 2001 to 2,169 m³ $/ \mathrm{s}$ in 1996; although, the 1964 peak is estimated to have been $2,420 \mathrm{~m}^{3} / \mathrm{s}$. The mean annual peak flow is $1,085 \mathrm{~m}^{3} / \mathrm{s}$ (ig. 2 ).

To extend the record of peak flows to encompass the 1939-2008 analysis period, we estimated peak flows prior to 1970 on the basis of a linear regression between the Chetco River streamflow-gaging station (14400000) and the USGS streamflow-gaging station on the Smith River (11532500), near Crescent City in northern California that has been in operation since October 1931 (fig. 2A). Although the Smith River drainage basin, at $1,590 \mathrm{~km}^{2}$, is 74 percent larger than the Chetco River drainage basin, both are coastal drainage basins within the Klamath Mountains physiographic area subject to similar hydrological conditions. 


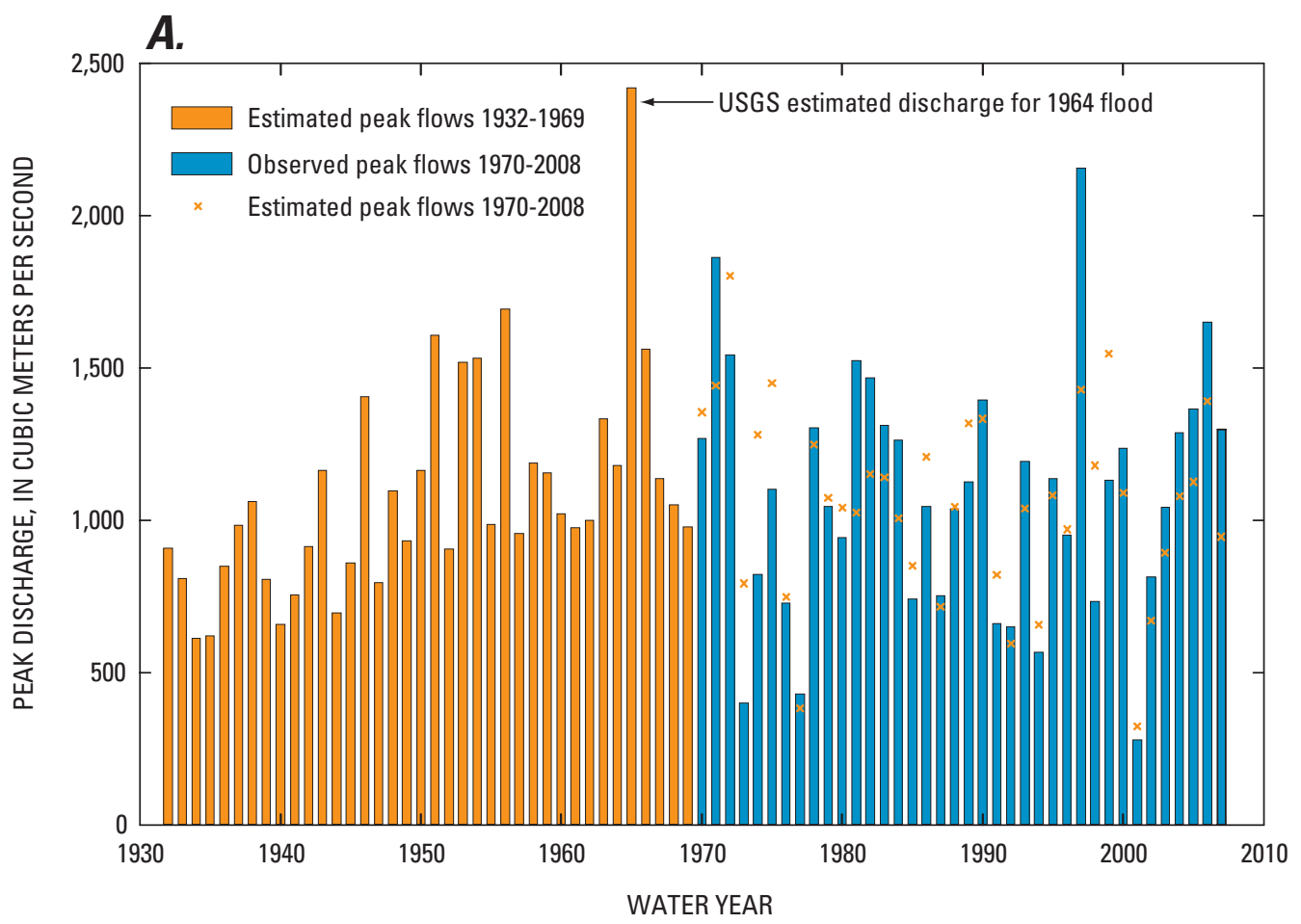

B.

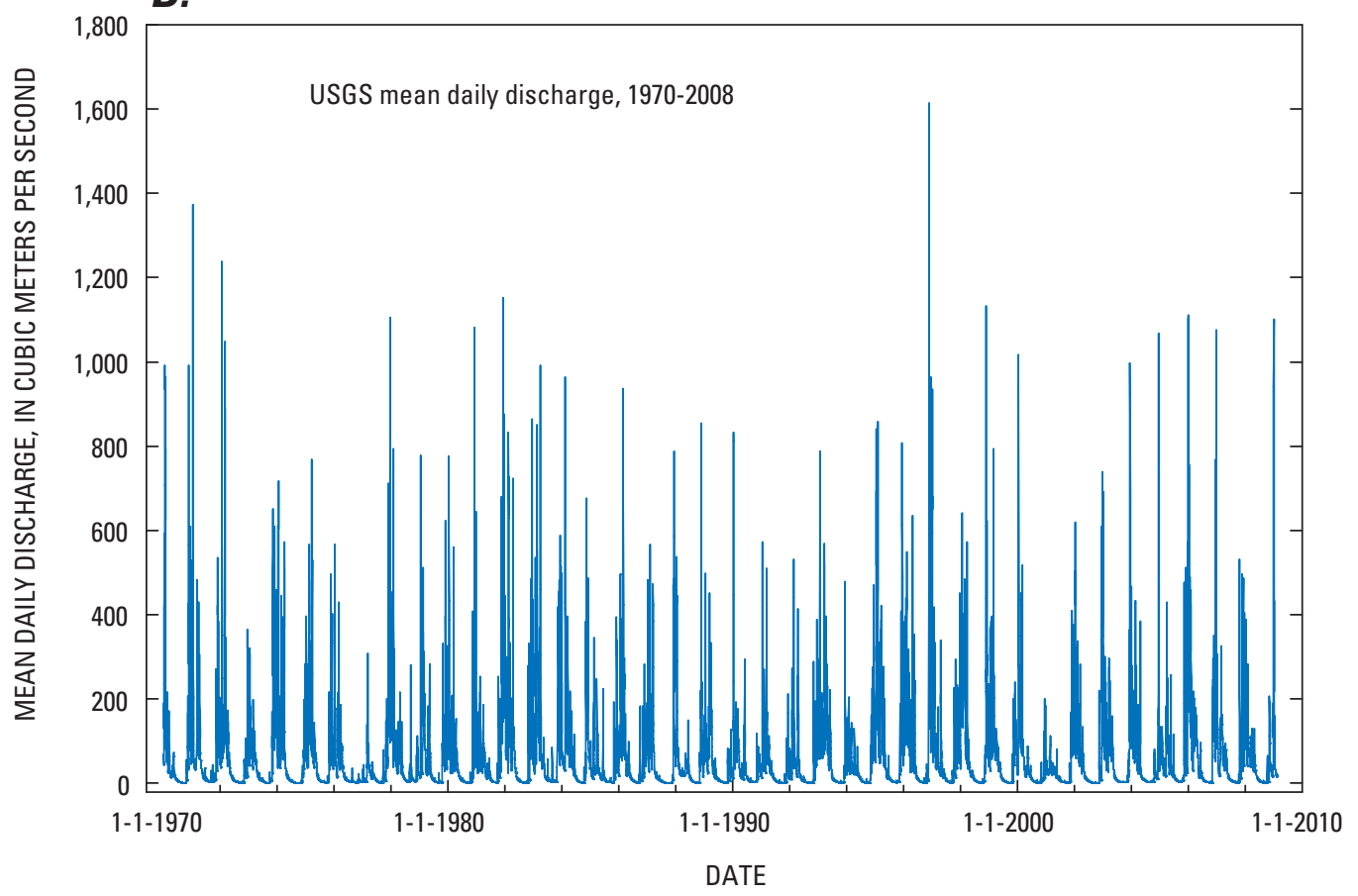

Figure 2. Flow records for USGS streamflow-gaging station 14400000 , Chetco River near Brookings, Oregon. (A) Estimated and observed annual peak flows for water years 19322008. (B) Mean daily discharge for water years 1970-2008. Annual peak flows measured for water years 1971-2008, estimated for 1964 on basis of high water mark and extension of rating curve, and estimated for all other years using data from Smith River USGS streamflow-gaging station (11532500) in northern California. Estimates from Smith River record were determined by regression of log-transformed values from period of overlap for which $\log$ Chetco River $Q_{\text {peak }}=0.6337 \times\left(\log\right.$ Smith River $\left.Q_{\text {peak }}\right)+1.4708(r=0.83)$. 
The reconstructed peak flow history for the Chetco River shows a pattern of increasing annual peak flows during water years 1931-72, with typical values ranging from $700 \mathrm{~m}^{3} / \mathrm{s}$ in the 1930 s to approximately $1,400 \mathrm{~m}^{3} / \mathrm{s}$ by 1970 (fig. 2A). Floods in the 1950 s (particularly the 1955 peak flow event) appear similar in magnitude to the recent floods of 1971 and 2006, consistent with anecdotal records (Soil Conservation Service, 1979) that describe widespread flooding and damage associated with each of these events. Large floods with discharges exceeding 2,000 m³ $/ \mathrm{s}$ are much less common, and were recorded only in 1964 and 1996, although historical records indicate similar, if not larger, peak discharges during the large regional floods of 1861 and 1890 (Maguire, 2001). The estimated peak flows for 1931-69 do not show the extremely low values (less than $500 \mathrm{~m}^{3} / \mathrm{s}$ ) such as those recorded in 1977 and 2001, although the regional drought in the 1930s coincides with generally lower annual peak flows for 1930-40.

\section{Study Area}

Our analysis focused on the lower $16 \mathrm{~km}$ of the Chetco River flood plain (fig. 1). The overall planform within the study area is that of a "wandering gravel-bed river" (Church, 1983) dominated by a single channel, but also having multichanneled reaches. The channel generally alternates position against opposite valley walls, forming deep scour pools where it flows against valley walls and shallow riffles where it crosses the valley floor between large gravel bars (Klingeman, 1993). The location and general shape of many of the expansive gravel bars (fig. 3) flanking the low flow channel are fixed by the control of valley geometry on high-stage flow hydraulics and consequent patterns of erosion and deposition. Within the study reach, the low flow channel as mapped in 2008 has an average slope of 0.0012 between FPkm 16 and FPkm 4.3, and a much flatter gradient in the tidally affected lower river and estuary. The channel has distinct pool-riffle morphology upstream of FPkm 4.5 (fig. 4).

Longitudinal patterns in gravel transport and channel change in the study area were characterized by dividing the area into five reaches of inferred similar transport on the basis of valley geomorphology, slope, and tributary locations (figs. 1 and 4, table 1). The Upper Reach (FPkm 13.2-16) extends from the upstream end of the study area to the Emily Creek confluence and is the most confined of all five reaches with an average flood-plain width of $213 \mathrm{~m}$. The valley and channel widen slightly through the Emily Creek Reach (extending between the confluences of Emily Creek and Mill Creek, FPkm 13.2-10.6). The Mill Creek Reach (FPkm 10.6-7.6)

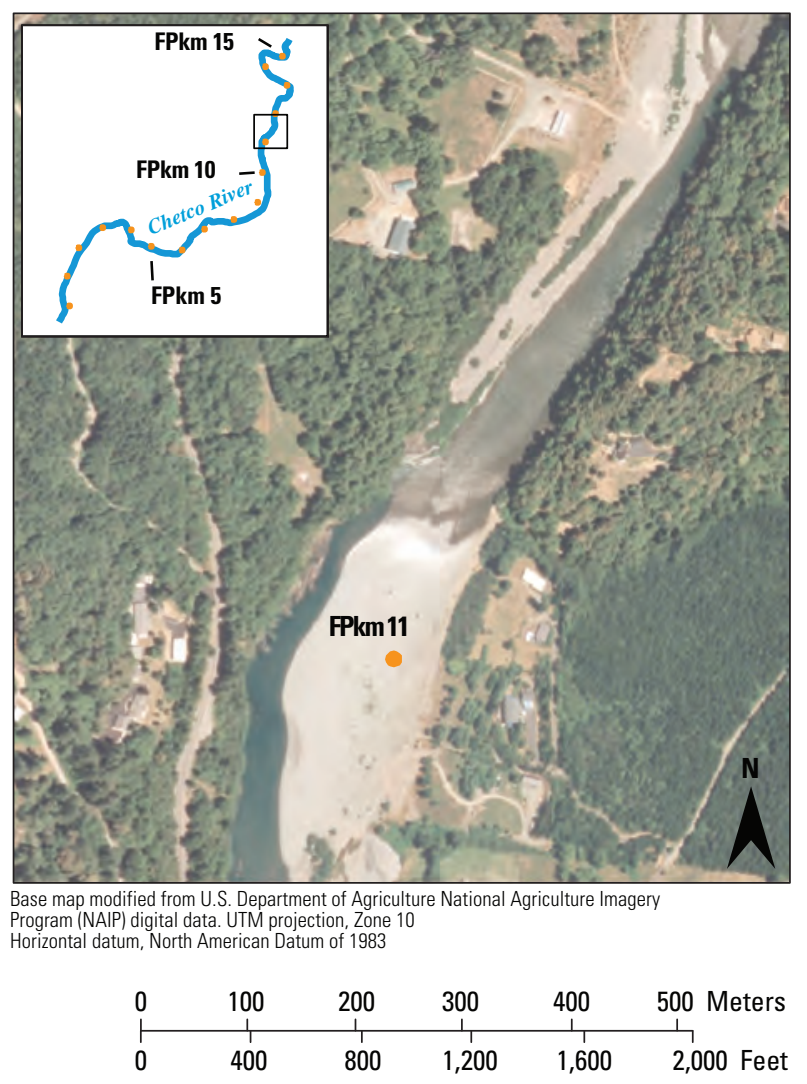

\section{EXPLANATION}

FPkm11 Flood-plain kilometer

Figure 3. Example of alternate bar sequence near flood-plain kilometer 11, Chetco River, Oregon. Digital orthophotograph from 2005 depicts large, channel-flanking gravel bars and low-flow channel. Flow is to the south. See figure 1 for FPkm locations.

encompasses the transition from the more stable upper reaches to the wider, more dynamic lower reaches, with flood-plain width increasing to $800 \mathrm{~m}$ as the Chetco River approaches its confluence with the North Fork of the Chetco River. The valley is widest along the lower part of the Mill Creek Reach and the North Fork Reach (FPkm 7.6-4.3), before narrowing and abruptly flattening as it enters the Estuary Reach, which corresponds to the tidally influenced zone from FPkm 4.3 (near the prominent local landmark, Tide Rock) to the mouth of the Chetco River (FPkm 0). 


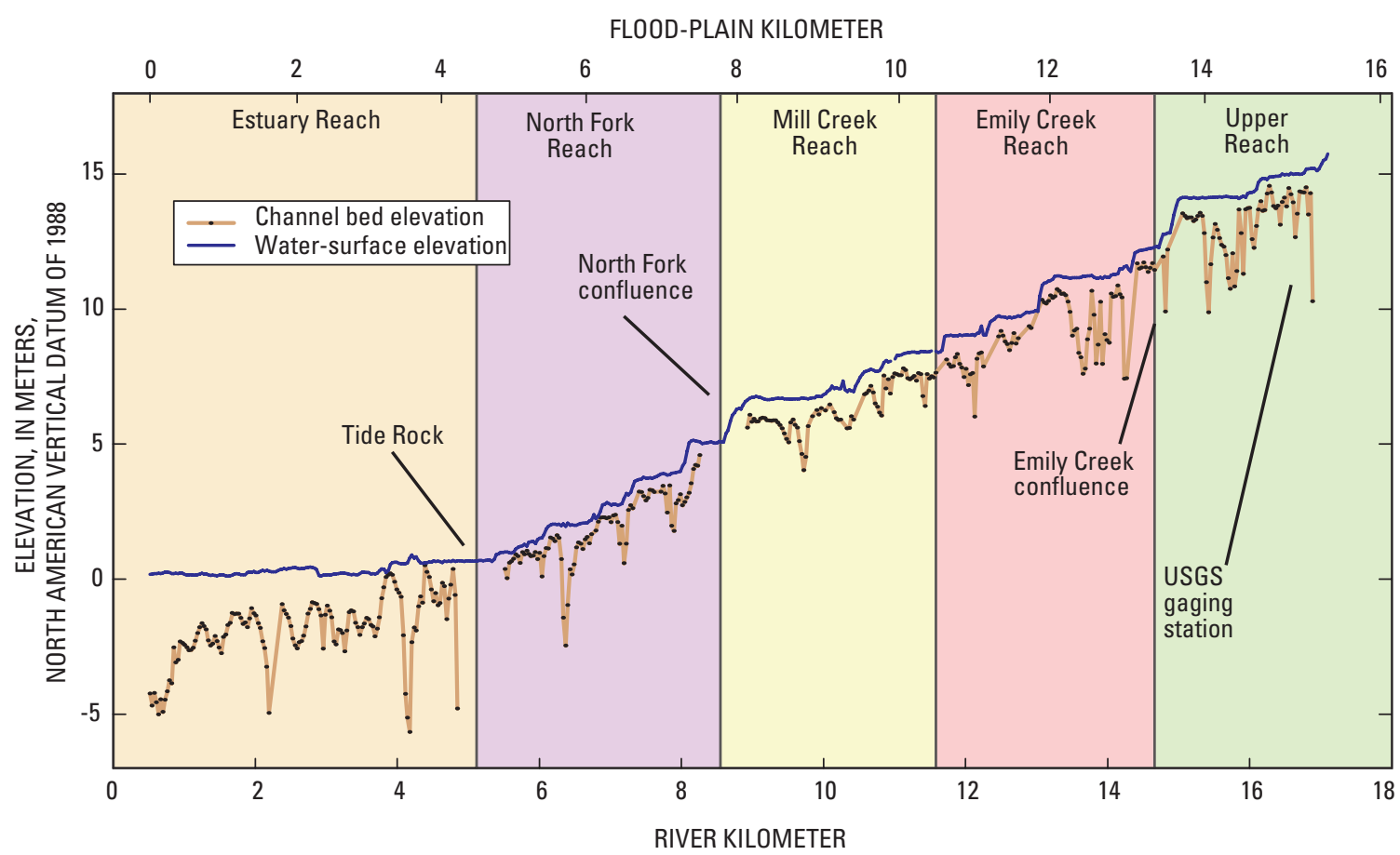

Figure 4. Channel bed and water-surface elevations along study area, Chetco River, Oregon. From USGS thalweg survey during autumn 2008; water surface from light detection and ranging (LIDAR) topography acquired during May and June 2008.

Table 1. Summary of reach attributes for the study area, Chetco River, Oregon.

[A bbreviations: m, meter; m/m, meter per meter; FPkm, flood-plain kilometer]

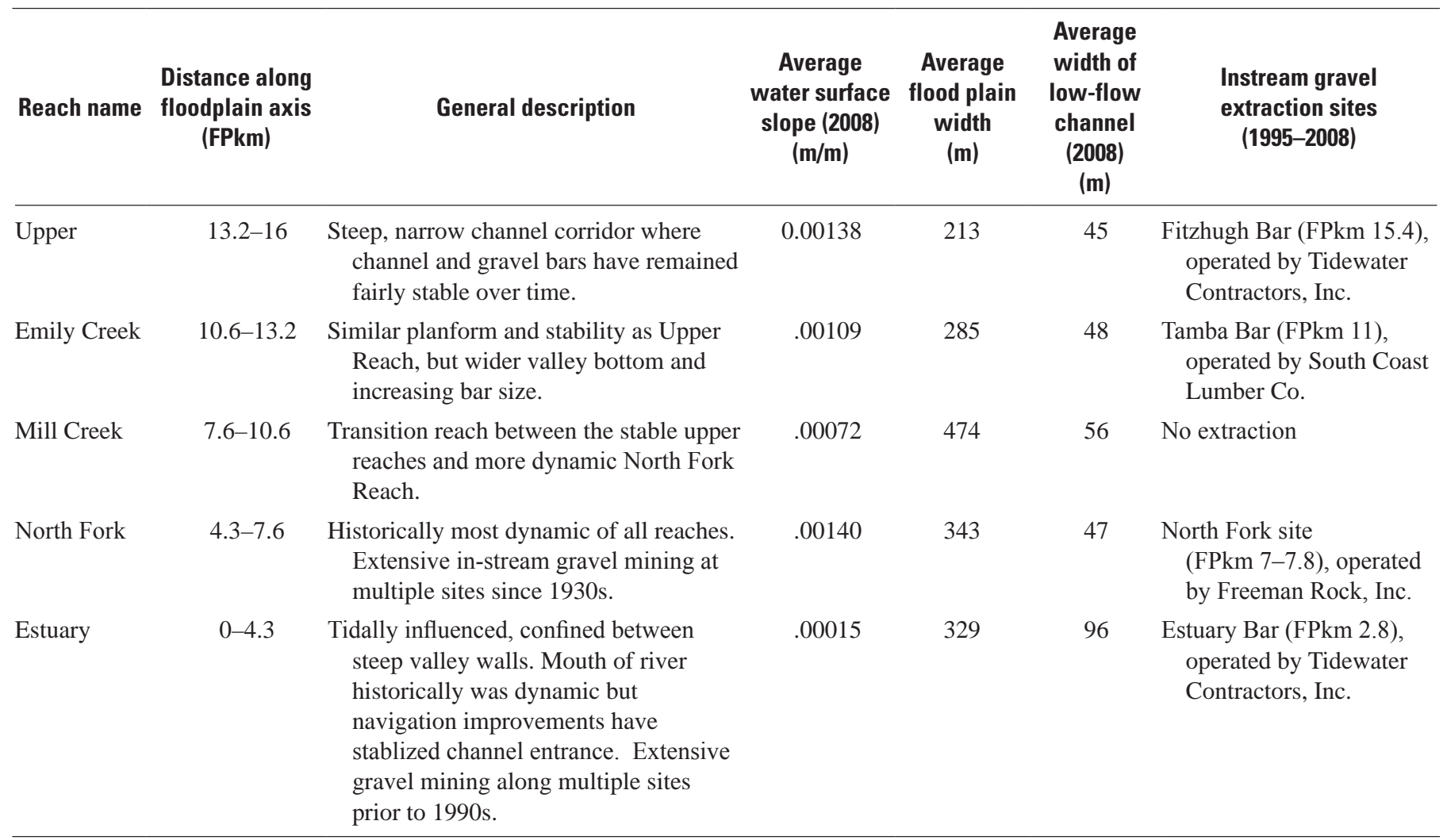




\section{Land-Use and Landscape Disturbance in Chetco River Basin}

Because of its rugged topography and remote location, the Chetco River basin was largely uninhabited until the early 20th century, and even today most of the drainage basin is publically owned and managed as forest lands and wilderness. Late in the 19th century, the U.S. Army Corps of Engineers (1893, p. 3,432) reported that "probably not over 100 people living in the whole Chetco Valley.” By the 1930s, individuals and lumber companies were logging on private lands along tributary valleys in the lower drainage basin (Chetco Watershed Council, 1995). Logging activity expanded to the upper basin during the peak harvest period of the 1950s-1960s, and then steadily decreased through the 1990s (John P. Williams, U.S. Department of Agriculture Forest Service, written commun., April 28, 2009). As of 2001, 97 percent of the Chetco River basin is managed as forest lands and wilderness by the U.S. Forest Service (USFS), Bureau of Land Management (BLM), and to a lesser extent, private timber companies (Maguire, 2001). More than one-half of the basin $\left(521 \mathrm{~km}^{2}\right)$, including much of the headwaters, is in the Kalmiopis Wilderness Area. Other land uses in the middle and lower basin include agriculture, rural residential development, and gravel quarries, which occupy 2 percent of the total basin area; whereas urban areas near the mouth of the Chetco River occupy only 1 percent of the basin (Maguire, 2001).

\section{Forest Management and Fire}

Although various natural and anthropogenic disturbances may influence channel conditions along the Chetco River, those disturbances likely to have the greatest effect in terms of sediment transport and channel planform along the study are watershed-scale disturbances such as floods, logging (and related) activities, forest fires; and activities within the study reach, including navigation improvements to the estuary, development and bank protection, and instream gravel mining. Logging and associated road building can increase peak flows (Wemple and others, 1996; Jones and Grant, 1996, 2001; Bowling and others, 2000) and the frequency of landslides (Kelsey and others, 1995), resulting in sedimentation along lower reaches of affected basins (Madej, 1995). Although data describing historical logging practices, road building, and resultant landscape change are sparse for the Chetco River, the peak logging in the 1950s and 1960s possibly affected sediment influx into the lower Chetco River.

In recent decades, two large regional fires burned parts of the upper Chetco River basin. The Biscuit Fire of summer 2002 was one of the largest historical forest fires in the Klamath Mountains, burning more than 57 percent of the Chetco River drainage basin with varying severity. In many places within the upper drainage basin, the Biscuit Fire overlapped with areas previously burned by the 1987 Silver Fire, although the Silver Fire burned only 10 percent of the basin (U.S. Forest Service, 2008). Possible long-term effects on Chetco River channel conditions resulting from the Biscuit Fire include enhanced runoff and erosion resulting from loss of vegetation (U.S. Forest Service and Bureau of Land Management, 2004), leading to downstream sedimentation.

\section{Navigation Improvements}

The Chetco River estuary is one of the smallest estuaries in Oregon, with a tidal prism extending approximately $5 \mathrm{~km}$ upstream of the Pacific Ocean, and its lateral extent constrained between steep valley walls (Ratti and Kraeg, 1979). Although the U.S. Army Corps of Engineers (1893, p. 3,431) originally declared that "the Chetco River estuary was unworthy of improvement” because of its small size and lack of regional commerce, expansion of the wood products industry and commercial fishing resulted in authorization of a series of navigational improvements as part of the 1945 River and Harbor Act (Slotta and Tang, 1976; Ratti and Kraeg, 1979). By 1959, a pair of jetties had been constructed at the mouth of the river, and an entrance channel was dredged through the bar that had historically blocked seasonal entrance to the estuary. Navigation and harbor improvements continued through the 1960s and 1970s, with the dredging of two boat basins in former tidelands areas and construction of a protective dike (Slotta and Tang, 1976; Ratti and Kraeg, 1979). The Port of Brookings completed these alterations by filling of a historical lagoon to reduce flooding and improve access to the moorages (Oregon Department of State Lands, 1972). Since the early 1960s, the U.S. Army Corps of Engineers dredged each year to maintain the entrance to the Chetco River channel, removing an average volume of 22,000 m³/yr (Judy Linton, U.S. Army Corps of Engineers, written commun., February 23, 2009; fig. 5). Only part of this dredged volume, however, is removed from the lowermost kilometer of the Chetco River, with the balance removed downstream of the jetties at the entrance to the channel. Additionally, it is uncertain how much of this dredged sediment, even that within the lowermost river, is derived from downstream river transport rather than marine transport into the lower Chetco River. For similar Oregon estuaries of the Yaquina and Alsea Rivers, most sand at the river mouth is of marine origin (Kulm and Byrne, 1966; Peterson and others, 1982). For the similarly sized (725 km²) Redwood Creek in northern California, Ricks (1995) showed that the sand in the estuary has a composition more similar to nearby Pacific beaches than that from the Redwood Creek drainage basin, indicating that a substantial part of the Redwood Creek estuary sand is from marine transport into the estuary. 


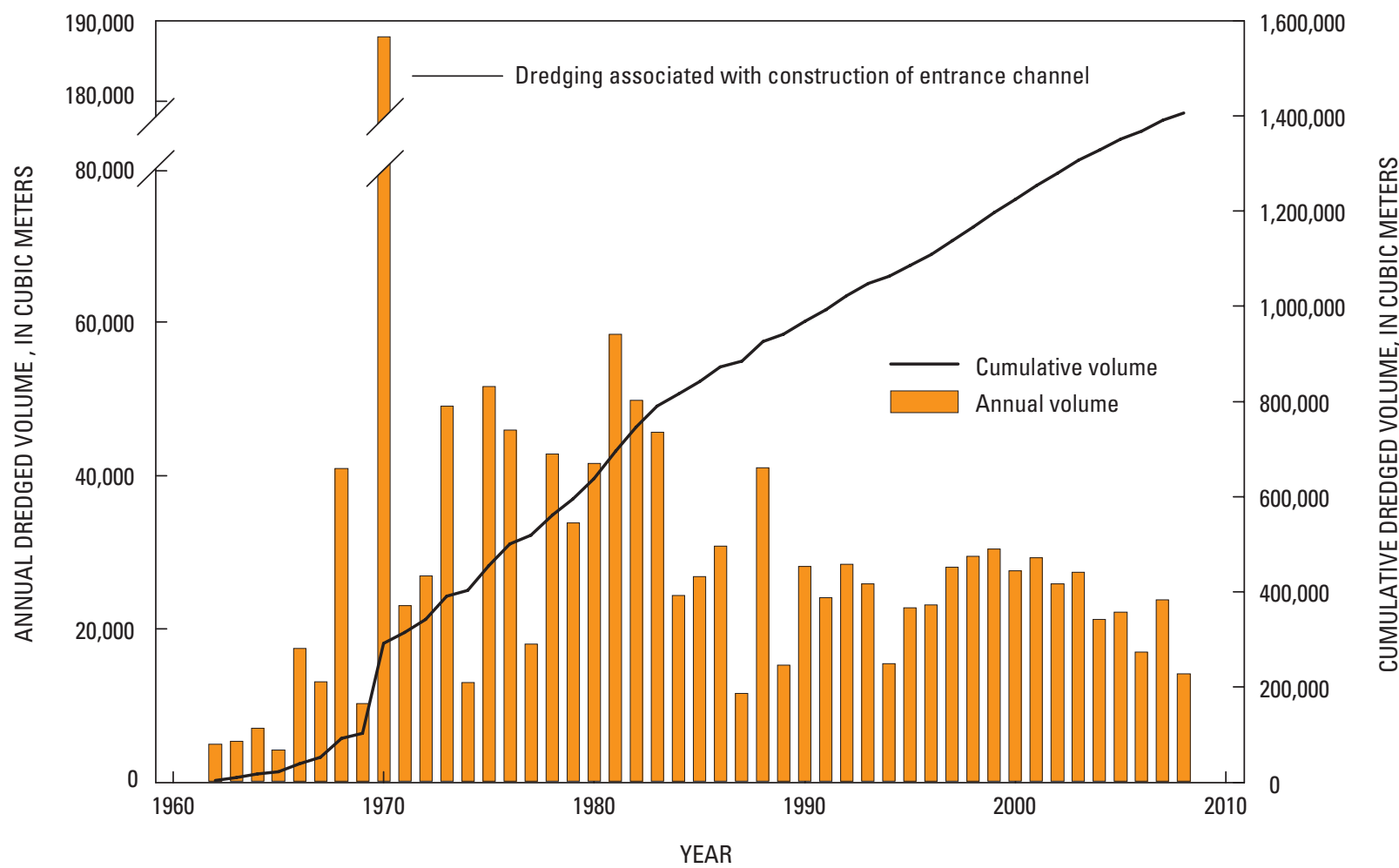

Figure 5. Annual and cumulative navigational dredging volumes, 1962-2008, Chetco River, Oregon. Dredging began in 1962 to maintain navigation clearance at the river mouth and the boat basin. Data source: Judy Linton, U.S. Army Corps of Engineers, written commun., February 23, 2009.

\section{Chetco River Gravel Mining}

Sand and gravel has been mined for aggregate from bars flanking the low flow channel of the Chetco River flood plain for nearly a century. All this removal has been downstream of FPkm 16 and primarily has been in the estuary and near the confluence of the North Fork Chetco River at FPkm 7.5. Although historical records of removal volumes and practices are incomplete, accounts from long-time residents indicate that gravel extraction began in the early 1900s when gravel was removed by drag line from the estuary, and by the 1930s, several bars below FPkm 7.5 were being mined (T. Freeman, Freeman Rock Inc., written commun., 2009). Prior to 1967, no permit was required for instream gravel extraction in the State of Oregon, and on many rivers, it was common for aggregate to be removed from deep pits that extended well below the water line. Although anecdotal accounts (M. McCabe, Oregon Department of State Lands, oral commun., 2009; T. Freeman, Freeman Rock Inc., oral commun., 2009) indicate that several mining operators used such pits along the lower Chetco River, and aerial photographs from the 1930s to 1960s show possible water-filled pits on gravel bars downstream of FPkm 6, no records are available to better describe or quantify the volume of mining from this period. After the 1960s, pit extraction was gradually replaced with bar "scalping" or "skimming" techniques using scrapers or other heavy equipment to remove only the surface of the gravel bar, typically to an elevation close to the low-flow water level.

On the Chetco River, removal of instream gravel for aggregate probably peaked in the 1970s and 1980s, when at least 15 instream gravel mines were operating in the study area, and removal volumes were much higher than during recent years. Records listing removal volumes from a small number of mine operators show that average annual extraction for $1976-80$ was about $140,000 \mathrm{~m}^{3} / \mathrm{yr}$ (Marquess and Associates, 1980), a rate three times greater than that for 1993-2008 (fig. 6). In 1994, the Chetco River was declared navigable (and hence publicly owned) by the State of Oregon, and royalty fees were assessed on instream gravel extraction. 


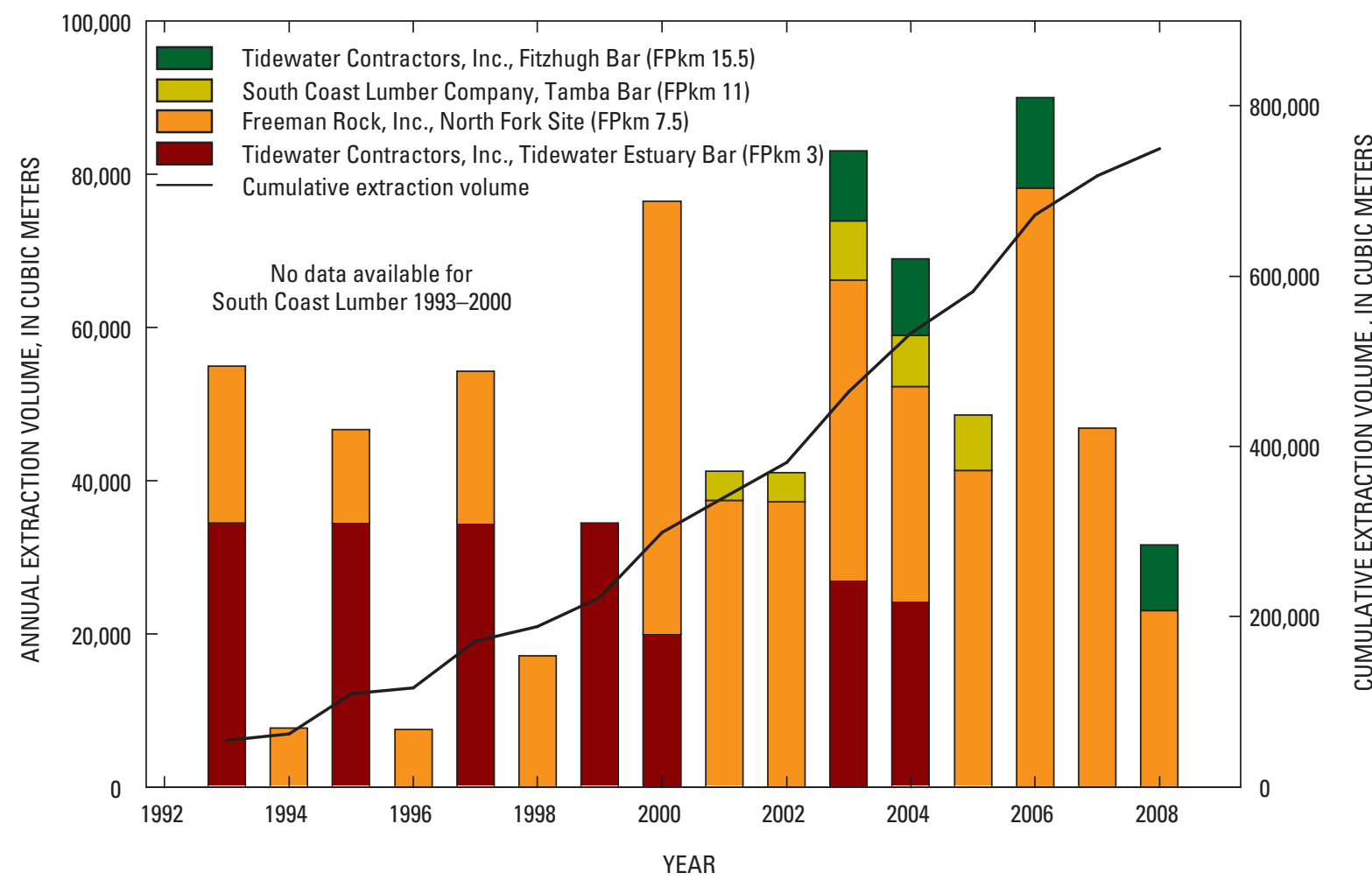

Figure 6. Annual and cumulative extraction volume for instream commercial gravel mining, Chetco River, Oregon, 1993-2008. Values as reported by commercial operators and corroborated with records of Oregon Department of State Lands. Values for Estuary Bar for 1993-99 are estimates provided by Robert Elayer (Tidewater Contractors, Inc., written commun., 2008).

Largely in response to tighter permitting conditions and fees, only three companies have continued commercial gravel extraction on the Chetco River, and so the annual volume of gravel removal has decreased substantially. From 1995 through 2008, instream gravel was mined at four primary sites along the Chetco River:

Fitzhugh Bar (FPkm 15.5), operated by Tidewater Contractors, Inc.

Tamba Bar (FPkm 11), operated by South Coast Lumber Company

Freeman North Fork site (FPkm 7.5), operated by Freeman Rock, Inc.

Tidewater Estuary Bar (FPkm 3), operated by Tidewater Contractors, Inc.

Information provided by the gravel operators for mined volumes between 2000 and 2008 (the period for which actual extraction volumes for all operators is available) indicate that on average, nearly 59,000 $\mathrm{m}^{3}$ of aggregate was removed annually between the three operators, with year-to-year values ranging between 32,000 $\mathrm{m}^{3}$ (2008) and 90,000 $\mathrm{m}^{3}$ (2006) depending on permit conditions and gravel replenishment at mining sites (fig. 6).

\section{Valley Bottom Mapping and Analysis of Historical Channel Change}

Historical and current channel maps, surveys, and aerial photographs provide a means for assessing planform and vertical changes to the Chetco River study area since the late 1930s, and also form a basis for future monitoring studies. In this study, planform changes to the morphology and land-cover types of the valley bottom are documented by analysis of multiple sets of aerial photographs dating back to 1939. Vertical changes to the channel and flood plain were assessed from sparse historical data, including 1939 and 1977 surveys, and the record of channel geometry documented at the USGS streamflow measurement station $(14400000)$ at FPkm 15.2. Current information on topography, bathymetry, and vegetation was based on (1) LIDAR topography acquired in spring 2008, provided by the Oregon LIDAR Consortium (Oregon Department of Geology and Mineral Industries, 2009), (2) channel and estuary surveys from the summer 2008, and (3) 0.5 meter orthoimagery for 2005 developed from summer 2005 aerial photographs as part of the U.S. Department of Agriculture National Agriculture Imagery Program (NAIP). 


\section{Historical Changes in Channel Planform and Vegetation}

Planview changes in channel morphology were quantified by mapping channel features from eight time periods using aerial photographs and the LIDAR topography. The time periods for channel mapping were selected to track channel change for the longest possible time period and to serve as a basis for assessing erosion and deposition for five time intervals: 1939-43, 1962-65, 1995-2000, 2000-2005, and 2005-08. These time intervals were selected on the basis of photograph availability and quality, and encompassed specific events possibly affecting channel morphology. During 1939-43 land use and gravel extraction in the Chetco River basin were minimal. The 1964 flood of record is included in the 1962-65 interval and represents an era of increasing land use throughout the basin, including navigational improvements near the mouth of the Chetco River and increased gravel extraction along the lower river corridor and timber harvest within the drainage basin. The three most recent time periods (1995-2000, 2000-2005 and 2005-08) postdate the era of most voluminous gravel extraction and timber harvest but encompass the two large floods of 1996 and 2006.

\section{Acquisition and Rectification of Historical Aerial Photographs}

Digital orthoimagery from 1995, 2000, and 2005 have been previously rectified and georeferenced and are in the public domain (table 2). By contrast, older sets of aerial photographs were available only as paper prints or negatives and required scanning, georeferencing, and rectification as part of this study (table 2). Coverage was complete for the entire study area for all photograph sets except for the photographs from 1939 which covered only as far as FPkm 13.5, leaving the upstream $2.5 \mathrm{~km}$ without coverage for 1939 . The aerial photographs and LIDAR topography were acquired during flows less than $15 \mathrm{~m}^{3} / \mathrm{s}$, well within the low-flow channel (tables 2 and $\underline{3}$ ).

Full details of georeferencing and rectifying are included in the metadata for the geographic information system (GIS) maps prepared in conjunction with this study (U.S. Geological Survey, 2009). The scanned historical aerial photographs were georeferenced in ArcGIS 9.2 using the orthophotographs from 2005 as a base layer and following the methodology of Hughes and others (2006). For the photographs from 1943, 1962, and 1965, we acquired 6-16 ground control points per photograph, and aimed to locate these control points as near as possible to the channel. A second order polynomial fit was applied to georeference the photographs, providing root mean square error (RMSE) values ranging from approximately 1 to $4.4 \mathrm{~m}$. The photography from 1939 was difficult to register because of the small area covered by each photograph (approximately $1.5 \times 2 \mathrm{~km}$ ) and the small number of feature points present in both the 1939 and 2005 photographs. Consequently, the photographs from 1939 were georeferenced using only 3-6 ground control points per photograph and rectified using a first order polynomial, which resulted in RMSE values of 0.35-3.6 m. Once georeferenced, each photograph was rectified and then combined to create a seamless mosaic of images for each period.

Table 2. Aerial photographs and orthophotographs used in the sediment transport study, Chetco River, Oregon.

[A bbreviations: FPkm, flood-plain kilometer; NAIP, National Agriculture Imagery Program; USACE, U.S. Army Corps of Engineers; USFS, U.S. Forest Service; USDA, U.S. Department of Agriculture; USGS, U.S. Geological Survey; m³/s, cubic meter per second; m, meter]

\begin{tabular}{|c|c|c|c|c|c|c|c|}
\hline Year & Original format & Coverage & Flight date & $\begin{array}{c}\text { Approximate } \\
\text { discharge at } \\
\text { photograph date } \\
\left(\mathrm{m}^{3} / \mathrm{s}\right)\end{array}$ & $\begin{array}{l}\text { Photo scale or } \\
\text { orthophotograph } \\
\text { resolution }\end{array}$ & $\begin{array}{l}\text { Original } \\
\text { source }\end{array}$ & $\begin{array}{c}\text { Rectification } \\
\text { source }\end{array}$ \\
\hline 1939 & Aerial photograph & FPkm 0-13 & 05-27-1939 & ${ }^{1} 11$ & $1: 10,200$ & USACE & This study \\
\hline 1943 & Aerial photograph & FPkm 0-16 & 08-03 to 8-04-1943 & 15 & $1: 40,000$ & USFS & This study \\
\hline 1965 & Aerial photograph & FPkm 0-16 & 06-22-1965 & 17 & $1: 20,000$ & USDA & This study \\
\hline 1995 & Orthophotograph & FPkm 0-16 & 05-27-1995 & 15 & 1 pixel $=1 \mathrm{~m}$ & USGS & USGS \\
\hline 2000 & Orthophotograph & FPkm 0-16 & $07-27$ to $08-14-2000$ & $3-4$ & 1 pixel $=1 \mathrm{~m}$ & USGS & USGS \\
\hline 2005 & Orthophotograph & FPkm 0-16 & 07-17-2005 & 9 & 1 pixel $=1 \mathrm{~m}$ & NAIP & NAIP \\
\hline
\end{tabular}

\footnotetext{
${ }^{1}$ Indicates estimated discharge, calculated by extending the Chetco River USGS gaging station data based on data from the Smith River USGS gaging station.
} 
Table 3. Map and survey data reviewed in the sediment transport study, Chetco River, Oregon.

[A bbreviations: FPkm, flood-plain kilometer; LIDAR, light detection and ranging; NAVD88, North American Vertical Datum of 1988; USACE, U.S. Army Corps of Engineers; GLO, General Land Office; SCS, Soil Conservation Service; USGS, U.S. Geological Survey; $\mathrm{m}^{3} / \mathrm{s}$, cubic meter per second]

\begin{tabular}{|c|c|c|c|c|c|}
\hline $\begin{array}{l}\text { Original source } \\
\text { for map or survey }\end{array}$ & $\begin{array}{l}\text { Type of map } \\
\text { or survey }\end{array}$ & $\begin{array}{l}\text { Date of map } \\
\text { or survey }\end{array}$ & Date(s) of survey & Coverage & Comments \\
\hline USACE & $\begin{array}{l}\text { Navigational } \\
\text { bathymetry } \\
\text { map }\end{array}$ & 1939 & June 20-July 14, 1939 & FPkm $0-4.5$ & $\begin{array}{l}\text { Scanned, rectified and digitized by } \\
\text { USGS personnel using } 1939 \text { aerial } \\
\text { photographs. }\end{array}$ \\
\hline GLO & Township survey & 1879 & $\begin{array}{l}\text { September } 16- \\
\text { October } 2,1845 \text { and } \\
\text { February } 25- \\
\text { March 12, } 1879\end{array}$ & FPkm 3-11.5 & $\begin{array}{l}\text { Survey to delineate township and } \\
\text { section lines; channel and gravel bar } \\
\text { locations were surveyed at the section } \\
\text { boundaries, with intervening areas } \\
\text { approximated. }\end{array}$ \\
\hline SCS & Flood study & 1979 & 1977 & FPkm 0-16 & $\begin{array}{l}\text { Cross sections converted to NAVD } 88 \\
\text { vertical datum (this study) for } \\
\text { comparison with } 2008 \text { data. }\end{array}$ \\
\hline $\begin{array}{l}\text { Watershed } \\
\text { Sciences, Inc. }\end{array}$ & LIDAR survey & $\begin{array}{l}\text { Expected release } \\
\text { in } 2009\end{array}$ & May 3-July 6, 2008 & FPkm 0-16 & $\begin{array}{l}\text { Discharge during LIDAR flight ranged } \\
\text { from approximately } 37 \mathrm{~m}^{3} / \mathrm{s} \text {. }\end{array}$ \\
\hline USGS & $\begin{array}{l}\text { Cross section and } \\
\text { long profile } \\
\text { survey }\end{array}$ & This study & October 7-9, 2008 & FPkm 3-16 & $\begin{array}{l}\text { See accompanying GIS layers and } \\
\text { metadata for map and survey } \\
\text { descriptions. }\end{array}$ \\
\hline
\end{tabular}

\section{Uncertainties and Limitations to Planimetric Mapping}

Even with established protocols and spatial analysis techniques, uncertainty and error result from interpretive mapping of land-surface features from aerial photographs of varying quality and light conditions and from different periods (Gurnell, 1997; Mount and Louis, 2005; Hughes and others, 2006). For this study, the quality and resolution of the photographs varied spatially and temporally but were sufficient for most of the study mapping objectives. The major source of mapping error for most features in this study resulted from imprecise registration and rectification of historical aerial photographs, especially for the older photographs for which few features were available to use as control points. The RMSE values indicate that horizontal position uncertainties are less than $5 \mathrm{~m}$; however, from test trials, positional errors for the historical aerial photographs resulting from the georeferencing and rectification process were determined conservatively to be almost everywhere less than $20 \mathrm{~m}$. Positional errors associated with the publicly available orthophotographs for 1995, 2000, and 2005 are less than $6 \mathrm{~m}$. Georeferencing errors have their greatest effect on analyses of photograph-to-photograph change, such as for quantitative estimates of channel movement and bar growth and erosion, but have little influence on measurements of total areas of features such as the for the channel and gravel bars.

Another consideration in comparing mapped features from several periods of time is differences in discharge between aerial photograph sets. Although all photography and LIDAR topography were acquired during low-flow periods (tables 2 and $\underline{3}$ ), small changes in discharge can influence delineation of channel and bar areas, particularly in areas where the channel is wide and shallow. We partly account for this in some analyses by determining the relations of bar and channel area to flow using a one-dimensional hydraulic model and the channel and flood-plain topography for 2008 (see complete model description in the Hydraulic Modeling 
section). This relation between bar and channel area to flow (fig. 7), indicates that as much as 15 percent of the total bar area is inundated within the range of flows in the analyzed photographs, and was used to normalize the channel width and bar area measurements for all analysis periods to a constant discharge of $2.8 \mathrm{~m}^{3} / \mathrm{s}$, a discharge slightly less than the lowest discharge associated with any of the photograph sets.

Tide level has an especially large influence on the mapping within the Estuary Reach, particularly for gravel bars submerged with each tidal cycle. Because tidal stage varied between photograph sets, only the part of bars inferred to be above tidal range during low flow periods were mapped. Mapping of the bars was possible because bars subject to daily tidal inundation have substantial algal growth, giving them a distinctly darker tint in the photographs. The tidally inundated parts of the bars were included in the primary channel map unit.

Considering registration errors and digitizing precision, the horizontal uncertainty of the digital channel and flood-plain maps was inferred to be less than $15 \mathrm{~m}$ for sharply defined features. For the maps from 1995 to 2008, positional uncertainty is probably less than $6 \mathrm{~m}$ as judged by the precise agreement between persistent features observable on this imagery. Flow variations between photograph sets add additional uncertainty, which can in part be accounted for by normalizing bar and channel area measurements to a reference discharge.

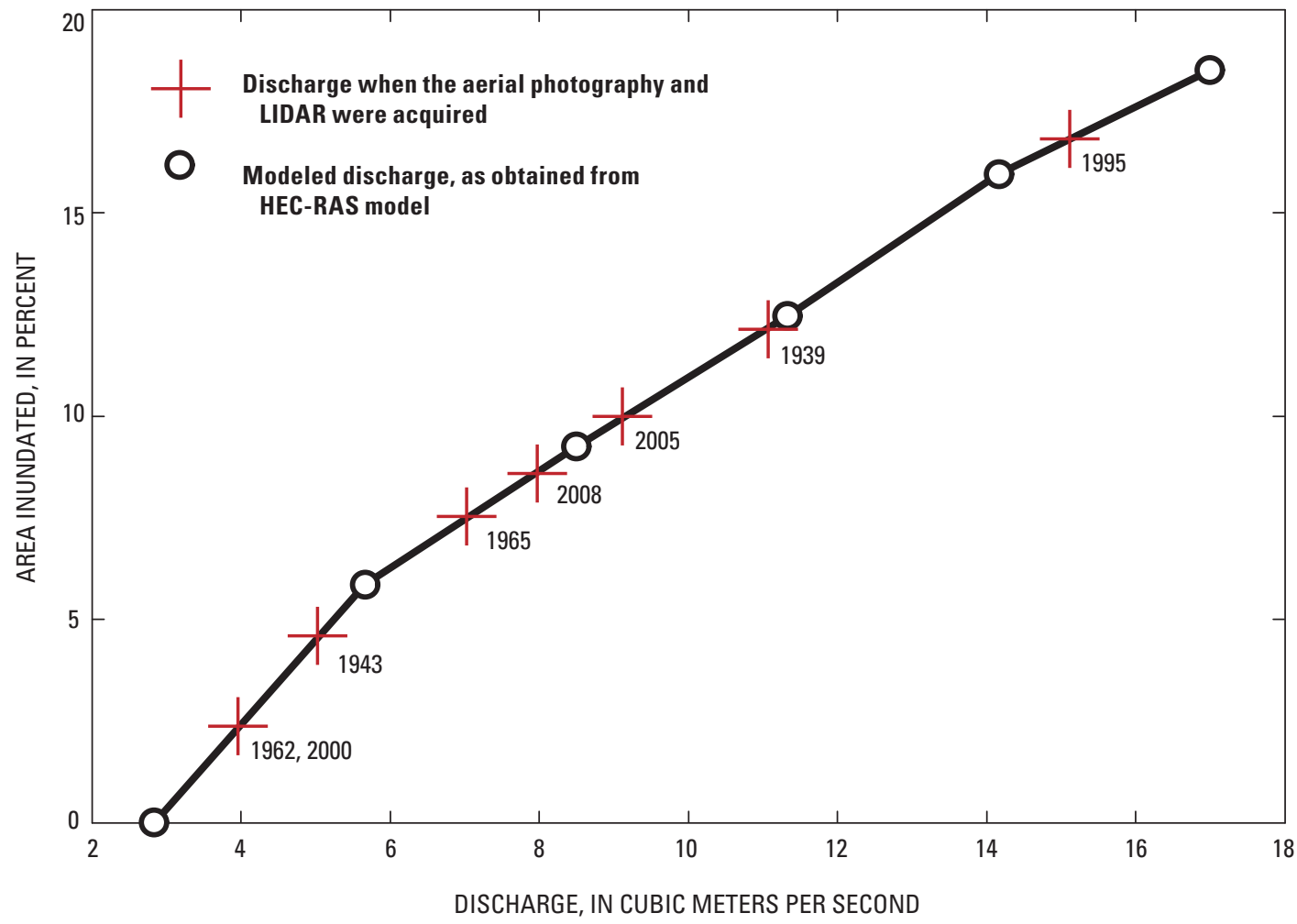

Figure 7. Bar area inundation compared with discharge, Chetco River, Oregon. Area inundated for each discharge was calculated on the basis of six modeled discharges between 2.8 and 17 cubic meters per second and overlaying corresponding inundated areas onto mapped bar areas. This relation was used to normalize bar and channel measurements from photograph sets to a common discharge of 2.8 cubic meters per second. Also shown are discharges for the seven photograph sets and the light detection and ranging (LIDAR) topography. 


\section{Mapping Channel Features, Flood-Plain Vegetation, and Bank Materials}

The photograph mosaics provide the basis for systematic mapping of channels and bars as well as broad scale landcover and vegetation characteristics. Geomorphic features were mapped for each of the seven photograph sets and for the LIDAR topography. The mapped features form a foundation for evaluating changes to channel and bar planform and support the analysis of depositional and erosional volumes. Land cover and vegetation were mapped for only the photographs from 1939, 1962, 1965, and 2005 to determine coarse patterns of change in vegetation cover and density within the geologic flood plain.

Mapping of geomorphic features was confined to the active channel, defined as the area typically inundated during annual high flows as judged by the presence of water and flow-modified surfaces (Church, 1988). Features within the active channel were divided into mapping units: (1) primary (low flow) channel, (2) gravel bars, (3) alcoves (side channels or other wetted areas connected to the primary channel), (4) tributaries, (5) jetties, (6) disconnected water features, and (7) the constructed boat basin. For each period of time, all such features larger than about $200 \mathrm{~m}^{2}$ were digitized at a scale of 1:1,000. All linework was reviewed at a scale of 1:3,000 by another project team member to ensure consistency between time periods.

The primary channel was mapped by digitizing the wetted perimeter of the main channel as shown on aerial photographs and the LIDAR topography. Gravel bars, defined as gravel-covered surfaces with evidence of recent mobilization (bare or sparse vegetation) were separated into two categories: flood-plain bars (sharing a margin with the flood plain) and island bars (completely surrounded by water). Tributary channels and tributary fans also were mapped where these features were discernable; however, because of differences in photograph resolution and vegetation, tributary features present in some periods were not always apparent in other periods. Disconnected water features were defined as any water body within the active channel area completely separated from other water features, and mostly consisted of ponds in swales on flood-plain bars. Constructed features consisted of the boat basin, jetties, and the dike alongside the boat basin.

Although geomorphic features were mapped for only the active channel corridor, basic land-cover attributes, including vegetation, were mapped for the entire geomorphic flood plain, but for only four time periods. The geomorphic flood plain was defined for this study as the relatively flat surface formed of recent alluvium occupying the valley bottom, and was mapped on the basis of topography and field inspection. The flood-plain boundaries depicted here do not necessarily correspond to inundation levels of specific flood discharges or flood frequency. Choices of map units for the land cover and vegetation mapping were based on review of historical and recent aerial photographs to ensure that each of the land cover classes could be distinguished from each set of photographs, supplemented by field inspections during September 2008. Species information was compiled from field manuals and with assistance from silviculturist Robyn Darbyshire (U.S. Department of Agriculture, Forest Service, oral commun., September 12, 2008).

Eight mappable classes of land cover were defined, with three of these classes also assigned vegetation density ranges. Detailed descriptions of each mapping category are provided in the metadata accompanying the GIS files (U.S. Geological Survey, 2009) and are only summarized here. All wetted features, including the primary channel and alcoves, are mapped as Water, whereas rocky outcrops, including "Tide Rock" and "Morris Rock" (fig. 1), are mapped as B edrock. Major paved roads, developments, and clusters of houses are mapped as D eveloped areas, although individual houses and small dirt roads are classified according to the surrounding land cover. Bare surfaces are nonbedrock terrestrial surfaces with less than 25 percent cover of discernable vegetation, typically appearing light colored on aerial photographs. Bare surfaces are chiefly gravel bars with recently disturbed surfaces (fig. 8). Sparse Vegetation is the designation for surfaces with 5-25 percent vegetative cover, and typically consists of isolated trees, grasses, and shrubs. These areas almost always are gravel bars vegetated with early successional species (fig. 8). Grasses, lawns, agricultural lands, and various herbaceous communities (including Vetch spp., Bacharis spp., and members of the composite family) are mapped as H erbaceous Vegetation, which has smooth texture and light brown or gray color in the aerial photographs (fig. 8). The Woody Shrub mapping unit is for areas with low canopies (chiefly less than $5 \mathrm{~m}$ ) sufficiently dense to appear relatively smooth in the aerial photographs. Woody shrub cover is typically composed of willows (Salix spp.) and small (less than $5 \mathrm{~m}$ tall) alders (Alnus spp.). This type of cover is found almost exclusively on gravel bars, commonly growing in narrow groves or thickets aligned parallel to the channel (fig. 8). Clusters of large trees were mapped as M ature Trees, and typically included black cottonwood (Populous balsamifera), myrtlewood (U mbellularia californica), and tall alders on flood-plain surfaces outside of the active channel area (fig. 8). Although mature trees typically had a distinct size and texture when compared with willows and other shrub-type vegetation in the aerial photographs, it was difficult to discern small trees from willows; hence, canopies associated with trees less than about $5 \mathrm{~m}$ tall were grouped together in the Woody Shrub category. Vegetation density values of moderate (25-75 percent cover) and dense (75-100 percent cover) were assigned to Herbaceous, Woody Shrub, and M ature Tree mapping units. 


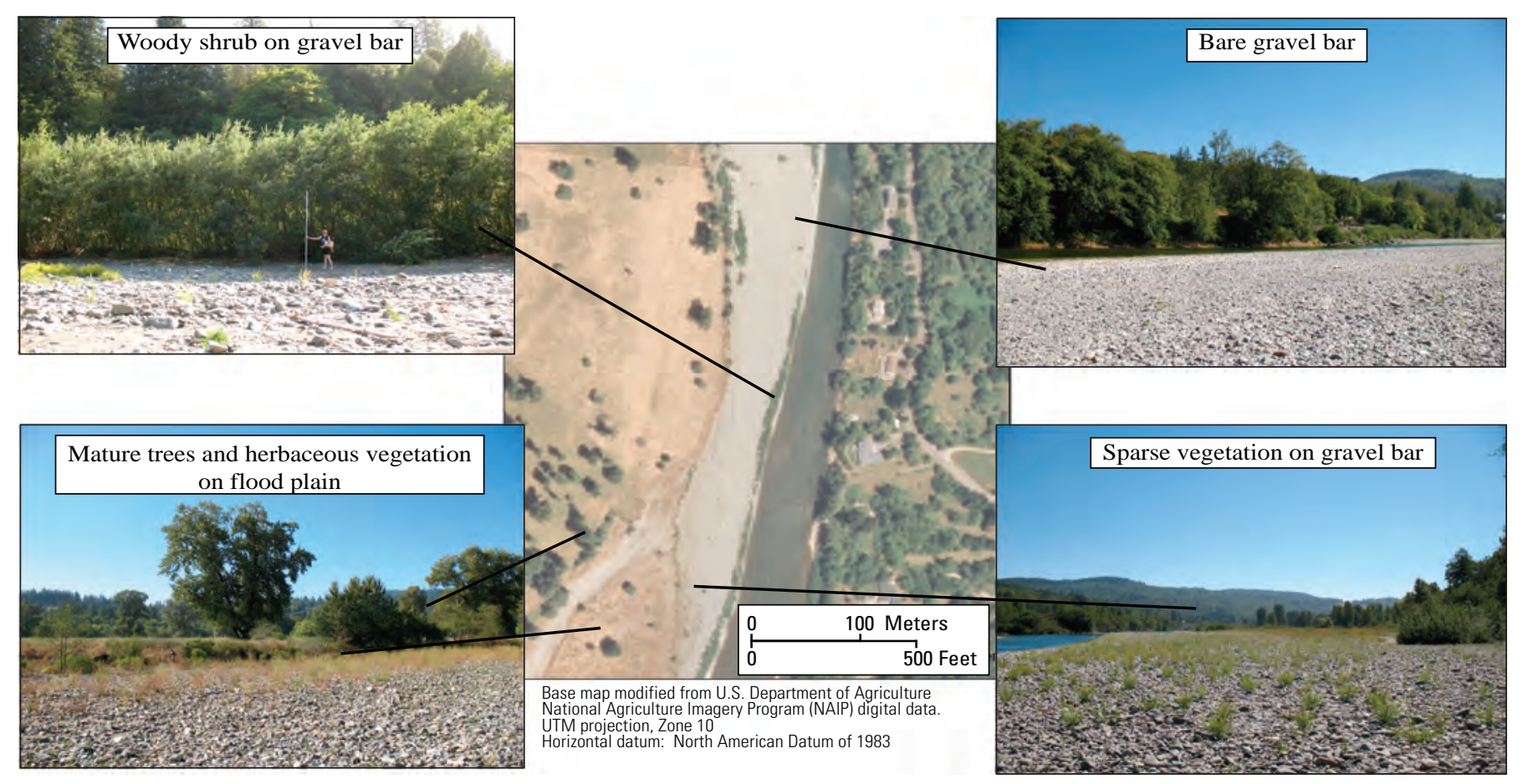

Figure 8. Showing examples of landcover mapping categories, as depicted in an orthophotograph from 2005 near flood-plain kilometer 9 of the Chetco River, Oregon. Land cover was mapped from aerial photographs and included five vegetation categories: Woody shrub, mature trees, herbaceous vegetation, bare gravel, and sparse vegetation. (Photographs by Scott Anderson, U.S. Geological Survey, September 2008.)

The bank materials along the Chetco River corridor were mapped in such a manner as to differentiate reaches bordered by erodible sediments from reaches flanked by more resistant bedrock or artificial revetment. Bank materials were defined as the natural or artificial material bordering the active channel and were mapped by walking the length of the study area and recording the condition and composition of the channel banks. Field observations were then compared with the recent orthoimagery and LIDAR topography to construct continuous maps of bank materials along both edges of the active channel at a scale of 1:5,000. The map units include the primary types of bank materials: (1) flood-plain risers formed of erodible sand and gravel contained in fluvial deposits flanking the active channel, (2) bedrock outcrops, and (3) artificial fill (primarily consisting of material used to fill the former tidelands near the present location of the boat basin at FPkm 0). Bank protection revetment, chiefly consisting of large angular boulders, was mapped as an overlay to the three primary categories of bank material.

\section{Results of Channel Mapping}

Overall trends for 1939-2008 for active-channel features of the study reach show evidence of a 34 percent reduction in gravel bar area and a slight decrease in channel sinuosity (fig. 9). Channel width has not changed systematically during this period. The reduction in bar area is much greater than can be attributed to differences in flow stage between photograph sets (igss. 9 and $\underline{10}$ ). These overall changes, however, reflect a temporally and spatially varied history of channel behavior. The largest change, the decrease in bar area, is almost entirely accounted for by the large reduction in flood-plain bar surfaces between 1965 and 1995. Prior to 1965 and subsequent to 1995, bar areas may have increased slightly for some reaches, especially between 2005 and 2008, although at smaller rates relative to uncertainties of mapping and the effects of different discharges on mapped areas (igs. 9 and $\underline{10}$ ). 

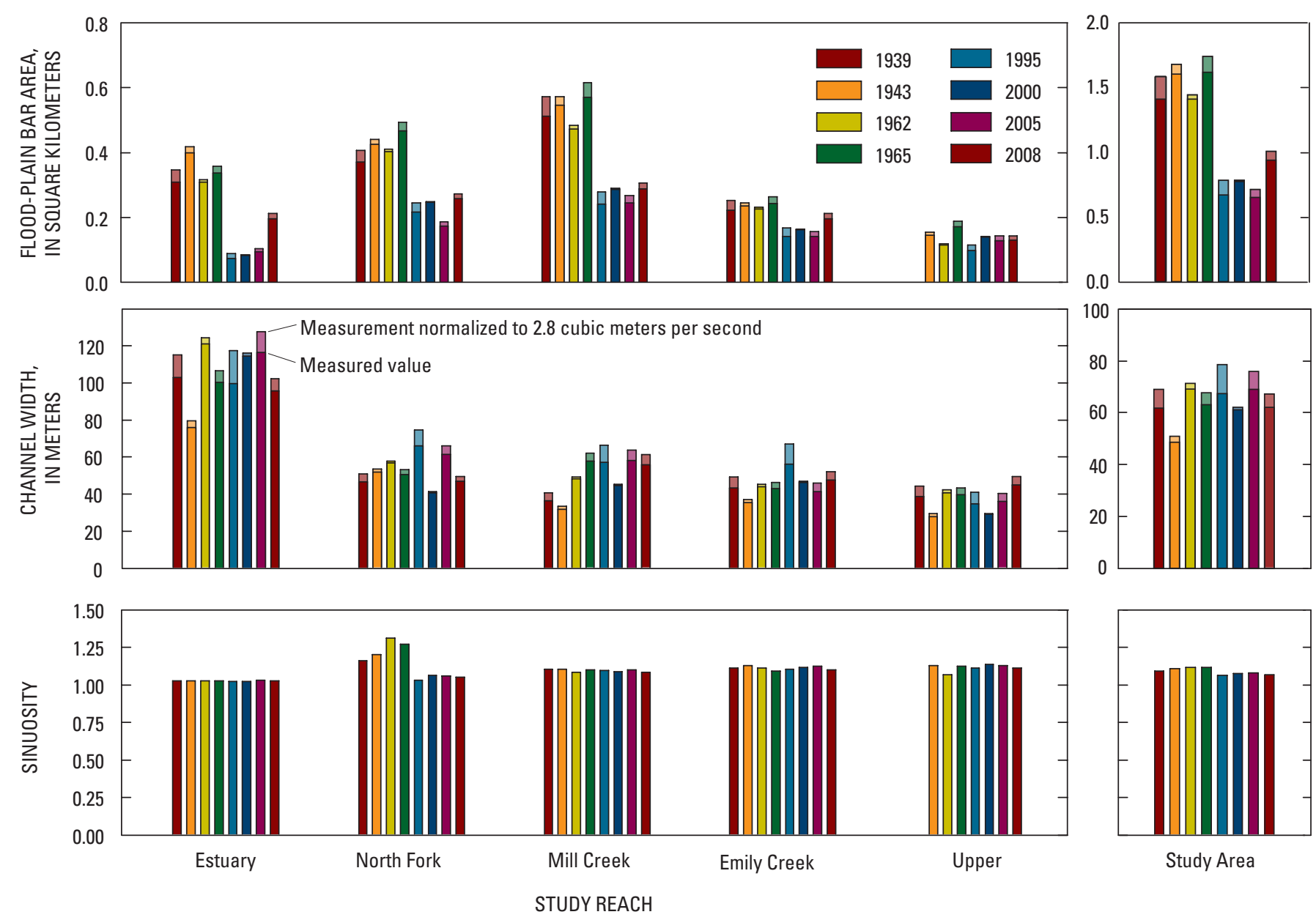

Figure 9. Summary of channel change in the study area, Chetco River, Oregon, 1939-2008. Bar extensions in lighter shades for bar area and channel width represent values normalized to a discharge of 2.8 cubic meters per second $\left(\mathrm{m}^{3} / \mathrm{s}\right)$. The photographs from 1939 only partly cover the Upper Reach; hence, no measurements from 1939 are available for bar area and sinuosity for that reach, and channel width is only a partial measurement.

Historical channel change for 1939-2008 for the Chetco River was greatest along the lower reaches where the valley bottom is wide and a greater percentage of the channel is bordered by more erodible flood-plain materials than the upper reaches (figs. 11-15). The North Fork (fig. 13) and lower Mill Creek (fig. 14) reaches have had the most planform change. For the North Fork Reach, the 1939 channel was relatively sinuous and narrow, with a sinuosity of 1.16 and an average width of $47 \mathrm{~m}$. The maps from 1995 to 2008 show the channel to be straighter, with a sinuosity in 2008 of 1.05. In conjunction with sinuosity changes, the average water-surface slope of the North Fork Reach has increased by about 10 percent between 1939 and 2008, from $0.000767 \mathrm{~m} / \mathrm{m}$ to $0.000849 \mathrm{~m} / \mathrm{m}$. Low-flow channel width changes have been more variable; for example, reach average width along the North Fork Reach was $66 \mathrm{~m}$ in 1995, $41 \mathrm{~m}$ in 2000, $61 \mathrm{~m}$ in 2005, and decreased to $47 \mathrm{~m}$ by 2008 (fig. 9). Between
1939 and 2008, normalized (for flow stage) total bar area for the North Fork Reach diminished from $0.4 \mathrm{~km}^{2}$ to $0.27 \mathrm{~km}^{2}$ (fig. 9). Similarly, bar area for the Mill Creek Reach has been reduced from almost $0.6 \mathrm{~km}^{2}$ in 1939 to about $0.3 \mathrm{~km}^{2}$ in 2008 (fig. 9). The net changes for these reaches, however, do not reflect continuous trends because of episodic increases in sinuosity and bar area within the overall record (figs. 9 and 10).

Inspection of the individual photograph sets shows that the changes along the North Fork Reach took place in several steps. During 1943-62, channel migration at rates of as much as $14 \mathrm{~m} / \mathrm{yr}$ between photograph sets created a large meander bend near the confluence of the North Fork Chetco River (FPkm 7.5). During winter 1969-70, a large bend near the confluence of Jack Creek ${ }^{1}$ (FPkm 6) was cut off and abandoned (probably during the January 1970 flood of nearly 1,900 m³/s). Between 1969 and 1976, two similar avulsions

\footnotetext{
${ }^{1}$ Timing of avulsion is based on inspection of unrectified aerial photographs provided by the Bureau of Land Management.
} 


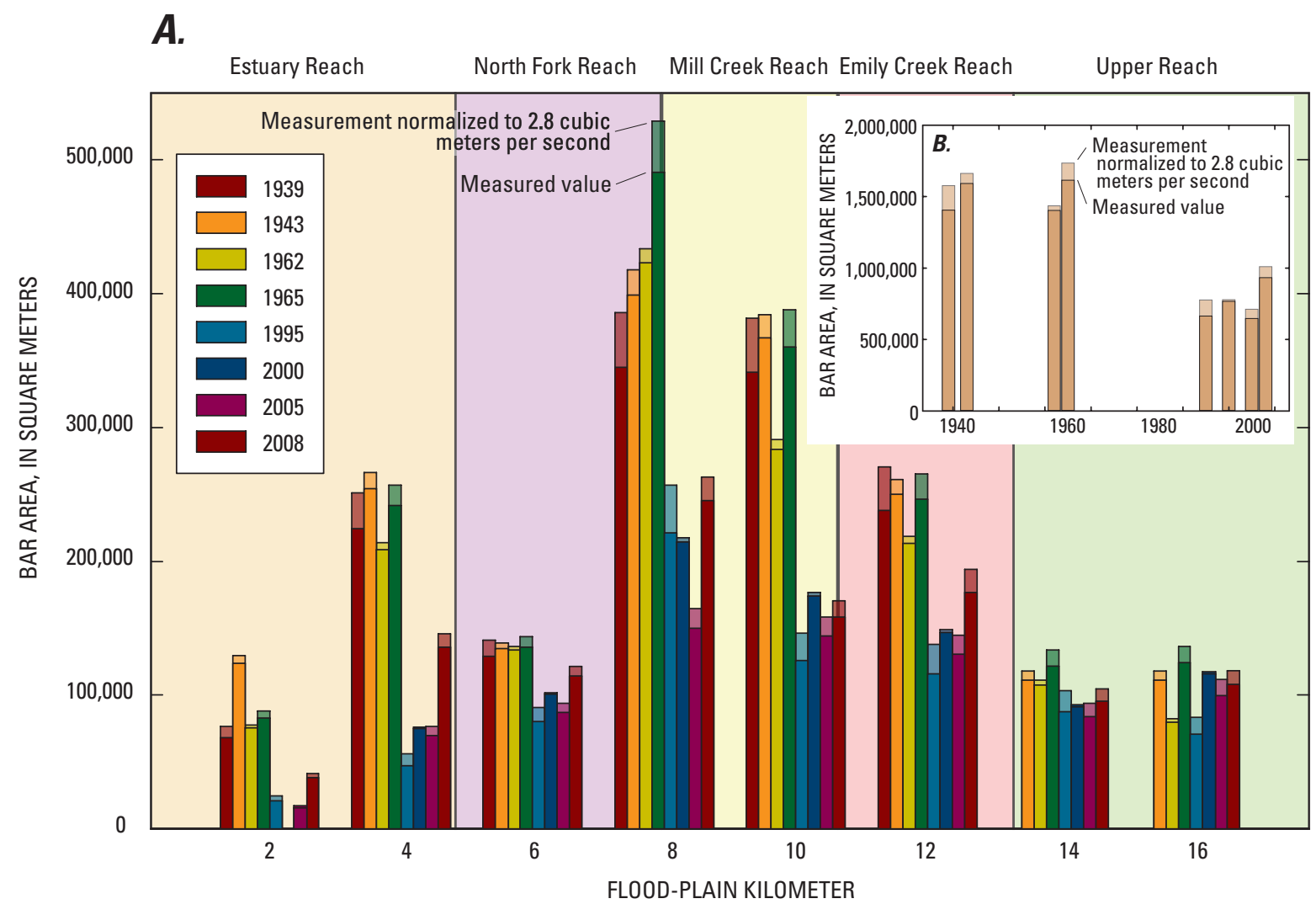

Figure 10. Spatial and temporal variation in gravel bar area for eight time periods, Chetco River, Oregon, 1939-2008. Bar extensions in lighter shades represent values normalized to a discharge of 2.8 cubic meters per second $\left(\mathrm{m}^{3} / \mathrm{s}\right)$. (A) Bar area aggregated by 2-kilometer lengths of flood-plain. No data for 1939 upstream from flood-plain kilometer 13. (B) Bar area for total study reach.

resulted in abandonment of the North Fork bend (FPkm 7.5) and a smaller bend near FPkm $6 .^{2}$ The two avulsions at FPkm 6 and 7.5 most likely were during the 1970-72 period of large floods with peak discharges of 1,300-1,900 m³ (fig. 2). These avulsions in the late 1960s and early 1970s account for the major decrease in sinuosity for the North Fork Reach between 1965 and 1995 (fig. 9). Partly as a consequence of these channel changes, bank revetment has been placed along these channel margins in the North Fork Reach, so that revetment and bedrock now border 47 percent of the reach in contrast to more than 75 percent of the North Fork Reach being historically bordered by erodible alluvial flood-plain materials (fig. 11). In recent decades, the lower Mill Creek Reach and North Fork Reach have been much less dynamic than for 1939-1965, shifting laterally at rates less than $6 \mathrm{~m} / \mathrm{yr}$ with no major avulsions (figs. 13 and $\underline{14}$ ).

Along the Estuary Reach, the overall style of planform change from 1939 to 2008 has been lateral shifting of the channel between the confining valley walls in conjunction with substantial loss of net bar area (igss. 9, $\underline{10}$, and 12). For example, near FPkm 3, channel maps from 1939 to 1965 show the low flow channel against bedrock along right bank, and a large (150,000 $\mathrm{m}^{2}$ ) gravel bar (known locally as "Tidewater Estuary Bar”) along the left bank. Between 1965 and 1989³, the channel shifted south to erode much of this bar (fig. 12). Additionally, higher elevation areas of Tidewater Estuary Bar, which appear bare and recently active in the photographs from 1939 to 1965, were protected by revetment and developed for residential and commercial use by 1989. The cumulative result of these types of changes is that bar area for the Estuary Reach has decreased 36 percent between 1939 and 2008, although bar area has recently increased between 2005 and 2008 (figs. 9 and 10 ). Development along the Estuary Reach has resulted in extensive bank stabilization; 41 percent of the channel margin is now bordered by revetment (fig. 11).

\footnotetext{
${ }^{2}$ Timing of these avulsions is based on inspection of photographs from 1969 provided by the Bureau of Land Management and aerial photographs from 1976 used as base map in the Flood Hazard study for the Chetco River (Soil Conservation Service, 1979).

${ }^{3}$ Timing of channel change is based on aerial photographs from 1965 (acquired by USDA and rectified in this study; see table 2, and unrectified aerial photographs from 1989 provided by the Bureau of Land Management.
} 


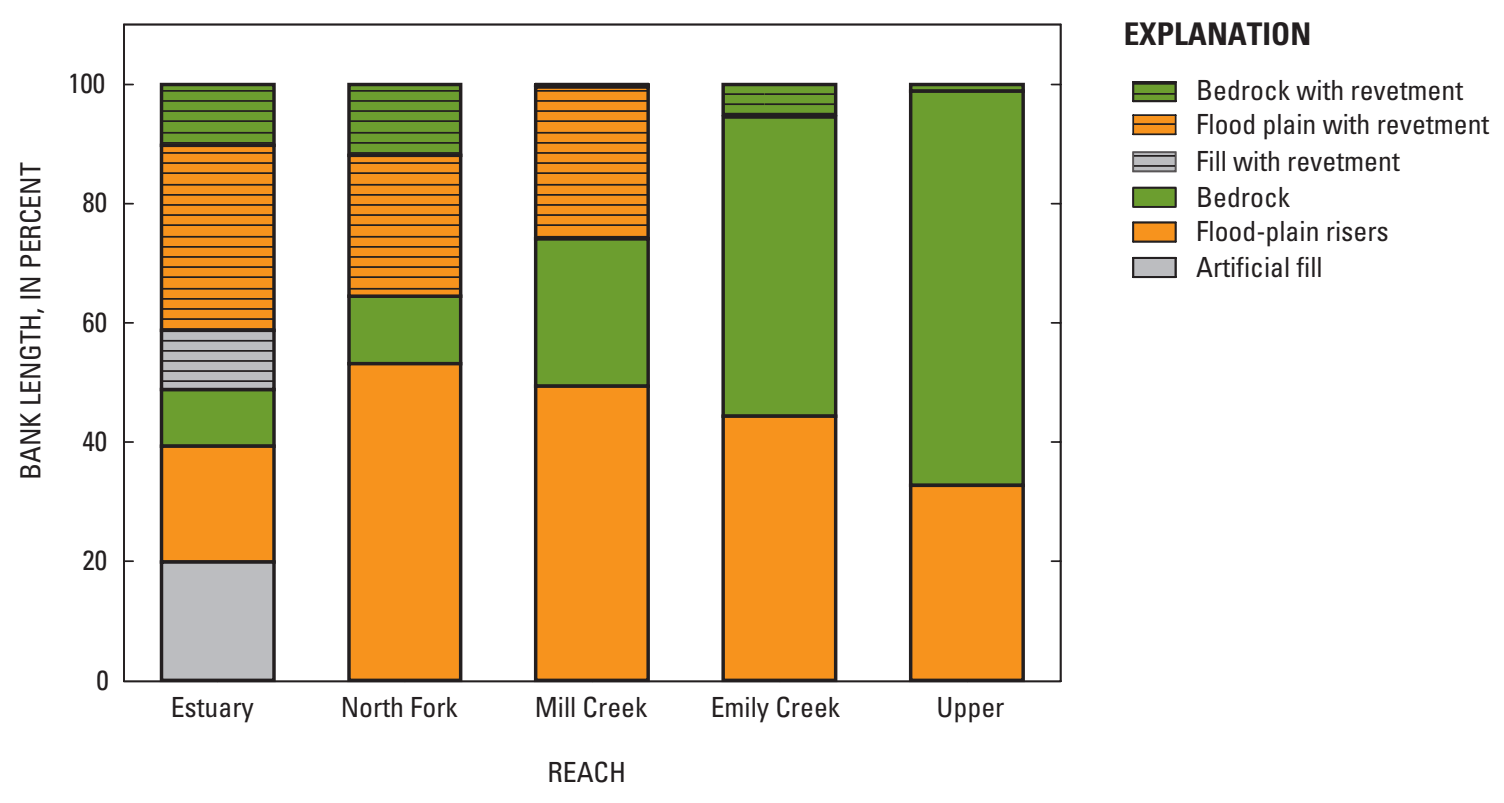

Figure 11. Reach-segregated distribution of bank material and revetment, Chetco River, Oregon.

Major changes to the mouth of the Chetco River are the result of 20th century development and navigational improvements that began in the 1950s. The aerial photographs from 1939 and 1943 depict the mouth of the Chetco River as about $200 \mathrm{~m}$ wide, with extensive sand bars and tidal lagoon. By 1962, a pair of jetties restricted channel width and closed off the former lagoon. By 1995, continued bank protection, jetty extension, and filling of former lagoon areas resulted in an overall straightening and narrowing of the channel so that channel width at the mouth presently ranges from 100 to $120 \mathrm{~m}$; about one-half the width shown on the earliest maps and photographs (fig. 12).

Channel change along the middle and upper reaches of the study area has been much less than for the lower Mill Creek, North Fork, and Estuary Reaches. Within the Emily
Creek and Upper reaches, and the upper part of the Mill Creek Reach, the channel crosses back and forth between the valley walls with intervening channel-flanking gravel bars. The general pattern and positions have remained generally stable with the most stable locations being where the channel abuts the bedrock valley walls (figs. 14 and $\underline{15}$ ). In isolated locations, the river has migrated laterally at rates as much as $6 \mathrm{~m} / \mathrm{yr}$ where crossing from valley side to side. Where the valley bottom widens towards the lower part of the Mill Creek Reach (FPkm 7.5-8.5), the channel has been more active, particularly in the period from 1943 to 1962 when rapid migration resulted in the formation of a large meander bend near the North Fork confluence (fig. 14). 


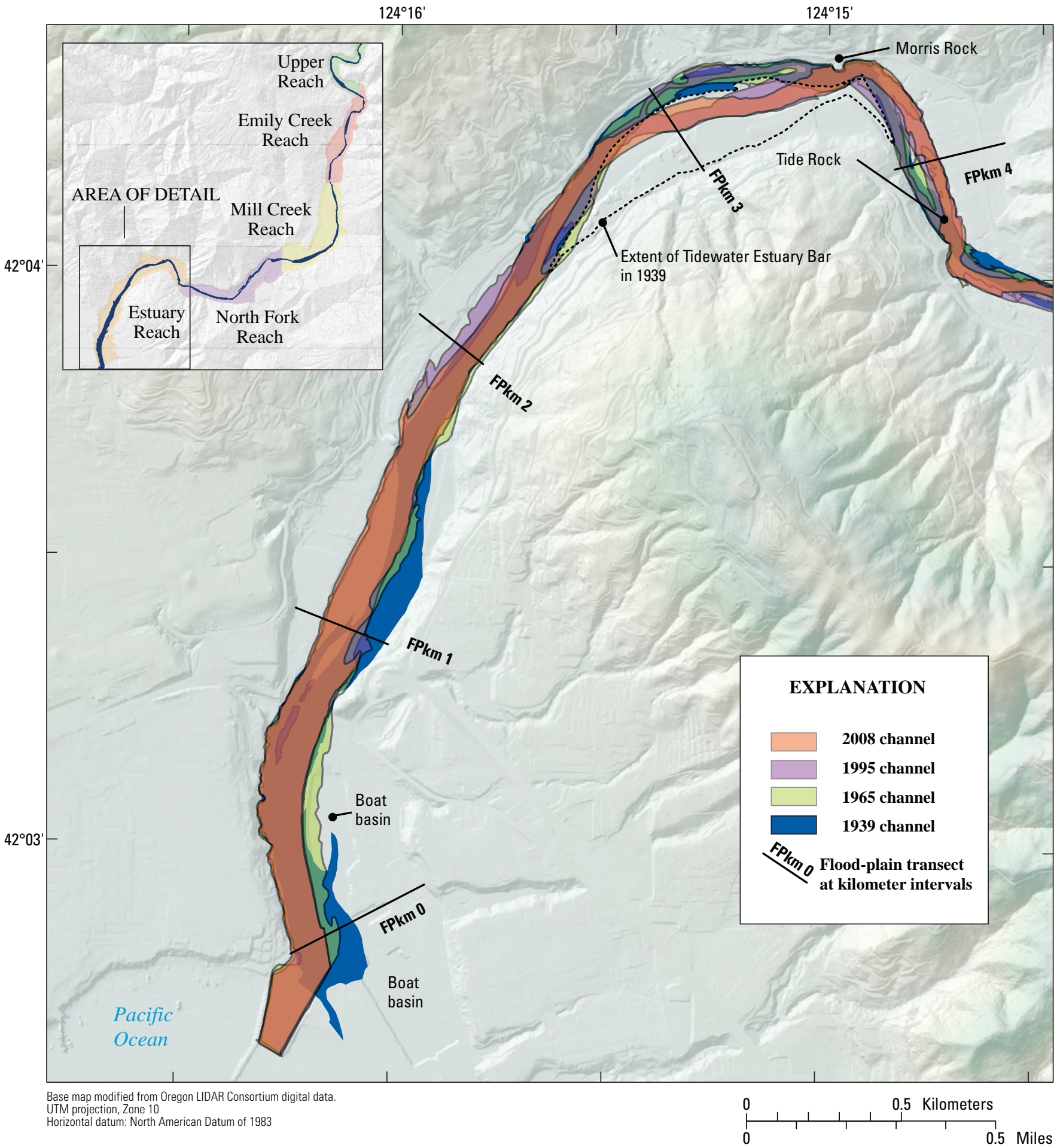

Figure 12. Channel changes between flood-plain kilometers 0 and 4.5 encompassing the Estuary Reach, Chetco River, Oregon, 1939-2008. FPkm, flood-plain kilometer. 


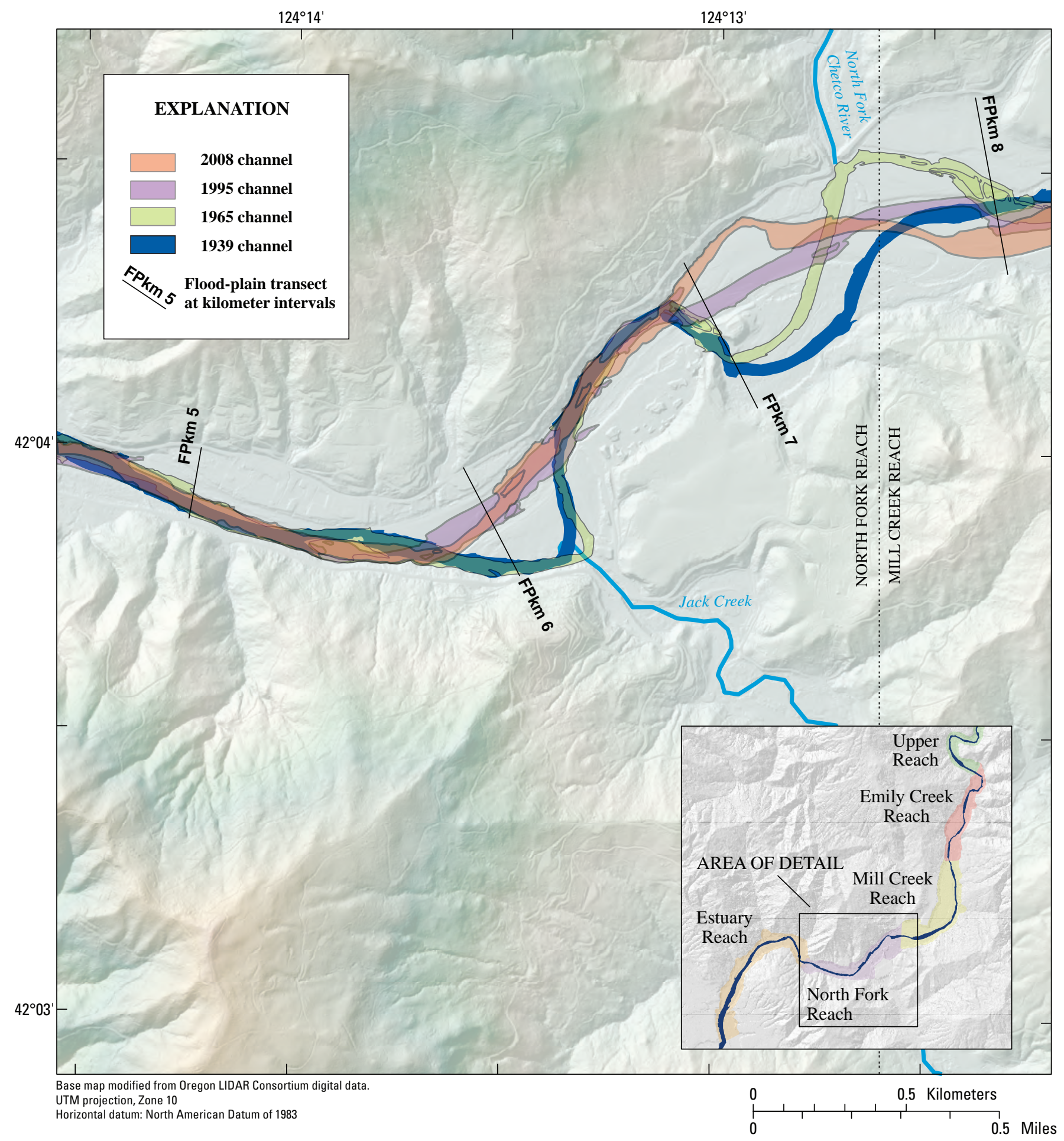

Figure 13. Channel changes between flood-plain kilometers 4.5 and 8.4 encompassing the North Fork Reach, Chetco River, Oregon, 1939-2008. FPkm, flood-plain kilometer. 


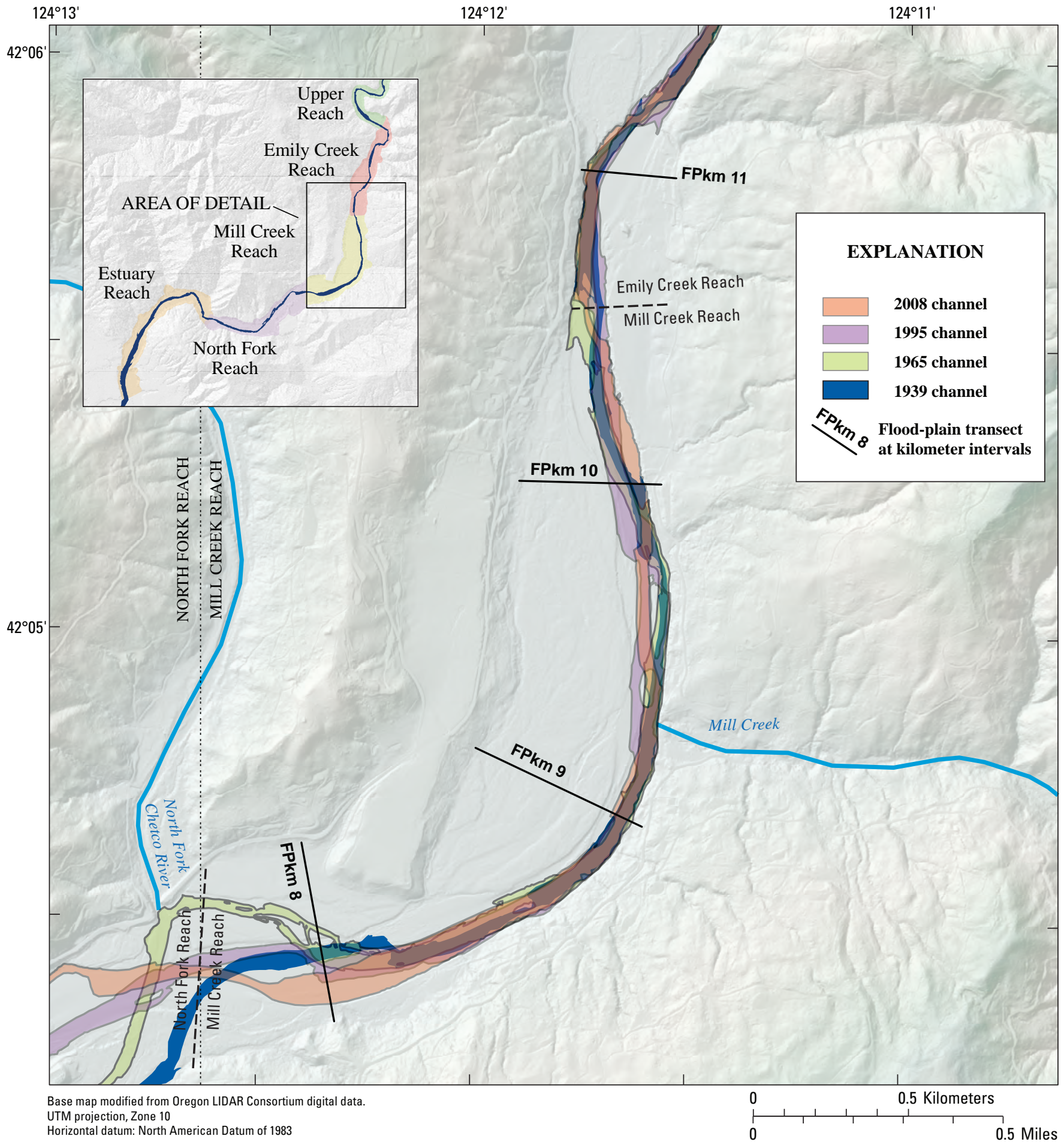

Figure 14. Channel changes between flood-plain kilometers 7.5 and 11.5 encompassing the Mill Creek Reach, Chetco River, Oregon, 1939-2008. FPkm, flood-plain kilometer. 


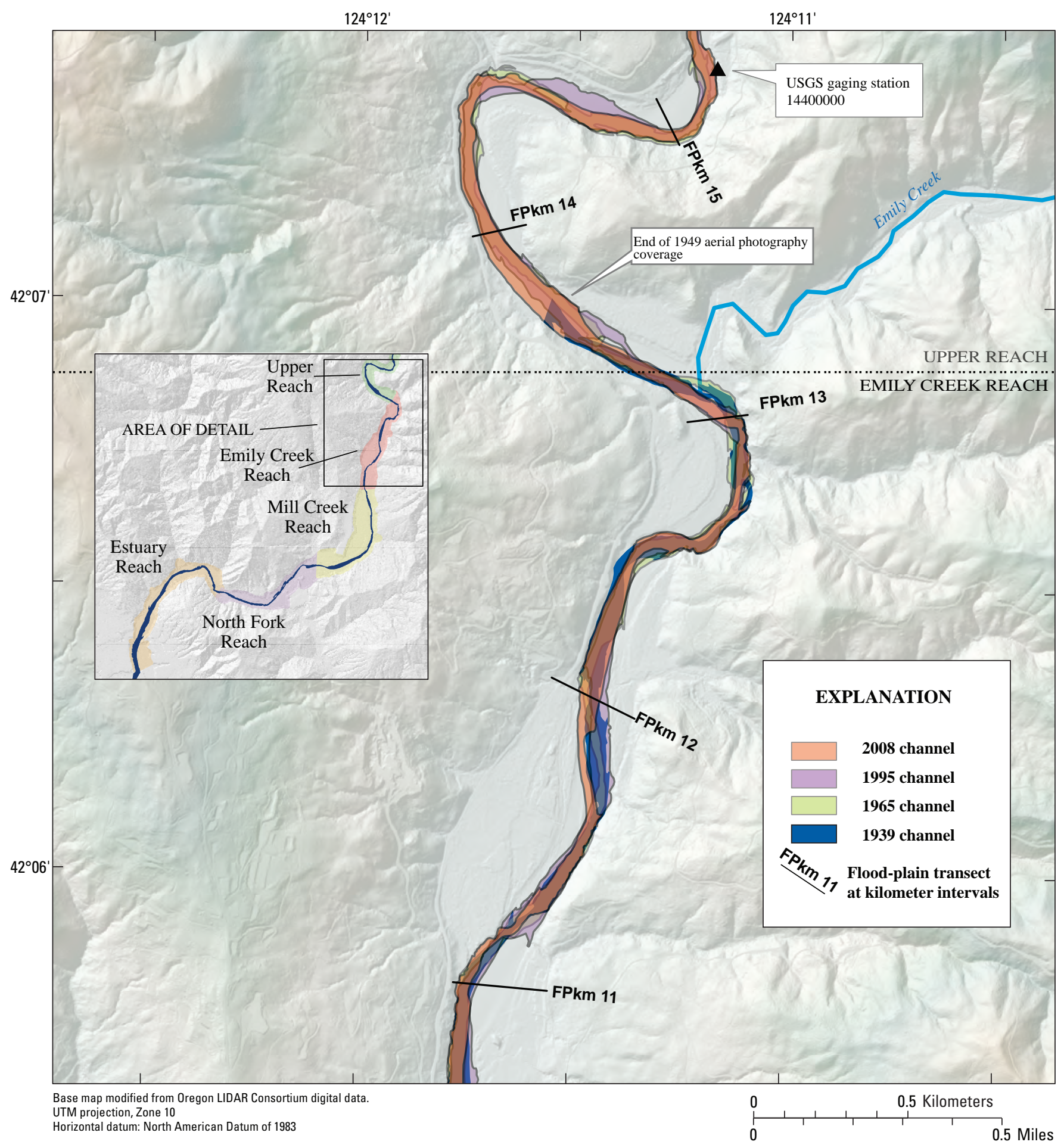

Figure 15. Channel changes between flood-plain kilometers 10.6 and 15.2 along the Emily Creek and Upper reaches, Chetco River, Oregon, 1939-2008. Coverage for 1939 extends only to flood-plain kilometer 13.7. FPkm, flood-plain kilometer. 


\section{Results of Land Cover Mapping}

The land cover and vegetation mapping shows that the dominant land cover for the geomorphic flood plain is Mature Trees, covering about 30 percent of the flood plain in 2005 and primarily consisting of flood-plain forests outside of the active channel (fig. 16). Water occupies about 20 percent of the flood plain at low flow. Developed area accounts for about 30 percent of the flood-plain area along the Estuary Reach in 2005. The M ature Trees category systematically decreases as a percentage of flood-plain area downstream, as does Water except for the North Fork and Estuary Reaches. D eveloped area is only substantial in the North Fork and Estuary Reaches, and primarily for the photographs from 1962 and more recent photographs. The most dynamic classes are the Bare, and the Sparse, Herbaceous, and Woody Shrub vegetation categories, which cover the greatest relative area in the Mill Creek and North Fork Reaches. These cover-type vegetation classes are chiefly associated with gravel bars subject to colonizing vegetation. No obvious trends are evident for these classes except that the combined area of Water, Bare, and Sparse vegetation was greatest for all four reaches in 1965, mostly at the expense of Woody Shrub and Mature Trees categories, likely indicating flood-plain erosion and vegetation removal by the flood in 1964.

\section{Vertical Changes in Channel Morphology and Bathymetry}

Although lateral channel changes may have significant resource, habitat, and hazard consequences, changes in the vertical position of the bed are more indicative of riverwide changes in the balance between sediment input and export (Schmidt and Wilcock, 2008). Vertical changes are also difficult to detect without systematic surveys of the channel. For this study, we compared two previous detailed surveys - a U.S. Army Corps of Engineers navigational survey in 1939 for the Estuary Reach between FPkm 0 and 4.5, and a Soil Conservation Service (1979) survey in 1977 for a flood study of the upstream reaches between FPkm 4 and 15-with the LIDAR topography acquired in 2008 and our own surveys during summer 2008 made as part of this study. Additional local bed elevation information is from repeat surveys of isolated cross sections in the fluvial reaches as well as the detailed information on channel bed changes from streamflow measurements at the USGS streamflow-gaging station at FPkm 15.24.
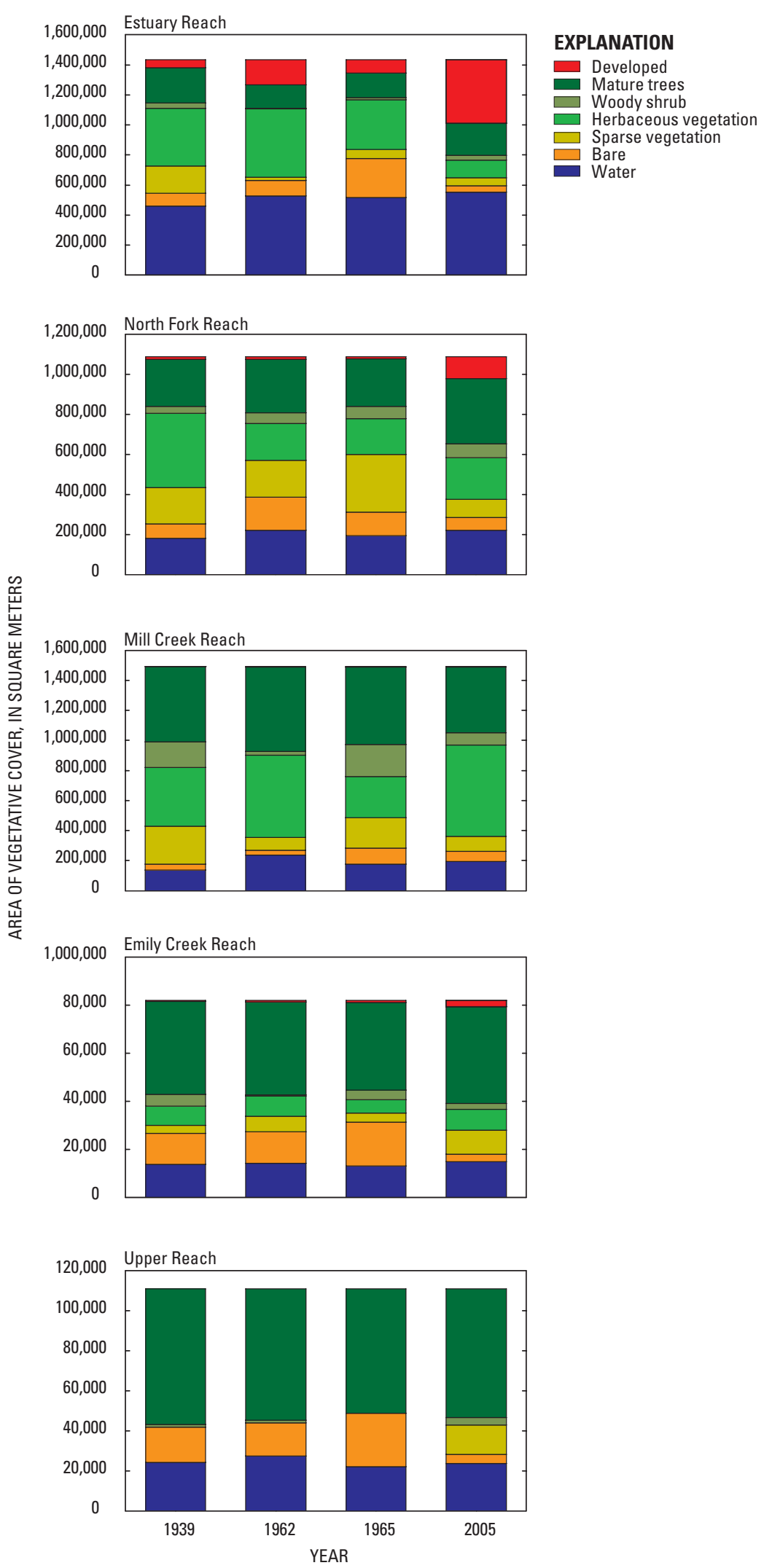

Figure 16. Changes in flood-plain land cover by reach, Chetco River, Oregon, 1939-2005. Upper Reach data include only the $0.5 \mathrm{~km}$ length of flood plain covered by the aerial photographs from 1939. 


\section{Survey Data Used in Study}

Of several early surveys near the mouth of the Chetco River (table 3), the most useful survey for characterizing channel morphology along the Estuary Reach is the navigational survey of 1939 (U.S. Army Corps of Engineers, 1939), in which closely spaced soundings and elevations in feet relative to Mean Lower Low Water (MLLW) are provided for FPkm 0 to 4.5. Details of digitizing, georeferencing, and datum conversion are included in the metadata for the accompanying GIS maps (U.S. Geological Survey, 2009). This survey included more than 1,000 points over the lower $4.5 \mathrm{~km}$ of channel. The survey from 1939 was compared to a USGS bathymetric survey completed in September and October 2008 between FPkm 0 and 3. This boat-based survey used a depth-sounding transducer mounted directly below a real-time kinematic (RTK) global positioning system (GPS) receiver. As the survey boat traversed the estuary at transects spaced at 30-50 m intervals, the depth-sounder recorded water depth, and the GPS recorded the boat position and GPS ellipsoid height for a total of nearly 200,000 points (complete metadata and GIS layers available in U.S. Geological Survey, 2009).

The bathymetric data of 1939 and 2008 for the Chetco River estuary were interpolated to three-dimensional surfaces using a modified version of the procedure of Merwade and others (2005), which transforms the data into a channel oriented coordinate system, interpolates a continuous surface using anisotropic kriging, and reprojects the surface back to the project coordinate system of UTM NAD83 (ig. 17). Once the bathymetric surfaces were created, longitudinal profiles of the channel thalweg from each time period were extracted and plotted against river kilometers for 2008.

To determine vertical channel changes along the upstream fluvial reaches of the study area between FPkm 4 and 15 , longitudinal profiles and cross sections were compiled from a 1977 survey and compared to 2008 elevation data and surveys. In 1977, 42 cross sections across the entire valley bottom between FPkm 0 and 15.5 were surveyed as part of a flood hazard study by the Soil Conservation Service (1979). The location of each survey transect was depicted on orthophotographs from 1976 and as cross-section data shown by plots of distance (in feet from an arbitrary point) against elevation (in feet referenced to NGVD 29 datum). From this information, cross section locations and data were digitized by visually plotting survey transects shown in the orthophotographs from 1976 onto the orthophotographs from 2005. The elevations for 1977 were shifted from NGVD 29 datum to the NAVD 88 datum using the CorpsCon conversion routine (http://crunch.tec.army.mil/software/corpscon/ corpscon.html, accessed January, 13, 2009) and by comparing elevations of benchmarks surveyed in 1977 and 2008 throughout the study area.

Nine of these cross sections from 1977 were approximately matched by (1) using RTK GPS and depthsounder surveys from October 2008 of the active channel at the estimated locations of the cross sections from 1977, (2) merging these channel surveys from October 2008 with the LIDAR topography from May to June 2008 to extend the surveys for 2008 across the valley bottom, and (3), where required, shifting the cross section data from 1977 laterally so obvious and stable topographic features such as road beds and steep banks were aligned with those features on the cross sections for 2008. Such adjustments were necessary in a few cases because the cross section locations for 1977 were not precisely located. The survey in 2008 also produced a nearly complete longitudinal profile of the channel thalweg from FPkm 4 to 15 (fig. 4), which can be compared to the minimum elevation for each of the 42 cross sections surveyed in 1977. These surveys were supplemented by ancillary survey data for 1980-82 reported by Klingeman (1993; fig. 18).

The final source of vertical change information is from analysis of the history of stage-discharge rating curves at the USGS streamflow-gaging station at FPkm 15.2. Following the approach of Klingeman (1973) and Smelser and Schmidt (1998), we completed a specific gage analysis for the available record from October 1, 1969, to May 1, 2009. The specific gage analysis allows detection of changes in streambed elevation by assessing changes in water elevation (stage) through time for a set of discharge values. At USGS streamflow-gaging stations, discharge is related to stage by a stage-discharge rating curve, which is based on multiple simultaneous measurements of stage and discharge. If channel conditions change substantially (as shown by consistent offsets of newer measurements from established rating curves), or if a station is moved, a new rating curve will be developed. The specific gage analysis evaluates trends in bed elevation as indicated by the sequence of rating curves. For situations where channel width and roughness remain stable, the sequence of stages for a given discharge directly relates to changes in bed elevation. For the Chetco River, the analysis is straightforward because there have been no relocations or datum shifts for the station, although the record is shorter than for many USGS streamflow-gaging stations and 3 of the 39 ratings were unavailable. 


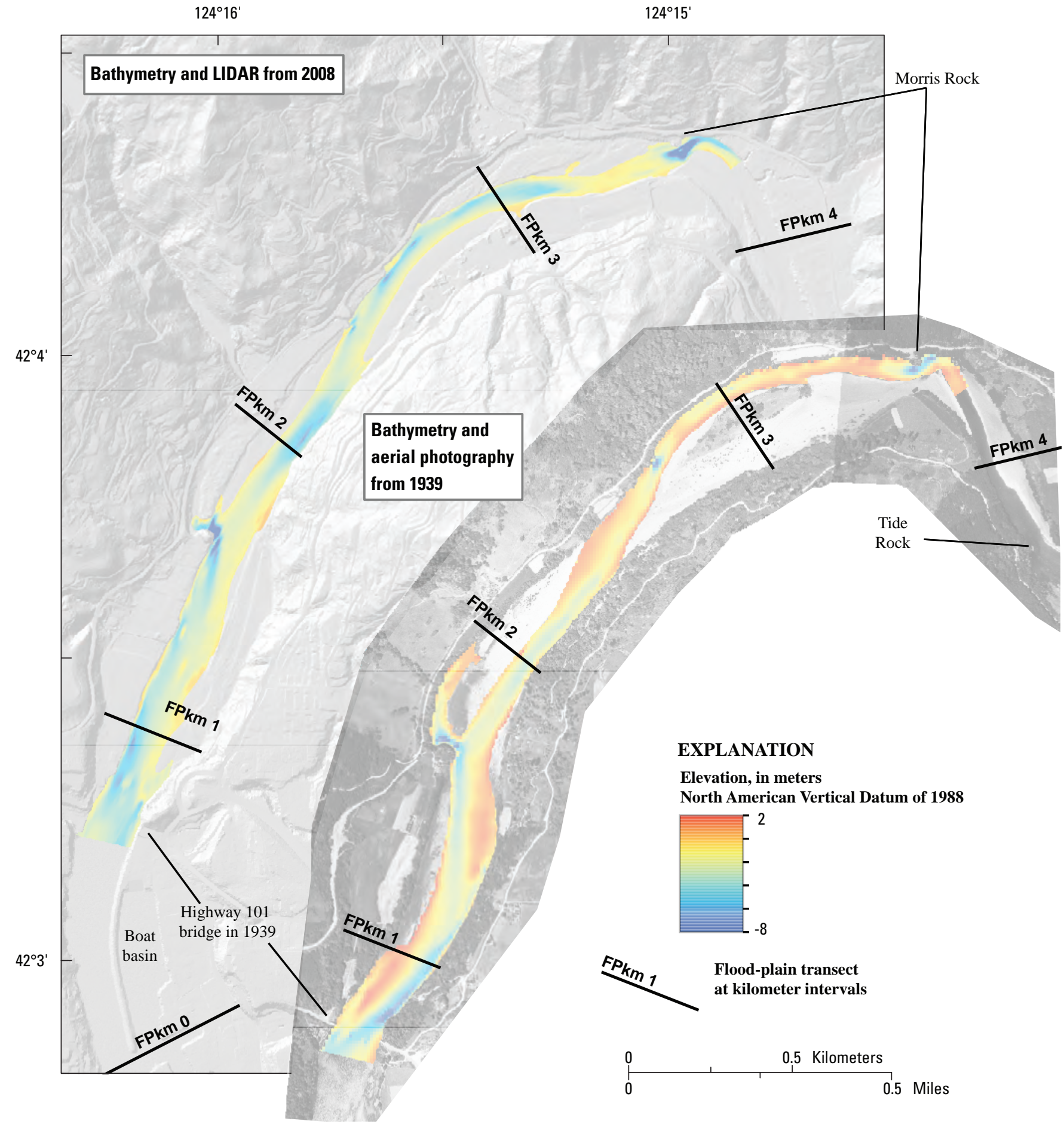

Figure 17. Bathymetry for 1939 and 2008 between flood-plain kilometer 0.6 and 3.7, Chetco River, Oregon. Bathymetry from 1939 derived from U.S. Army Corps of Engineers (1939); bathymetry for 2008 from this study. Map and survey processing described in metadata for the supporting GIS files is available from the USGS (U.S. Geological Survey, 2009). 
FLOOD-PLAIN KILOMETER

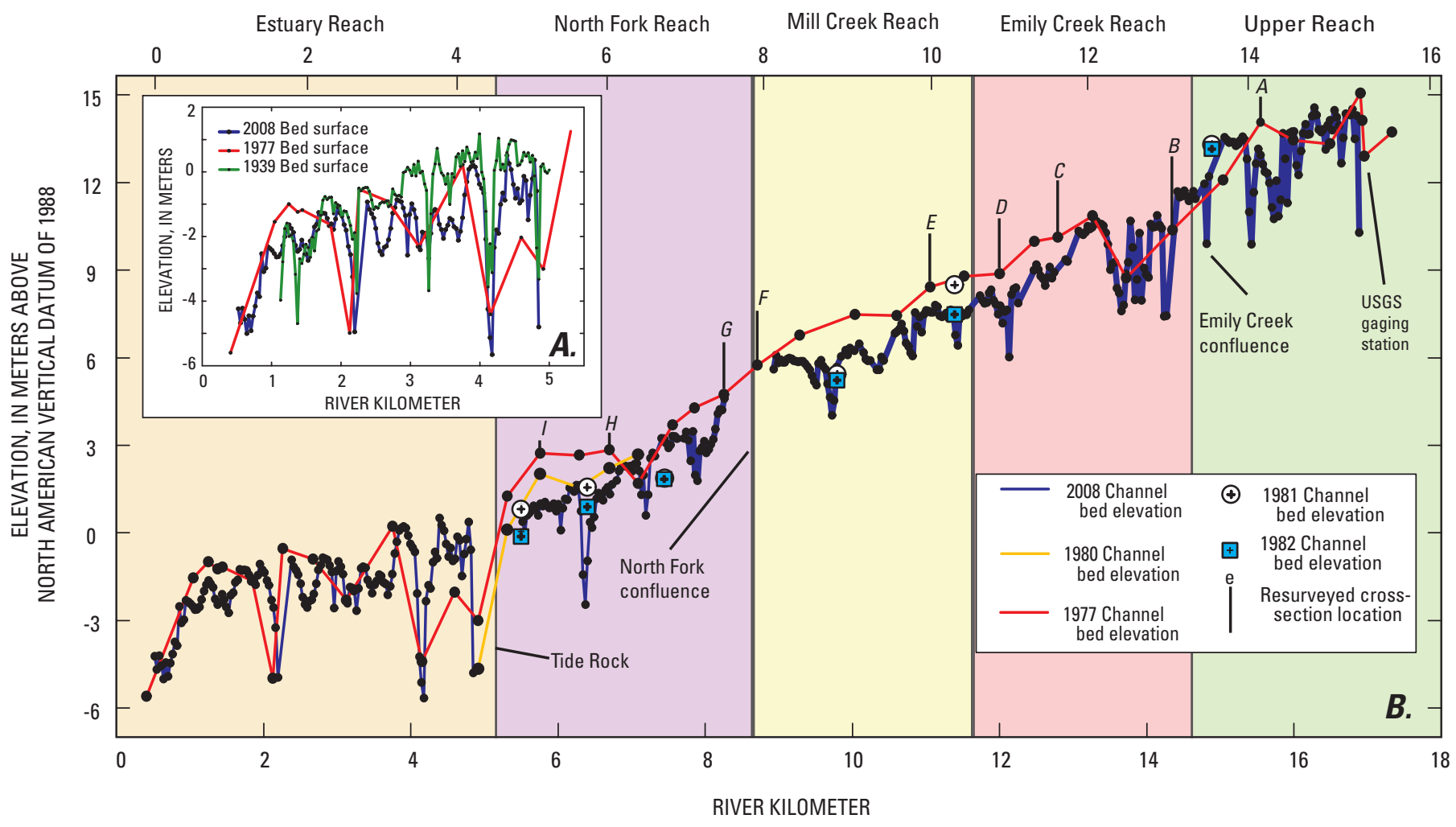

Figure 18. Channel thalweg profiles downstream of river kilometer 18, Chetco River, Oregon. $(A)$ Channel thalweg profiles for Estuary Reach extracted from (1) bathymetric survey of 1939 (U.S. Army Corps of Engineers, 1939), (2) cross sections from 1977 flood study survey (Soil Conservation Service, 1979), and (3) bathymetric survey in 2008 by U.S. Geological Survey. (B) Channel thalweg profiles from bathymetric flood study survey in 1977 (Soil Conservation Service, 1979), and channel survey in 2008 by U.S. Geological Survey. Thalweg elevations for surveys in 1980-82 are from Oregon Department of State Lands surveys, as reported by Klingeman (1993). Upper case letters show locations of resurveyed cross sections.

\section{Uncertainty and Limitations Associated with the Repeat Survey Data}

The total uncertainty regarding the bathymetric surfaces created from the survey data of 1939 and 2008 is a function of the original data and the processing involved with creating digital maps and interpolated surfaces of the bathymetries. Although the accuracy of the original map from 1939 is unknown, the process by which the original map was registered, rectified, and digitized may have introduced uncertainty on the order of $\pm 20 \mathrm{~m}$ for the horizontal positioning of points, but in most locations is substantially less. The interpolation procedure introduces additional error and uncertainty, thus the total accuracy of the bathymetry for 1939 is estimated to be $\pm 20 \mathrm{~m}$ for the horizontal dimension and $\pm 1 \mathrm{~m}$ in the vertical dimension as determined from distribution of differences between the digitized survey points and the gridded elevation data. Each of the points from the bathymetric survey in 2008 has a horizontal accuracy of $\pm 0.015 \mathrm{~m}$ and a vertical accuracy of approximately $\pm 0.05 \mathrm{~m}$.
The interpolated bathymetric surface in 2008 generally is within $\pm 0.3 \mathrm{~m}$ of the original survey elevations.

The survey in 1977 by the Soil Conservation Service (1979) was in support of a flood hazard study and preparation of flood hazard maps. The survey is described (Soil Conservation Service, 1979, p. E-1) as a "third order field survey" using USGS base elevations. For such surveys, elevation tolerances (RMSE) are typically less than $0.15 \mathrm{~m}$ (American Society of Civil Engineers, 1999, p. 6). The conversion of the original sea level (NGVD 29) datum to NAVD 88 is straightforward and the converted data match resurveys in 2008 of benchmarks used in 1977 to within $0.05 \mathrm{~m}$. Therefore, the primary source of uncertainty regarding the survey in 1977 is its horizontal positioning. The only available information for the precise location of the measurements for 1977 is the $1: 4,800$ photomosaic maps in the Soil Conservation Service (1979) report. On the basis of these maps, the cross section locations for 1977 were digitized onto the photomosaic map for 2005 used for this analysis by reference to stable features visible on both photograph sets. 
The uncertainty associated with the horizontal placement of the cross sections from 1977 on the maps for 2005 were determined to be less than $150 \mathrm{~m}$. Such an offset in conjunction with the 0.001 average slope of the study reach would introduce vertical errors of less than $0.15 \mathrm{~m}$ attributable to uncertainty in horizontal cross section position for thalweg and water-surface elevations (assuming uniform slope and depth). The accuracy of the cross-section data surveyed in 2008 as a part of this study is approximately \pm 0.015 $\mathrm{m}$, whereas vertical accuracy is approximately $\pm 0.05 \mathrm{~m}$. Discrepancies between the cross-section alignments in 1977 and 2008 cause some cross sections of 1977 to portray slightly different areas of the bar and flood plain than are depicted in the matching cross section of 2008; therefore, the cross sections are best viewed in terms of overall trends, especially for thalweg elevations, as differences in bank geometry do not necessarily indicate channel shifting.

\section{Results of Repeat Surveys}

Comparison of bathymetric surfaces within the Estuary Reach from 1939 and 2008 shows that the bed of the Chetco River was generally lower in 2008 than in 1939 (fig. 17). A difference calculation for the bathymetric surfaces for 1939 and 2008 between FPkm 0.5 and 3.5, corresponding to the reach between the Highway 101 Bridge to Morris Rock, indicates a net loss of $150,000 \mathrm{~m}^{3}$ of channel substrate between 1939 and 2008. This net loss corresponds to an average lowering of the entire channel bottom by about $0.5 \mathrm{~m}$. Locally, however, channel shifting in three primary locations has resulted in much greater magnitudes of incision and aggradation (igs. 17 and 18). Near FPkm 3, the channel historically flowed against the right bank with bottom elevations of approximately $0.5 \mathrm{~m}$ (NAVD 88). By 2008, the channel had shifted toward the left bank and had deepened by 0.2 to $2.0 \mathrm{~m}$, with the bed elevations in 2008 ranging from 0.3 to $-1.5 \mathrm{~m}$ (NAVD 88). Near FPkm 1.7 a large alcove in 1939 extended nearly $0.5 \mathrm{~km}$ from the right bank. By 2008, this alcove had aggraded by approximately $1 \mathrm{~m}$, and the main arm of the alcove currently is filled with sediments and partially vegetated. Near FPkm 1.0 and just upstream of the Highway 101 Bridge, the channel in 1939 flowed against the left valley wall, carving a deep channel with bed elevations ranging from -1.5 to -4 m (NAVD 88). By 2008, the channel had shifted to the right bank, and the thalweg from 1939 currently is an alcove with bed elevations of about $-0.6 \mathrm{~m}$. The thalweg of 2008 in this area is shallower (bed elevations of -1.5 to $-2.5 \mathrm{~m}$ NAVD 88) and lacks the deep pool depicted in the survey from 1939.

For the short reach between FPkm 1.5 and 4.3, where all three surveys overlap, the longitudinal profiles from 1939, 1977, and 2008 indicate net lowering of the channel thalweg between 1939 and 2008 (fig. 18A). The magnitude of lowering is as great as $2 \mathrm{~m}$, with the reach upstream of FPkm 2 showing the most consistent bed lowering. The resolution of the survey in 1977 is not sufficient to clearly indicate whether most of the channel incision in the estuary was before or after 1977, but the survey in 1977 does show that the channel had at least locally aggraded by nearly $1 \mathrm{~m}$ near the Highway 101 bridge at FPkm 0.85 between 1939 and 1977 before incising back to its 1939 elevation by 2008.

Upstream of the Estuary Reach and the extent of the bathymetric surveys, comparison of longitudinal profiles derived from surveys in 1977 and 2008 shows mainly bed lowering, especially between FPkm 4.5 and 6 in the North Fork Reach and between FPkm 8 and 12 in the Mill Creek and Emily Creek reaches. In these locations, the channel is consistently 1-2 m lower in 2008 than in 1977 (fig. 18B). This apparent lowering exceeds plausible uncertainties owing to survey accuracy. For the Upper Reach upstream of FPkm 12, net changes in bed elevation between the surveys in 1977 and 2008 have been small. In the Estuary Reach, the difference between the surveys in 1977 and 2008 indicates possible thalweg aggradation for the kilometer downstream of Tide Rock; however, the resolution of the survey in 1977 is poor compared to the bathymetric surveys (fig. 18A), which show net incision of about $1 \mathrm{~m}$ between 1939 and 2008.

Sparser measurements from 1980, 1981, and 1982, which were surveyed in relation to the survey in 1977 (Klingeman, 1993), indicate that a substantial part of the channel lowering in the Estuary, North Fork, and Mill Creek reaches occurred before 1982 at some locations (fig. 18B). Examination of the repeat surveys of the cross sections surveyed in 1977 and 2008 (fig. 19) indicate that channel lowering between FPkm 4 and FPkm 12 (corresponding to Rkms 5-13) was independent of the rest of the active channel, as bar elevations appear similar in 1977 and 2008 (particularly for cross sections E, F, and G in fig. 19).

Information collected during the course of flow measurements at the USGS streamflow-gaging station at $\mathrm{FPkm} 15.24$ provides another source of quantitative information on channel change (fig. 20). The specific gage analysis (fig. 20A) encompasses 39 ratings over nearly 30 years. The large number of ratings is indicative of frequent changes in local geometry and substantial bed-material transport. For comparison, the South Umpqua River near Brockway has had only 11 ratings since 1942 (O'Connor and others, 2009). The ratings for the lower discharges are sensitive to scour and fill of low-flow pools and riffles near the measurement section, and consequently show more variation. For example, the rating for the $5.5 \mathrm{~m}^{3} / \mathrm{s}$ flow shows an overall trend of bed lowering after a period of slightly higher stages in the late 1970s, consistent with the ratings for all discharges, but with a total variation of $1.2 \mathrm{~m}$. The ratings for the larger flows reflect more general reach scale channel and flood-plain conditions, including the volume of gravel in the bar flanking the left margin of the channel (fig. 20B), and indicate an overall lowering of flow-stage elevations since 
A.

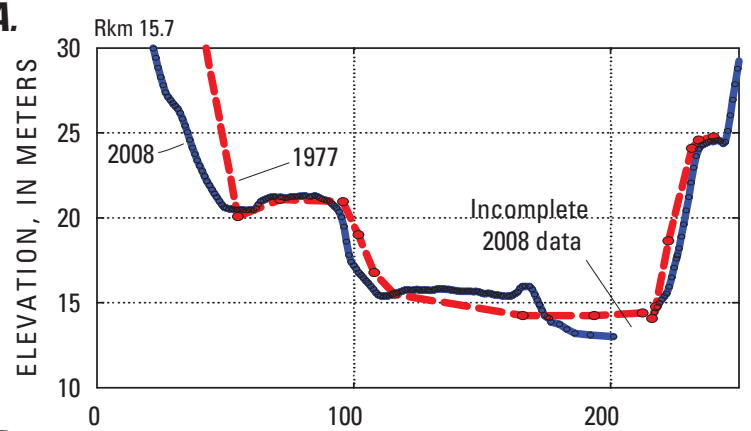

B.

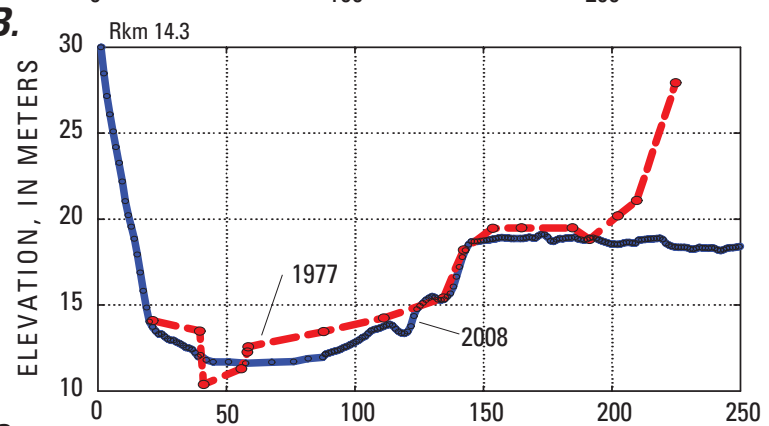

C.

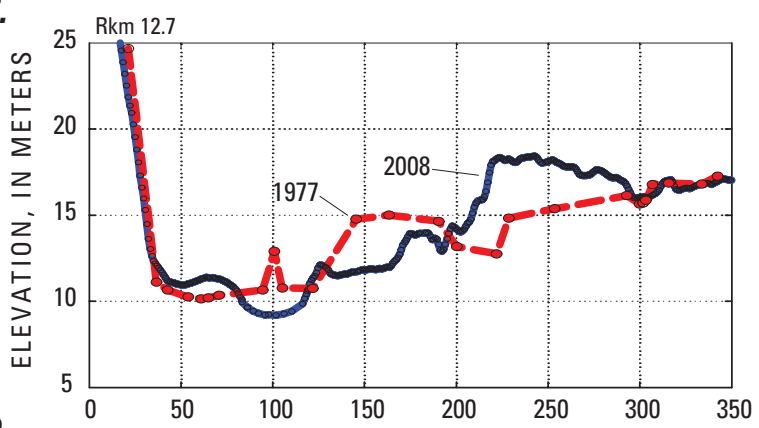

D.

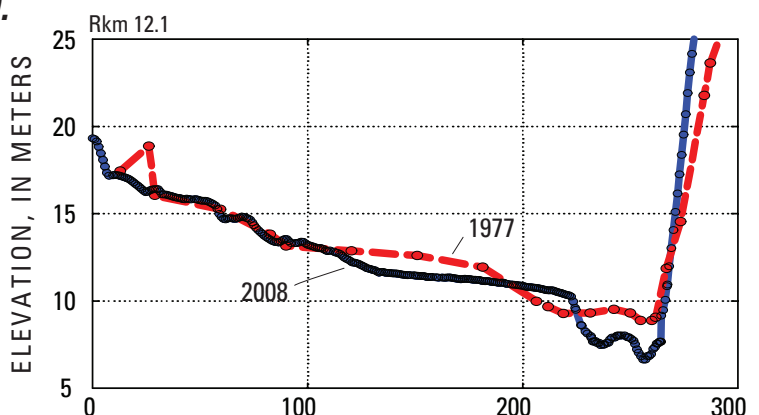

E.

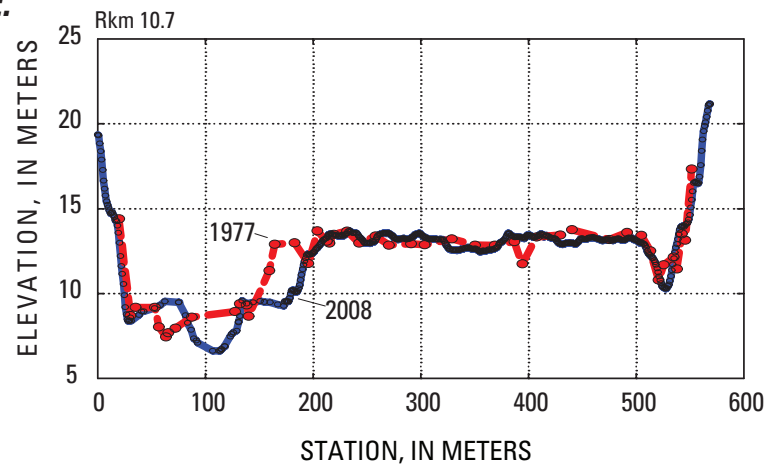

$\boldsymbol{F}$.

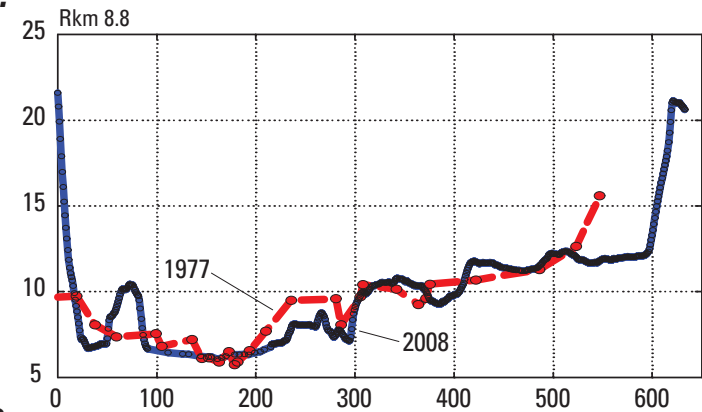

G.

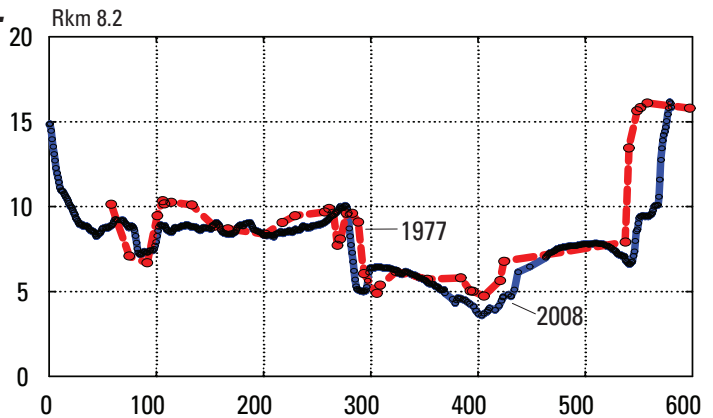

H.

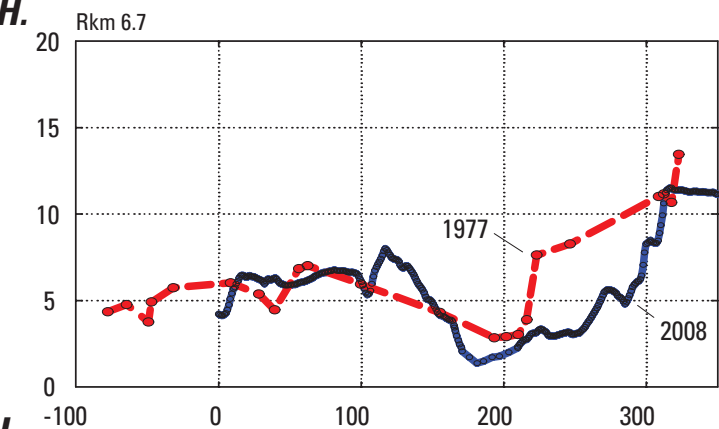

l.

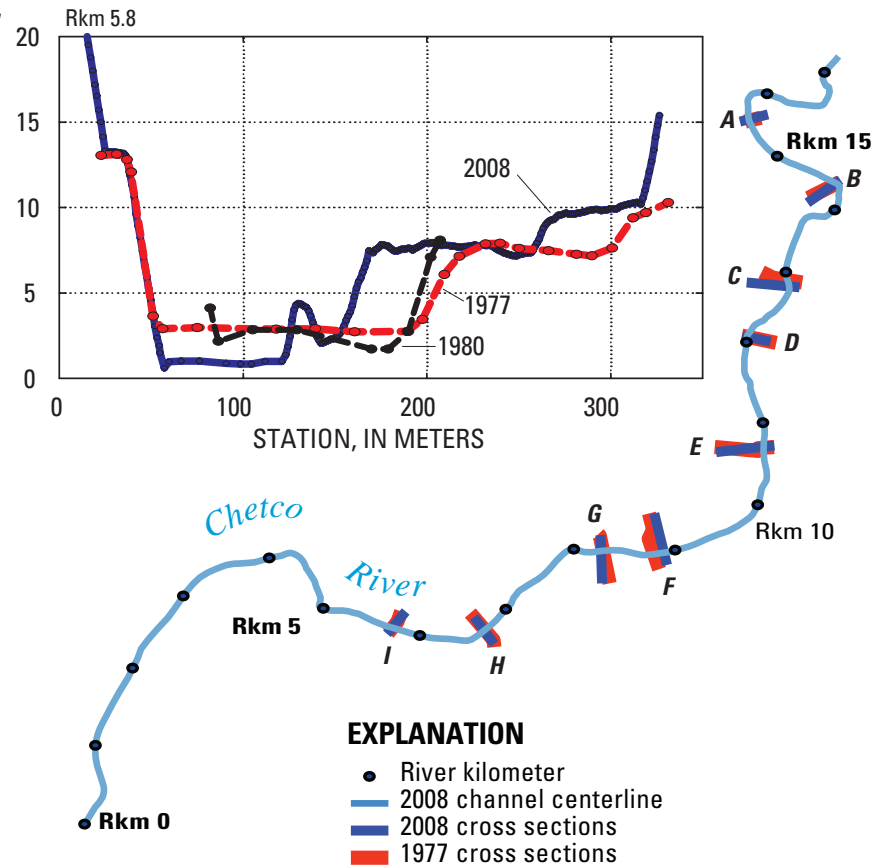

Figure 19. Cross sections from the flood study survey in 1977, digitized from Soil Conservation Service (1979), and approximately relocated during the U.S. Geological Survey resurveys in September 2008, Chetco River, Oregon. Imperfect relocation results in discrepancies for some sections, but all are judged to be within $150 \mathrm{~m}$ of original location. Cross section locations also are shown in figure $18 B$. 
1970, although with smaller magnitudes of change. Within the overall lowering trend, however, the high-flow ratings show evidence of aggradation and narrowing in the late 1970s and in 1997, after the $2,169 \mathrm{~m}^{3} / \mathrm{s}$ peak discharge in 1996 . For all flow ratings, however, the overall trend has been a net decrease of stage associated with specific discharges, ranging from $0.86 \mathrm{~m}$ for the low discharges to $0.28 \mathrm{~m}$ for the high analyzed discharges. The series of ratings, especially for the larger discharges, also indicate aggradation of approximately 0.2-0.3 m culminating between 1976 and 1978, followed by nearly continuous decrease until an episode of aggradation in the late 1990s, interrupted by aggradation and narrowing after the 1996 flood. Since 2000, all ratings have decreased between 0.2 and $0.4 \mathrm{~m}$ (fig. 20A).

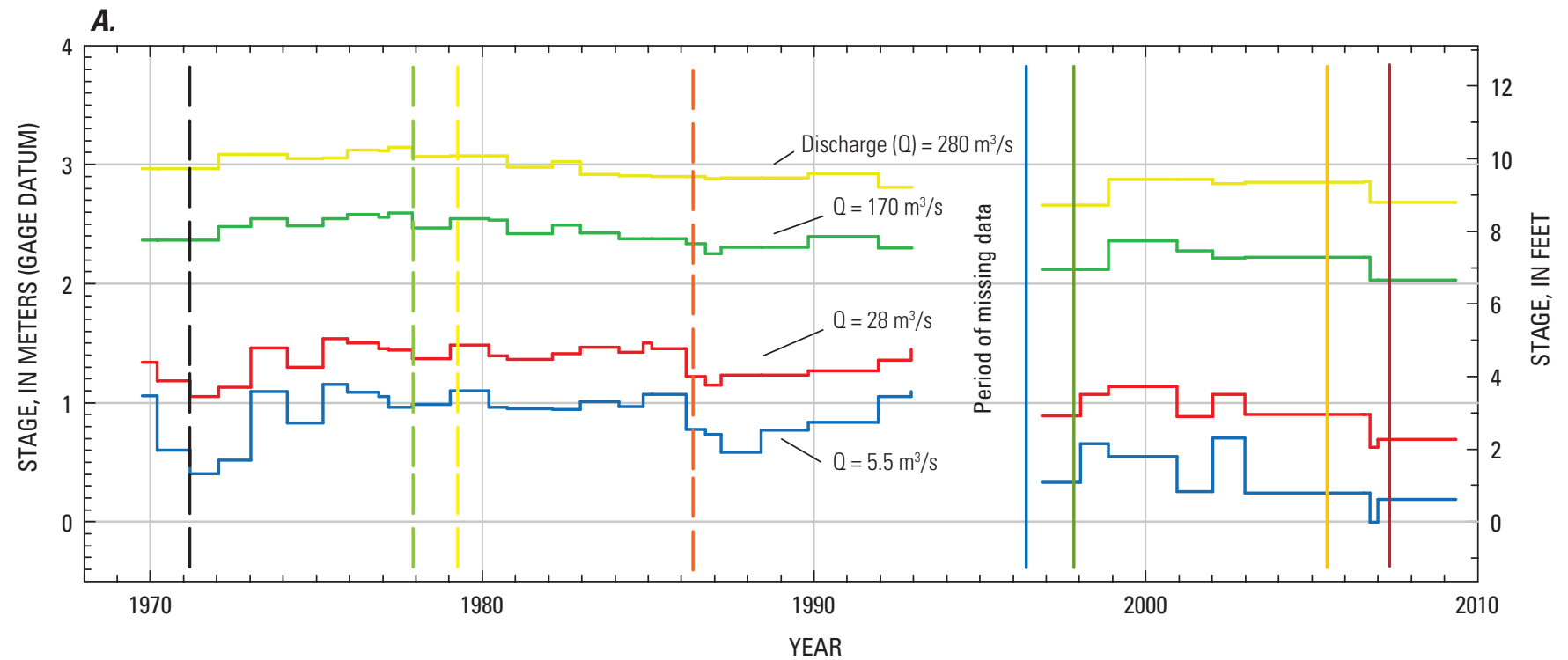

B.

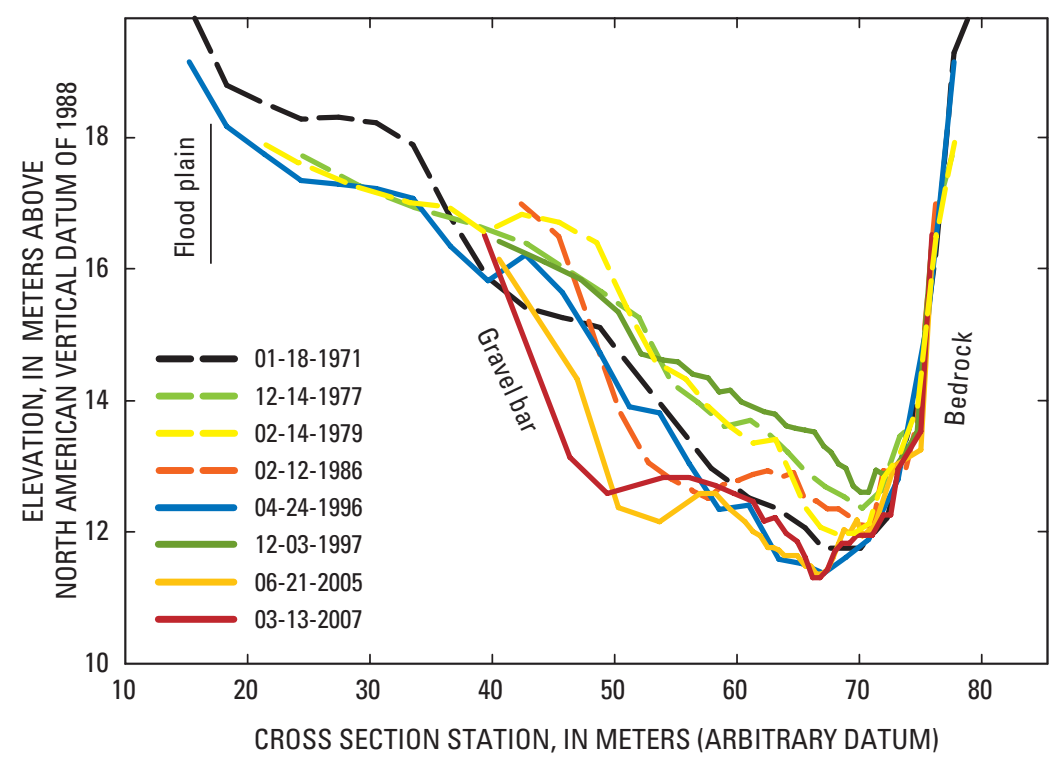

Figure 20. Specific gage analysis and discharge-measurement cross sections for the USGS streamflow-gaging station, Chetco River near Brookings, Oregon (14400000). (A) Specific gage analysis following approach of Klingeman (1973) and encompassing 39 ratings used between 1970 and 2008. Rating curves available at the Oregon Water Science Center in Portland, Oregon. Data for ratings 28-30 not available. $(B)$ Selected cross sections extracted from flow measurements at gaging station cableway. Cross sections extend to flow edge for each measurement. 


\section{Historical Channel Change}

The main observation from the planview mapping is a large decrease in bar (and bare gravel) area along the entire study area between 1939 and 2008. Historical changes in bar area, channel width, and sinuosity have been greatest near the confluence of the North Fork Chetco River, within the Mill Creek and North Fork Reaches, and downstream through the Estuary Reach. The largest changes were between 1965 and 1995, with the periods before and after showing little change or perhaps even opposite trends. The repeat surveys and specific gage analysis indicate that the overall historical vertical change has been bed lowering. Repeat surveys in the estuary show that the channel in 2008 was on average about $0.5 \mathrm{~m}$ lower than in 1939. Similarly, stretches of the Emily Creek, Mill Creek, and North Fork reaches appear to have channel thalweg elevations as much as $2 \mathrm{~m}$ lower in 2008 than in the surveys of 1977, with much of the lowering perhaps between 1977 and 1981. The specific gage analysis at FPkm 15.2 (Upper Reach) indicates episodes of aggradation in the late 1970s and late 1990s, but overall a long-term trend of bed lowering.

Many factors are likely responsible for these changes, including (1) direct physical alteration of the river corridor by bank stabilization and development, (2) bars evolving to flood plain by accumulation of overbank sediment and vegetation colonization, (3) changes in the volume of bed-material sediment brought into the study reach from upstream and tributary sources, either because of flow history or drainage basin conditions, (4) changes in the volume of sediment transported out of the study area by fluvial processes or by dredging and gravel extraction, and (5) floods, which are commonly a catalyst for change.

For the Estuary Reach, the channel and flood plain have been extensively modified by dredging, jetty construction and development between FPkm 0 and 2. Upstream within this reach, commercial aggregate removal may be a factor in decreased bar areas, but bank protection, fill, and development also has reduced bar area.

For the North Fork and Mill Creek reaches, the planview changes reflect the complicated interplay between the normal pattern of meander growth followed by cutoffs in wandering and sediment-rich rivers (Church, 1983; O'Connor and others, 2003), episodic tributary sediment input from the North Fork Chetco River and possibly Jack Creek, large mainstem floods triggering episodes of channel change, and the direct channel disturbance and indirect consequences of the long history of substantial gravel extraction in this reach.
The channel lowering, decreased recent rates of channel migration, diminished bar area, and lesser amounts of bare gravel and sparse vegetation are all mutually consistent changes indicative of transformation from sediment surplus to bed-material deficit. Such transformations would promote the conversion of bars to flood-plain surfaces as illustrated in figure 21.

The Upper and Emily Creek reaches have had more stable planforms, reflecting the strong control imposed by the closer valley walls. Although bar elevations were similar in 1977 and 2008, the Emily Creek reach shows evidence of decreased bar area (fig. 9) and local bed lowering (fig. 18) between 1939 and 2008. Similarly, the specific gaging station analysis shows general trends of bed lowering and bar erosion near the gaging station in the Upper Reach since the late 1970s (fig. 20). The changes in these two reaches could be either the result of reduced supply from upstream relative to transport capacity or incision propagating from downstream areas where there has historically been substantial gravel extraction.

An important factor in the evolution of channel and flood plain of the lower Chetco River is the history of large flows, because they are probably responsible for bringing in large volumes of sediment and triggering channel change. The largest recorded flow was $2,155 \mathrm{~m}^{3} / \mathrm{s}$ on November 19 , 1996, but a flood with an estimated discharge of 2,420 m3/s on December 22, 1964, (http://wdr.water.usgs.gov/wy2008/ pdfs/14400000.2008.pdf), was of exceptional duration and is the largest known flood for the river (Soil Conservation Service, 1979). Anecdotal accounts describe substantial sedimentation along the Chetco River as a consequence of the 1964 flood (Maguire, 2001, p. 9), similar to that documented for several northern California drainages along the Pacific coast (Stewart and LaMarche, 1967; Kelsey, 1980; Madej, 1995). The flood of 1964 in particular caused major and persistent sedimentation in the Klamath Mountains area because of the great volumes of hillslope material eroded and delivered to the channels during the storm and ensuing flood (Hickey, 1969; Waananen and others, 1971; Lisle, 1981; Harden, 1995). For several southern Oregon and northern California coastal drainage basins, the large volumes of sediment transported to the main channels led to periods of aggradation for mainstem rivers, including the nearby Smith River, for as long as 15 years after the flood, followed by periods of channel incision (Lisle, 1981). Some changes on the lower Chetco River, such as the late 1970s aggradation at the USGS streamflow-gaging station and the subsequent channel lowering (and the attendant reduction in bar areas) may be a similar decadal time-scale response to this particularly significant flood. 
A.
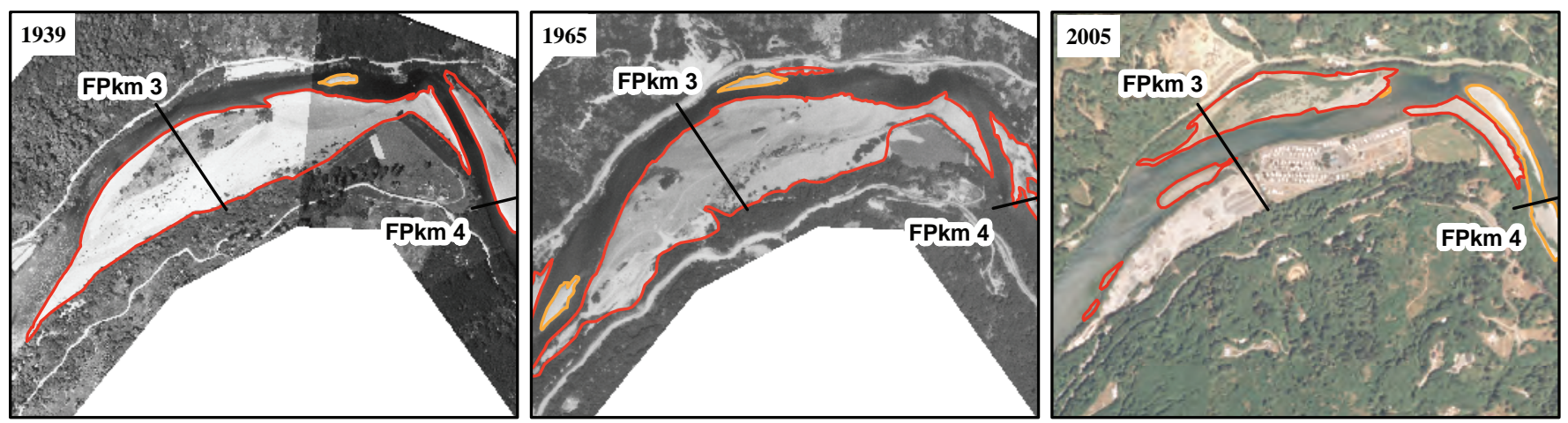

B.
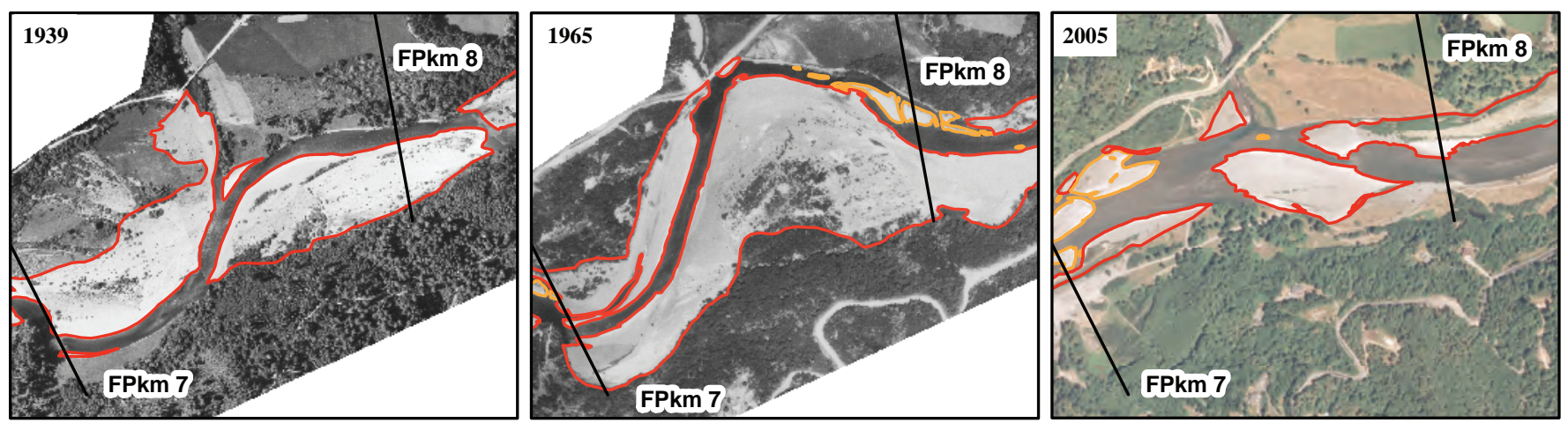

C.
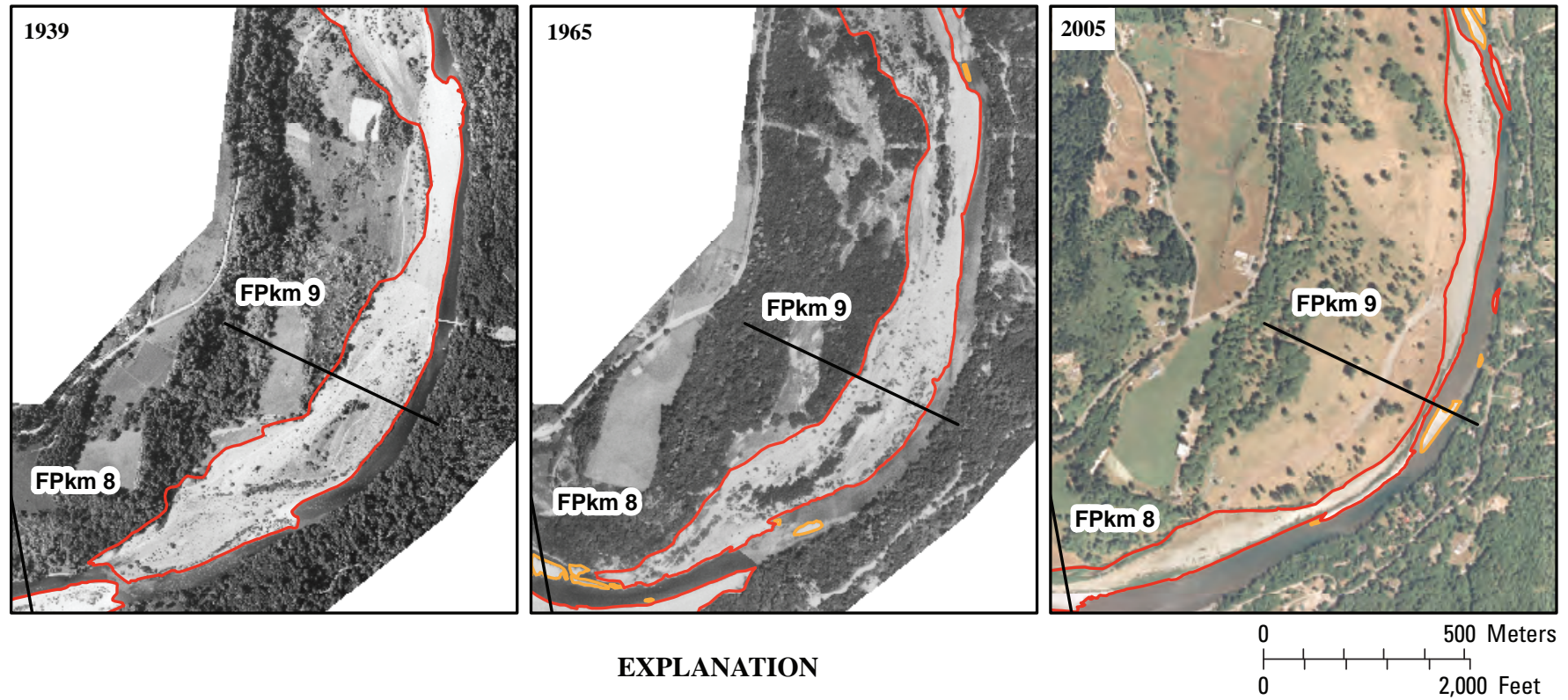

\section{EXPLANATION}

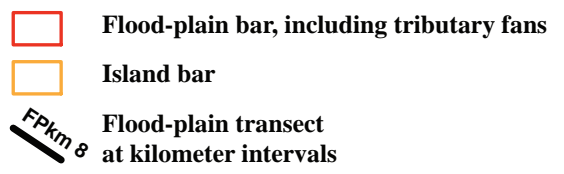

Figure 21. Examples of bar evolution to flood-plain and developed areas between 1939 and 2005, Chetco River, Oregon. (A) Gravel bar near flood-plain kilometer (FPkm) 3 (Estuary Reach) evolving to developed area. (B) Dynamic bars between flood-plain kilometers 7 and 9 (North Fork and Mill Creek reaches). (C) Example of vegetation colonization on upper bar surface near flood-plain kilometer 9 (Mill Creek Reach). 


\section{Bed Material-Characterization, Transport, and Budget}

Partly building on the channel mapping, a primary objective of this study was to estimate the volume of bed material entering the lower Chetco River and the distribution of this material during transportation and deposition within the study reach. Because of the multiple uncertainties and factors in such an analysis, we have adopted multiple measurement and analysis approaches. The overall analysis framework is that of a sediment budget (for example, Reid and Dunne, 1996, 2003), accounting for the various inputs and outputs of bed-material affecting the 16-km-long study reach.

The analyses focused on bed material, the sediment along the bed of the active channel. For the Chetco River, bed material includes the substrate of the low-flow channel and the flanking gravel bars, and consists chiefly of sand and gravel (clast diameters greater than $0.063 \mathrm{~mm}$ and ranging up to $250 \mathrm{~mm}$ ). These materials are transported through the river corridor primarily as bedload by bouncing, sliding, or rolling along the bed, although some sand (clasts with diameters between 0.063 and $2 \mathrm{~mm}$ ) may be transported as suspended load, supported higher in the flow by turbulence. The specific factors that require consideration for a bed-material budget are the (1) volume of bed-material transported into the reach from upstream, (2) volume of bed material transported directly into the reach by tributaries, (3) volume of bed material leaving the reach by fluvial transport into the Pacific Ocean, (4) volume leaving by other means (dredging, gravel extraction), (5) change in storage within the reach (owing to channel and bar deposition and erosion), and (6) attrition of bed-material clasts by mechanical breakage as they are transported and conversion of some mass of the bed-material load into finer materials. Adding to the challenge posed in considering all these factors is that the fluxes can vary tremendously in space and time (Gomez, 1991).

Two independent approaches were applied to assess bed-material transport rates and storage throughout the study reach: (1) a transport equation approach in which bedmaterial transport was calculated on the basis of prescribed flow, channel geometry, and sediment conditions, and (2) a mapping based approach in which bed-material fluxes were estimated from spatial and temporal changes in the volume of stored sediment along the study reach. Underlying these approaches were basic characterization of the sediment and flow conditions, in addition to the mapping of active channel features as described above.

\section{Bed-Material Characterization and Source}

There were two objectives in characterizing the bed material. The first was to assess the size distribution of the bed material to support analyses of transport rates and bar-surface armoring. The second was to assess sediment sources and possibly particle attrition rates by evaluating spatial patterns in clast lithology.

\section{Gravel Distribution and Textures}

A robust description of the Chetco River bed material is central to understanding overall patterns of sediment storage along the study area. Particle size information also supports sediment flux calculations by bedload-transport equations, and inferences of relations among sediment supply, channel morphology, and shear stress (for example, Dietrich and others, 1989; Lisle and others, 2000).

The active gravel bars along the Chetco River study area are expansive (iggs. $3, \underline{8}$, and $\underline{21}$ ), some extending for lengths greater than $1 \mathrm{~km}$ with widths exceeding $0.25 \mathrm{~km}$. The total bar area within the study reach in 2008 is about $0.9 \mathrm{~km}^{2}$, approximately equal to the total low flow channel area. The mean bar height above the channel thalweg is $3 \mathrm{~m}$, as determined from the mapping, LIDAR topography, and longitudinal profile survey.

\section{Sampling}

Bed-material textures were characterized by sampling 12 mainstem Chetco River gravel bars along the length of the study reach during September 2008. These data were supplemented by measurements at three tributary channels (table 4). For each of these bars, surface-particle sizes on the bar apex were measured. For three of the Chetco River mainstem bars, additional surface samples at the middle and downstream areas of the bar were measured, and substrate was sampled at the bar apex (table 4). Surface material sampling was by a modified grid technique (Kondolf and others, 2003), measuring grain size for 200 particles at $0.3-\mathrm{m}$ increments along two parallel 30-m tapes. The tapes were spaced 1-2 m apart and were aligned parallel to the long axis of the bar. Clast measurements were by aluminum template (Federal Interagency Sediment Project US SAH-97 Gravelometer).

Subsurface samples were collected to assess the difference between the bed surface and subsurface textures (a measure of "armoring”) and to support transport 
Table 4. Sediment sampling locations used in the sediment transport study, Chetco River, Oregon.

[Samples collected September 15-19, 2008, using methods of Wolman (1954). Unless otherwise noted, samples were collected at bar apices. Location names are informal descriptions of bars based on local landmarks. Eastings and northings are in meters and refer to the UTM zone 10 projection using the North American Datum of 1983. G rain-size diameter: $d_{16}$, grain-size diameter in millimeters, where 16 percent of the sample is finer by volume; $d_{50}$, grain size diameter in millimeters, where 50 percent of the sample is finer by volume; $d_{84}$, grain size diameter in millimeters, where 84 percent of the sample is finer by volume]

\begin{tabular}{|c|c|c|c|c|c|c|c|c|c|}
\hline \multirow{2}{*}{$\begin{array}{c}\text { Sample } \\
\text { identification } \\
\text { No. }\end{array}$} & \multirow{2}{*}{ Location } & \multirow{2}{*}{$\begin{array}{c}\text { River } \\
\text { kilometer }\end{array}$} & \multirow{2}{*}{$\begin{array}{l}\text { Flood-plain } \\
\text { kilometer }\end{array}$} & \multirow{2}{*}{ Easting } & \multirow{2}{*}{ Northing } & \multirow{2}{*}{$\begin{array}{l}\text { Sample } \\
\text { type }\end{array}$} & \multicolumn{3}{|c|}{ Grain-size diameter } \\
\hline & & & & & & & $d_{16}$ & $d_{50}$ & $d_{84}$ \\
\hline \multirow[t]{2}{*}{$1 \mathrm{a}$} & Fitzhugh Bar & 17.4 & 16.3 & 402185 & 4664607 & Surface & 7.76 & 47.19 & 103.57 \\
\hline & & & & & & Subsurface & 2.27 & 31.08 & 121.87 \\
\hline $1 b$ & Fitzhugh Bar; mid-bar & 17.3 & 16.0 & 402067 & 4664588 & Surface & 10.00 & 31.72 & 72.21 \\
\hline 1c & Fitzhugh Bar; bar toe & 17.0 & 15.5 & 401898 & 4664363 & Surface & 16.73 & 40.91 & 74.54 \\
\hline 2 & Second Bridge Bar & 16.7 & 15.1 & 401900 & 4664111 & Surface & 11.52 & 28.87 & 57.42 \\
\hline 3 & Emily Creek Bar & 14.5 & 13.2 & 401916 & 4663279 & Surface, tributary & 7.08 & 22.14 & 47.00 \\
\hline 4 & Loeb Park Bar & 14.3 & 13.0 & 401955 & 4662994 & Surface & 17.98 & 37.15 & 63.07 \\
\hline 5 & Tamba Bar & 12.4 & 11.3 & 401353 & 4661413 & Surface & 10.14 & 36.33 & 72.13 \\
\hline 6 & Mill Creek Bar & 10.5 & 9.5 & 401281 & 4659622 & Surface & 20.95 & 53.26 & 89.40 \\
\hline 7 & Freeman Bar & 8.6 & 7.8 & 400003 & 4658583 & Surface & 24.26 & 57.83 & 101.94 \\
\hline 8 & North Fork Bar & 8.3 & 7.6 & 399729 & 4658916 & Surface, tributary & 16.24 & 39.22 & 96.55 \\
\hline \multirow[t]{2}{*}{ 10a } & Social Security Bar & 6.7 & 6.1 & 398602 & 4657732 & Surface & 14.21 & 39.72 & 85.94 \\
\hline & & & & & & Subsurface & 1.51 & 19.01 & 59.43 \\
\hline 9 & Jack Creek Bar & 6.5 & 5.9 & 398949 & 4657514 & Surface, tributary & 15.38 & 31.43 & 70.50 \\
\hline $10 \mathrm{~b}$ & $\begin{array}{l}\text { Social Security Bar; } \\
\text { mid-bar }\end{array}$ & 6.3 & 5.6 & 398249 & 4657614 & Surface & 4.32 & 18.89 & 39.48 \\
\hline 10c & $\begin{array}{l}\text { Social Security Bar; bar } \\
\text { toe }\end{array}$ & 6.0 & 5.4 & 397969 & 4657655 & Surface & 10.10 & 19.75 & 37.96 \\
\hline 11 & Tide Rock Bar & 5.1 & 4.4 & 397114 & 4657964 & Surface & 6.15 & 23.88 & 58.76 \\
\hline \multirow[t]{2}{*}{$12 \mathrm{a}$} & Tidewater Estuary Bar & 3.5 & 3.0 & 396039 & 4658364 & Surface & 1.80 & 17.26 & 45.00 \\
\hline & & & & & & Subsurface & .89 & 7.17 & 31.29 \\
\hline $12 b$ & $\begin{array}{l}\text { Tidewater Estuary Bar; } \\
\text { mid-bar }\end{array}$ & 3.4 & 2.9 & 395999 & 4658335 & Surface & 3.87 & 16.18 & 38.50 \\
\hline $12 \mathrm{c}$ & $\begin{array}{l}\text { Tidewater Estuary Bar; } \\
\text { bar toe }\end{array}$ & 3.3 & 2.8 & 395903 & 4658268 & Surface & 3.45 & 11.91 & 28.42 \\
\hline
\end{tabular}

calculations with substrate-based bed-material transport equations. Subsurface samples at the bar-apex surfacesample measurement sites were collected from three barsFitzhugh Bar (FPkm 15.5), Social Security Bar (FPkm 6.1), and Tidewater Estuary Bar (FPkm 3.0) (table 4). Each subsurface sample was collected by removing the surface layer, consisting of the approximate depth equivalent to the median surface particle diameter, and then collecting 15-20 L from an excavation about $40 \mathrm{~cm}$ deep and $20 \mathrm{~cm}$ in diameter. Subsurface-sample masses ranged from 33 to $39 \mathrm{~kg}$, and are probably not large enough to adequately characterize the distribution of clasts greater than $64 \mathrm{~mm}$ (Church and others, 1987; Kondolf and others, 2003). These samples were dried, sieved, and weighed by the USGS sediment laboratory in Vancouver, Washington. For each of the subsurface samples, one clast was in the largest size bin, accounting for 15 percent, 5 percent, and 2 percent of the samples at Fitzhugh Bar, Social Security Bar, and Tidewater Estuary Bar, respectively. For Fitzhugh Bar in particular, this single large 128-256 mm clast forms a relatively large proportion of the total sample, possibly biasing the gradation curve to larger values and resulting in a calculated $d_{50}$ (and other percentile) value larger than would be derived from a larger sample, which would presumably have a relatively smaller volume in the largest size categories. 


\section{Assessment of Bed-Material Sizes}

For all main stem Chetco River bar-apex surface samples, the median particle diameter $\left(\mathrm{d}_{50}\right)$ ranged from 57 to $17 \mathrm{~mm}$ (fig. 22). The three tributary samples were also bracketed by this range of median particle diameters. The surface material size distributions show a trend of coarsening between FPkm 14.5 and the confluence of the North Fork Chetco River at FPkm 7.6, followed by fining towards the estuary (FPkm 3). For the three bars with multiple surface samples, median particle size decreases by approximately $30-50$ percent along the length of the individual bars (fig. 23). The bar apices also show bimodal size gradations, the apex sites have similar or greater amounts of fine sediments (less than $10 \mathrm{~mm}$ ) than at the distal bar sites, probably because of sand and fine gravel deposition on these typically lower elevation sites by waning or later smaller flows after bar mobilization events.

The three subsurface samples were substantially finer than the surface-material samples measured at the same locations (fig. 23). Previous studies have shown that the relative coarseness of the surface layer increases as a function of the excess transport capacity and that reaches where sediment supply exceeds transport capacity should have little to no armoring, whereas reaches with excess capacity would show increasing levels of armoring (Dietrich and others, 1989; Buffington and Montgomery, 1999). Although the exact relations are uncertain, the degree of armoring (defined as the ratio of $d_{50}$ surface material to $d_{50}$ substrate) can be used as an indication of sediment supply relative to transport capacity (Bunte and Abt, 2001). Generally, armoring ratios of about 1 indicate high sediment supply, whereas armoring ratios greater than 2 typically indicate channels with excess transport capacity (Bunte and Abt, 2001). On the Chetco River, armoring ratios at Fitzhugh Bar, Social Security Bar, and Tidewater Estuary Bar were 1.52, 2.09, and 2.41 respectively, indicating high sediment supply relative to transport conditions at the upstream end of the study reach (although the Fitzhugh Bar armoring ratio may actually be higher if the subsurface sample is biased as described above), but could indicate excess transport capacity relative to sediment supply in the North Fork and Estuary Reaches. The increasing ratio of median surface layer diameter to subsurface median diameter is also counter to typical conditions where armoring ratios decrease with channel slope (Pitlick and others, 2008), a possible indication of downstream changes in sediment supply relative to transport capacity.

\section{FLOOD-PLAIN KILOMETER}

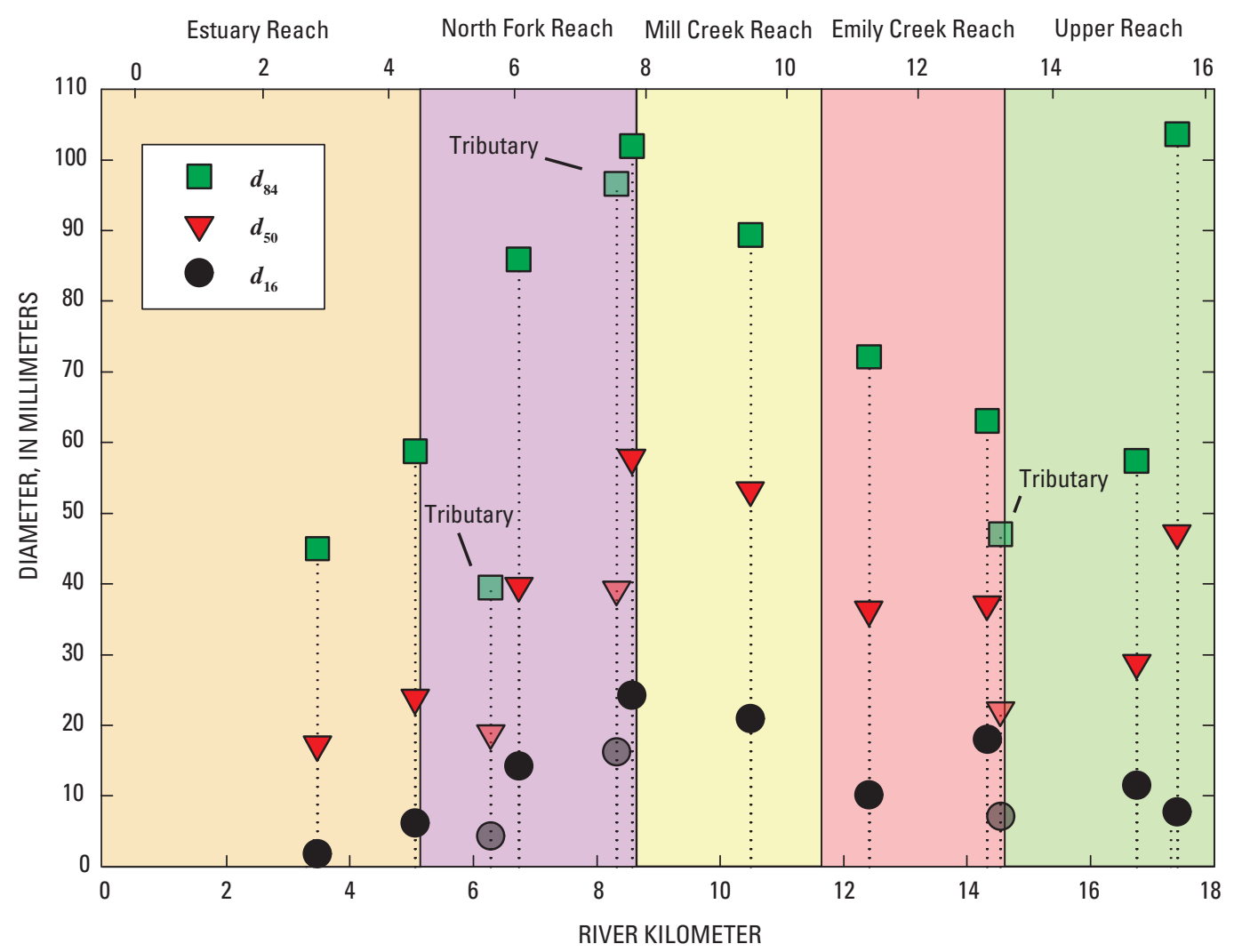

Figure 22. Longitudinal variation in surface-particle size for bar apices along the study area, Chetco River, Oregon. Surface material was sampled at 12 mainstem Chetco River gravel bars and 3 tributary channels using Wolman (1954) particle count procedure with measurement template. 
Fitzhugh bar, flood-plain kilometer 15.5 (Rkm 17)

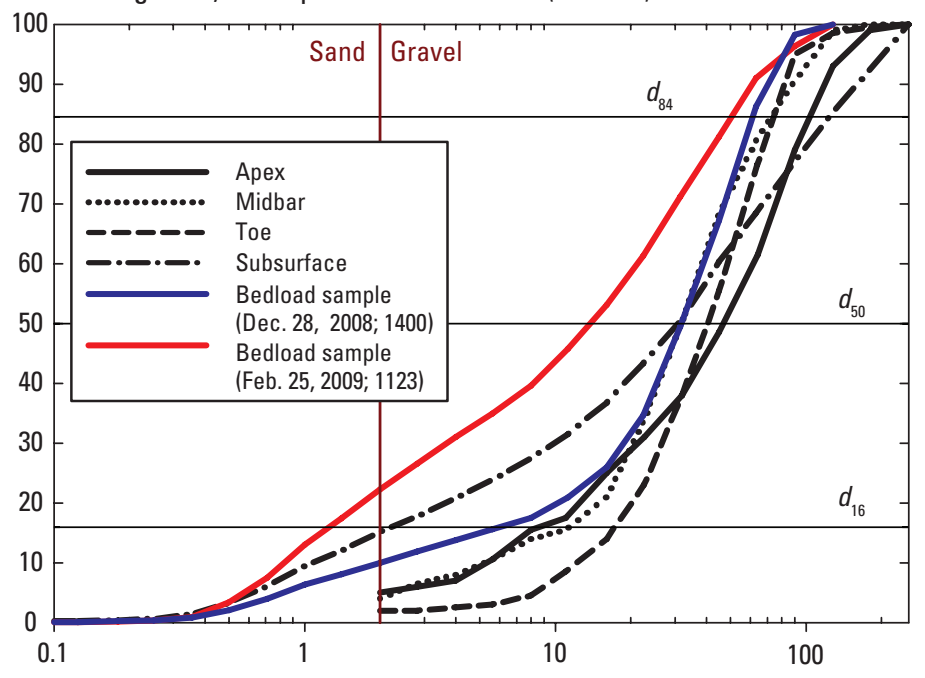

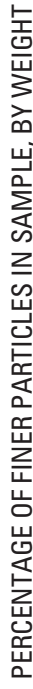

Social Security bar, flood-plain kilometer 6 (Rkm 6.7)

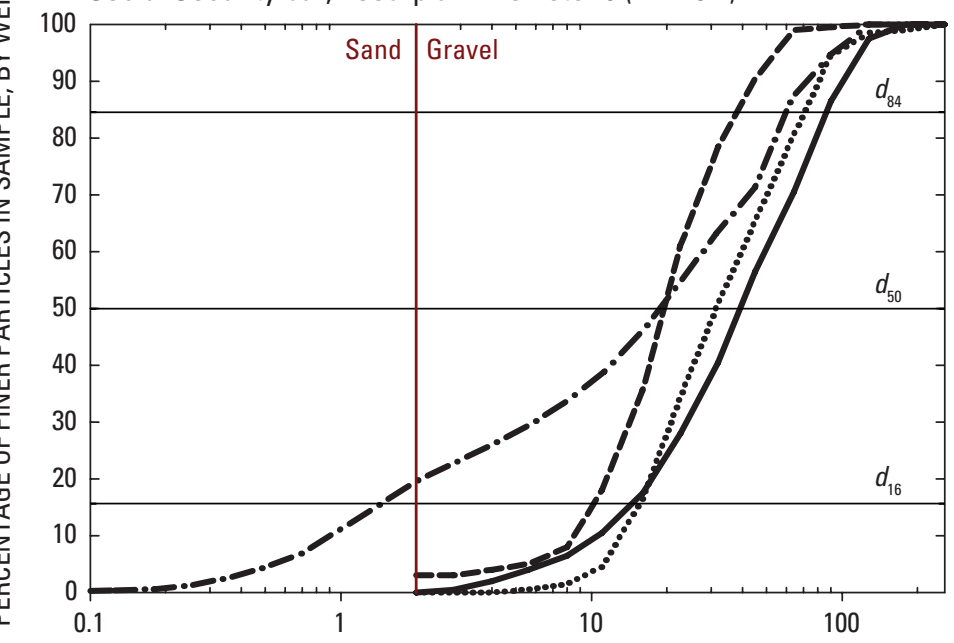

Tidewater Estuary bar, flood-plain kilometer 3 (Rkm 3.4)

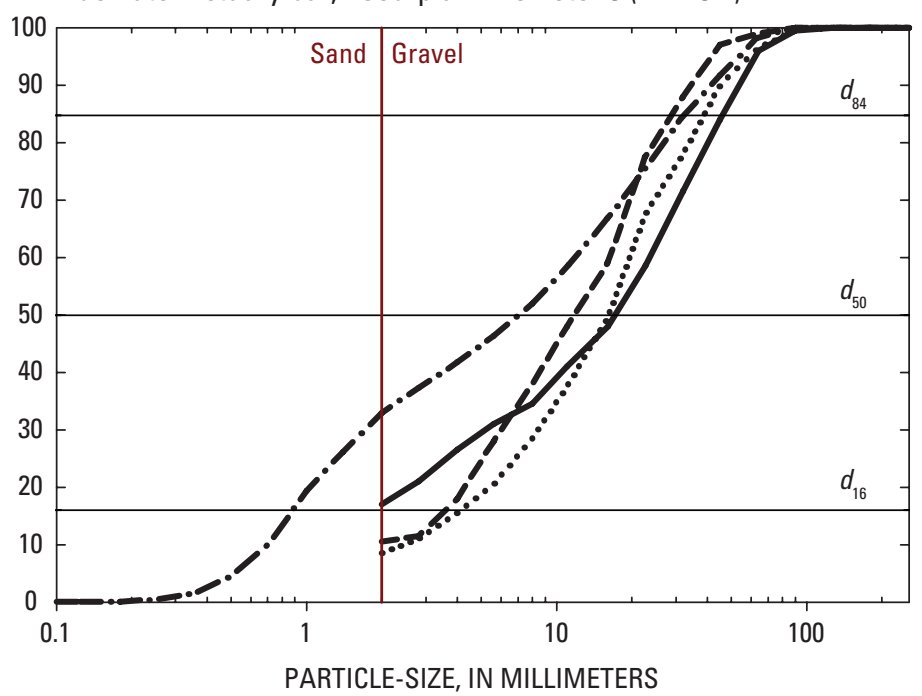

Figure 23. Particle size distributions for surface and subsurface samples at Fitzhugh Bar (flood-plain kilometer 15.5), Chetco River, Oregon, Social Security Bar (flood-plain kilometer 6.1), and Tidewater Estuary Bar (flood-plain kilometer 3). At each bar, surface material was sampled at three locations along the bar axis: bar apex, midbar, and toe of bar using Wolman (1954) particle count procedure with measurement template. Subsurface material sampled volumetrically at bar apex and sieved by U.S. Geological Survey sediment laboratory in Vancouver, Washington. Bedload sample size distributions for December 28, 2008, and February 25, 2009, sampling trips shown for comparison with the surface and subsurface samples from the nearby Fitzhugh Bar. Bedload samples analyzed by U.S. Geological Survey sediment laboratory in Vancouver, Washington. 


\section{Bed-Material Lithology and Sources}

An important component of the overall sediment budget is the volume of material entering the study reach by tributaries. At the upstream end of the study reach, the contributing drainage area is $702 \mathrm{~km}^{2}, 77$ percent of the total basin area at the mouth of the Chetco River. The largest tributaries are Emily Creek (FPkm 13.2, drainage area $32 \mathrm{~km}^{2}$ ), North Fork Chetco River (FPkm 7.6, drainage area $104 \mathrm{~km}^{2}$ ), and Jack Creek (FPkm 5.8, drainage area $22 \mathrm{~km}^{2}$ ), together accounting for $158 \mathrm{~km}^{2}$ of the $211 \mathrm{~km}^{2}$ of drainage area gained by the Chetco River through the study reach. All three of these tributaries have small fans at their junction with the mainstem Chetco River that have episodically grown and eroded, indicating that bed-material is entering from these tributary catchments. The simplest approach to estimating the volume of bed material entering the Chetco River from the tributaries is to assume that sediment volume is proportional to contributing area. This assumption, however, fails to account for possibly different sediment production rates within the drainage basin because of geology, physiography, and land use (Maguire, 2001). To independently assess the contributions of tributaries, clast lithology at all sites of particle size analysis were evaluated, taking advantage of the distinct geologic terranes contributing sediment to different parts of the drainage basin.

For all bed-material size measurements, clasts greater than $11 \mathrm{~mm}$ were classified according to lithology. The lithologic classifications used in this study were not complete identifications traceable to specific geologic units, but simple categories facilitating rapid and consistent hand sample identification. A total of 16 lithologic categories were developed, but 3 of these categories - quartzite (metasandstone), sandstone, and basalt—dominated the total assemblage of particles sampled. Surface material was classified in the field during the particle size counts, and lithologies of subsurface material were determined on the sieved samples after size analysis by the USGS sediment laboratory.

The dominant clast type for all mainstem sampling sites was a dark grey and very hard metasedimentary rock designated as "quartzite," composing 50-80 percent of most mainstem samples (fig. 24), followed by fine- to coarse-grained lithic sandstones typically composing 20-40 percent of the sampled clasts. These clast types are likely derived mainly from the Dothan Formation, which underlies the western part of the drainage basin, and they enter the study reach from upstream and from tributaries. Several clast types are unique to the upper drainage basin and the mainstem Chetco River at the upper end of the study are, including coarse-grained igneous and metamorphic rock, and ultramafic rocks, but they typically compose less than 10 percent of the sampled rock types. Bed material was sampled at the three major tributaries, Emily Creek, North Fork Chetco River, and Jack Creek, for which the percentage of sandstone was greater than most main stem sample sites.

The small number of distinctly upper-basin lithologic classes and their variation among samples precludes strong inferences regarding the contribution of bed material by the tributaries except that these clast types, in relatively similar percentages all the way to the estuary, indicate that the bed material brought in by tributaries is not a substantial percentage of the sampled distributions. A mixing model analysis of the ratio of sandstones to quartzites applied to samples from Emily Creek and North Fork Chetco River with adjacent mainstem samples indicates that the North Fork contributes as much as 7 percent of the total bed-material volume at its confluence (compared to the 12 percent of the total basin area at the confluence), and that Emily Creek contributes 7-31 percent at its confluence (compared to the 4.4 percent of the total basin area at the confluence), although these values are highly sensitive to the selection of local main stem distributions. Given the ranges permitted by this analysis, it is assumed that bed-material sediment influx from tributaries is related to drainage area, indicating that about 25 percent of the bed material in the study reach is contributed by local tributaries.

\section{Bed-Material Particle Attrition}

In contrast to the bed material introduced by tributaries is the bed material worn down by fracture, abrasion, dissolution, and weathering as it moves downstream. Particle attrition reduces bed-material sediment volumes because some of the finer particles created by mechanical breakage will become part of the suspended load that leaves the active channel environment either for overbank flood-plain deposition or to the Pacific Ocean. Primary evidence for such attrition is the downstream fining of bed material typically seen in gravel-bed rivers (Mackin, 1948; Schumm and Stevens, 1973), made stronger by instances of differential fining of distinct clast lithologies (Plumley, 1948; Shaw and Kellerhals, 1982; Kodama, 1994). Many studies, however, have shown that such fining results chiefly from sorting by selective deposition (Paola and others, 1992; Hoey and Ferguson, 1994; Rice 1999). For the Chetco River, a decreasing trend in the size of sandstone clasts relative to quartzite clasts in the downstream direction indicates some particle breakdown (fig. 24). Although complicated by many factors such as the introduction of tributary sandstone clasts, the approximately 40 percent reduction in particle diameter for the sandstone clasts relative to quartz would indicate nearly an 80 percent volume reduction of sandstone. If the sandstone clasts were the only clast type with considerable attrition, the volume reduction of the gravel would be less than 10-20 percent given the small percentage of sandstone composing the greater than $11 \mathrm{~mm}$ sediment. 
A.

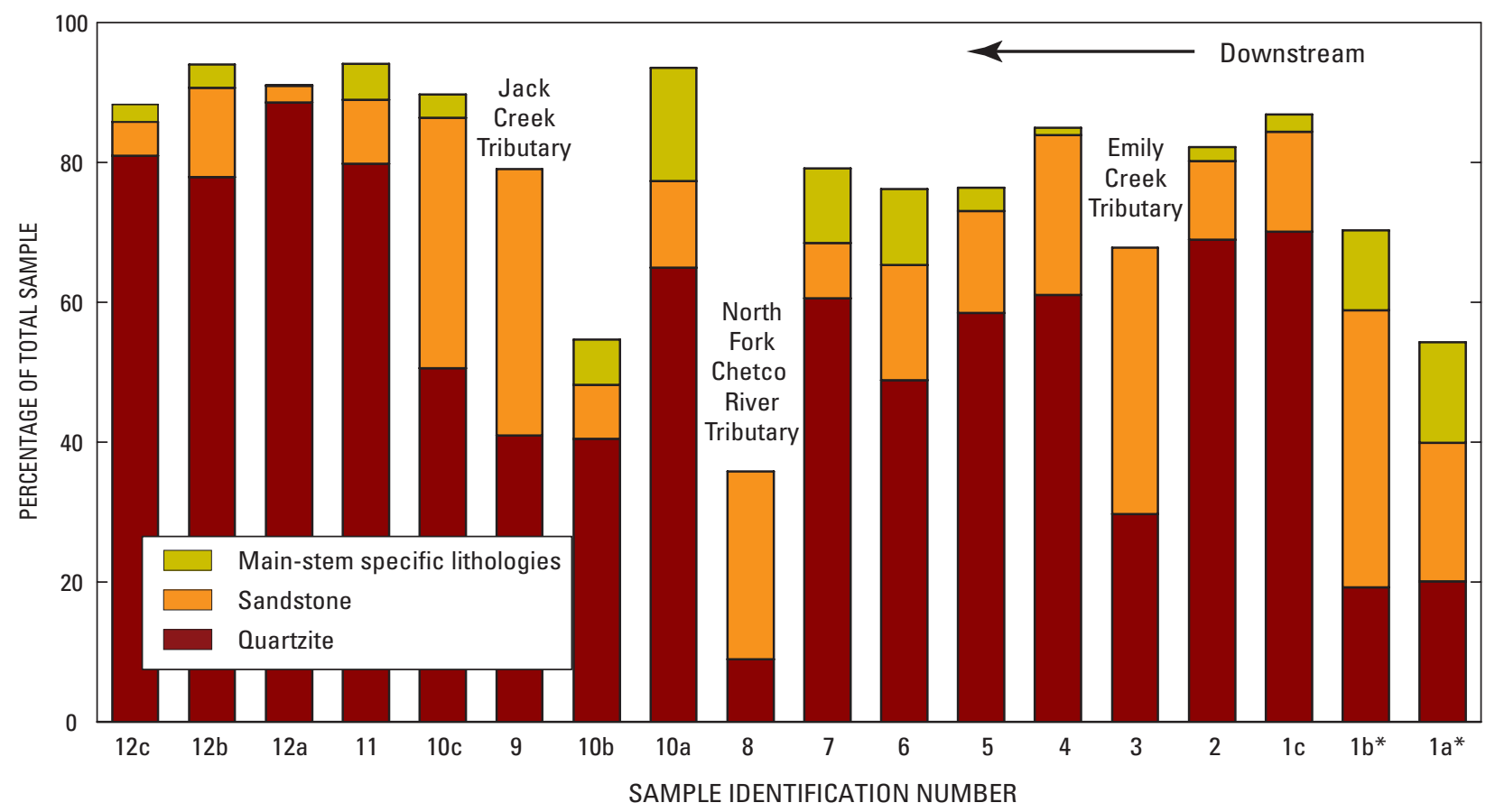

B.

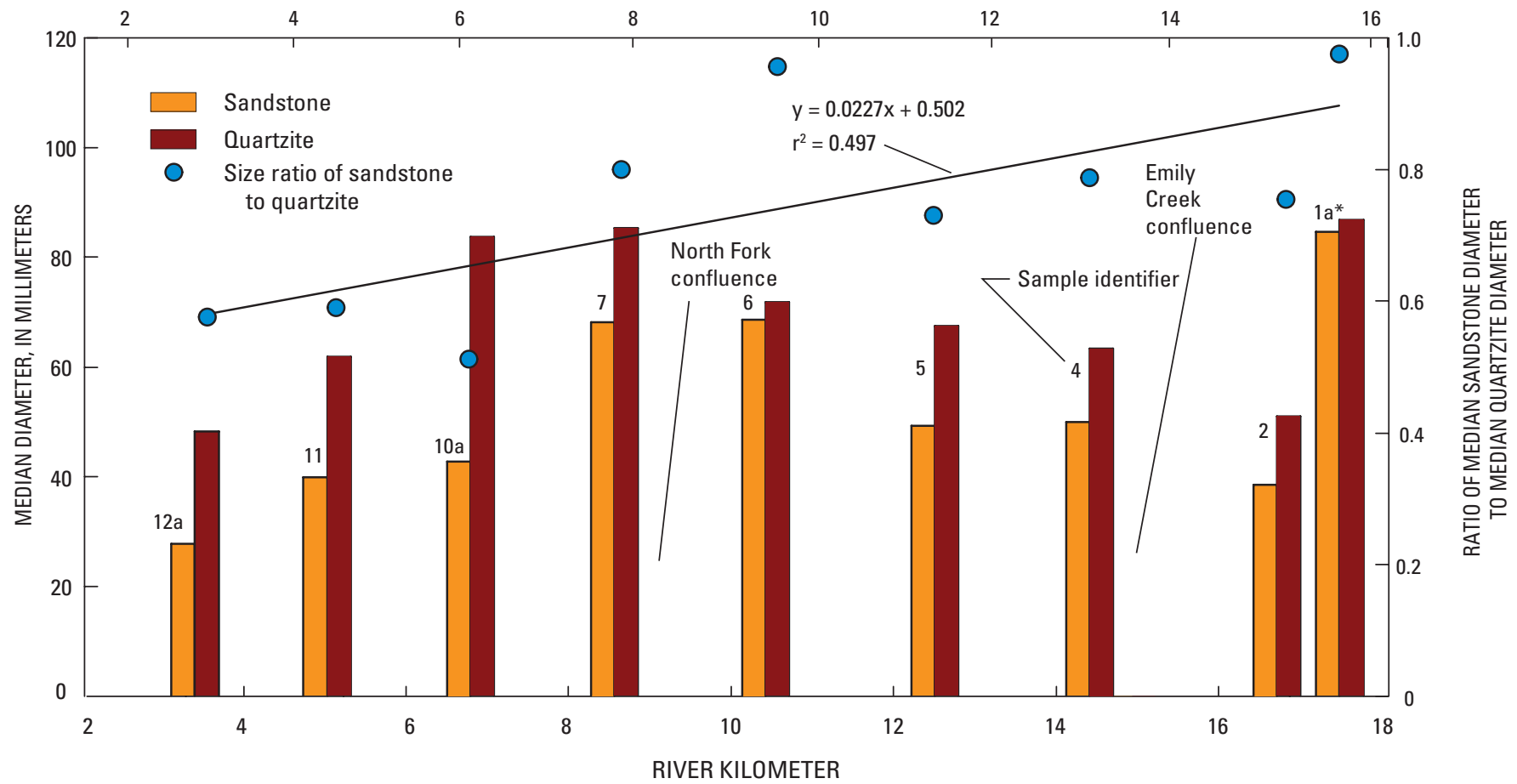

Figure 24. Variation in clast lithology and size ratio of sandstone and quartzite clasts for sites along the study area, Chetco River, Oregon. $(A)$ Variation in clast lithology for each of the 18 surface-material samples taken from 12 bars along the mainstem Chetco River and 3 tributary bars. Sample locations are listed in table 4, but locations proceed downstream in order of sample identifier. Quartzite, sandstone, and a blend of upper-drainage-basin specific lithologies (including coarse-grained igneous, metamorphic, and ultramafic rocks) were the dominant lithologies at the mainstem Chetco River sampling sites. Samples 1b and 1a were done with slightly different protocol, so results not directly comparable. Totals do not sum to 100 percent because unidentified and minor local clast types are not included. $(B)$ Median diameter $\left(d_{50}\right)$ of sandstone and quartzite particles at each of the mainstem Chetco sites where surface material was sampled, and downstream trend in the ratios of median diameters. The ratios of sandstone to quartzite $d_{50}$ at each site indicate a general downstream trend of decreasing sandstone size relative to quartzite size. 
Downstream volume loss was also assessed by applying the attrition coefficients provided by (1) the fractional diameter reduction of quartzites in natural rivers of $0.0017 / \mathrm{km}$ by Shaw and Kellerhals (1982), giving a volume reduction of 5.5 percent for length of channel between FPkm 15 and 5; and (2) the experimental tumbler results by Collins and Dunne (1989) for Olympic Peninsula rocks that indicate fractional diameter reduction rates equating to a 10-30 percent volumetric reduction by abrasion between FPkm 15 and 5 . The Collins and Dunne (1989) attrition rates were determined to be the maximum plausible volumetric reduction because of the likely greater hardness of the Chetco River bed materials. Taken together, the volumetric bed-material attrition rate along the length of the Chetco River study reach was determined to be between 5 and 30 percent.

\section{Flow Modeling}

The driver of bed-material transport is streamflow, including the temporal sequence of high flows over the years and the spatial distribution of hydraulic conditions along the channel. The sequence of past flows for the Chetco River comes from records of the USGS streamflow-gaging station at FPkm 15.2 (fig. 2). To determine the spatial distribution of hydraulic conditions produced by this range of flows on the Chetco River, a one-dimensional hydraulic model of the study reach was constructed. The results from this model support the equation-based predictions of bed-material transport described subsequently.

For the Chetco River study area, the Hydrologic Engineering Center's River Analysis System (HEC-RAS) Version 4.0 model (U.S. Army Corps of Engineers, 2006) was applied. The HEC-RAS model calculates one-dimensional (cross section averaged) energy-balanced water surface profiles for a series of cross sections, specified discharges, and energy loss coefficients. Calculated values include cross-section-average water-surface elevations and energy slopes $\left(S_{f}\right)$ for each cross section. Calculations proceed upstream for applications in subcritical flow regimes.

For this analysis, valley-bottom geometry was defined using 68 cross sections between FPkm 0.5 and FPkm 15.5. Cross sections spanned the entire valley bottom and were spaced at intervals approximately equal to the active channel width (typically about $300 \mathrm{~m}$ ), but with a maximum spacing of $900 \mathrm{~m}$. The cross sections were developed from the LIDAR topography merged with bathymetric surveys, from 2008, and from streamflow measurement surveys at the USGS streamflow-gaging station. The upstream-stepping flow computations for each simulated discharge were started at normal depth at the downstream cross section at FPkm 0.5. Discharge was assumed to increase by 14 percent at the North Fork Chetco River confluence at FPkm 7.6, consistent with incremental area contributed by this basin relative to the drainage area at the upstream end of the reach. Flow from other tributaries entering the Chetco River within the study area was not considered because the North Fork Chetco River is the only tributary basin with large enough area likely to contribute substantial discharge at, or near, the same time that discharge is peaking in the main stem Chetco River.

The HEC-RAS model was calibrated by comparing the calculated water-surface elevations to the rating curve in use during summer 2008 at the USGS streamflow-gaging station at FPkm 15.2 near the upstream end of the modeled reach of the Chetco River. A suitable fit resulted from applying Mannings $n$ values of 0.04 to the channel bed and banks for the entire study reach. The calculated profiles from this model closely match the water-surface profile determined from the LIDAR topography survey of 2008, when flow was approximately $7.8 \mathrm{~m}^{3} / \mathrm{s}$ according to the stage-discharge relation at the USGS streamflow-gaging station and water-surface elevations during the flow at $1,440 \mathrm{~m}^{3} / \mathrm{s}$ on December 29, 2008. From this calibrated model, water-surface elevation and $S_{f}$ were calculated for each of the 68 cross sections and for 20 discharges ranging between 5.5 and 2,270 $\mathrm{m}^{3} / \mathrm{s}$, encompassing the range of flows likely to transport bed material as well as all recorded flood peaks since 1970 (fig. 25).

The calculated water-surface and energy profiles generally match the thalweg and low-flow water-surface profiles, but become more regular with increasing discharge (fig. 25). This transformation is due to the decreasing influence of channel morphology, such as pool-and-riffle geometry, and increasing influence of overall valley geometry on flow hydraulics as discharge increases. Because of the specified downstream boundary condition of normal depth, the modeling results do not account for the approximately $2 \mathrm{~m}$ tidal range affecting the Estuary Reach, which has a significant effect on low flows, but is not likely to affect mean sediment transport conditions during high flows. All profiles show a gradient inflection for low flows that corresponds to the upstream limit of tidal influence and a slight change in the thalweg slope near FPkm 5. The gradient inflection for high flows moves upstream into the Mill Creek Reach, approaching FPkm 10 for flows of 2,000 m³/s, corresponding to the substantial increase in valley-bottom width near the North Fork confluence. This change in slope has implications for reach-scale bed-material transport. The flow modeling also shows that most bars are inundated by flows of $250-500 \mathrm{~m}^{3} / \mathrm{s}$. 


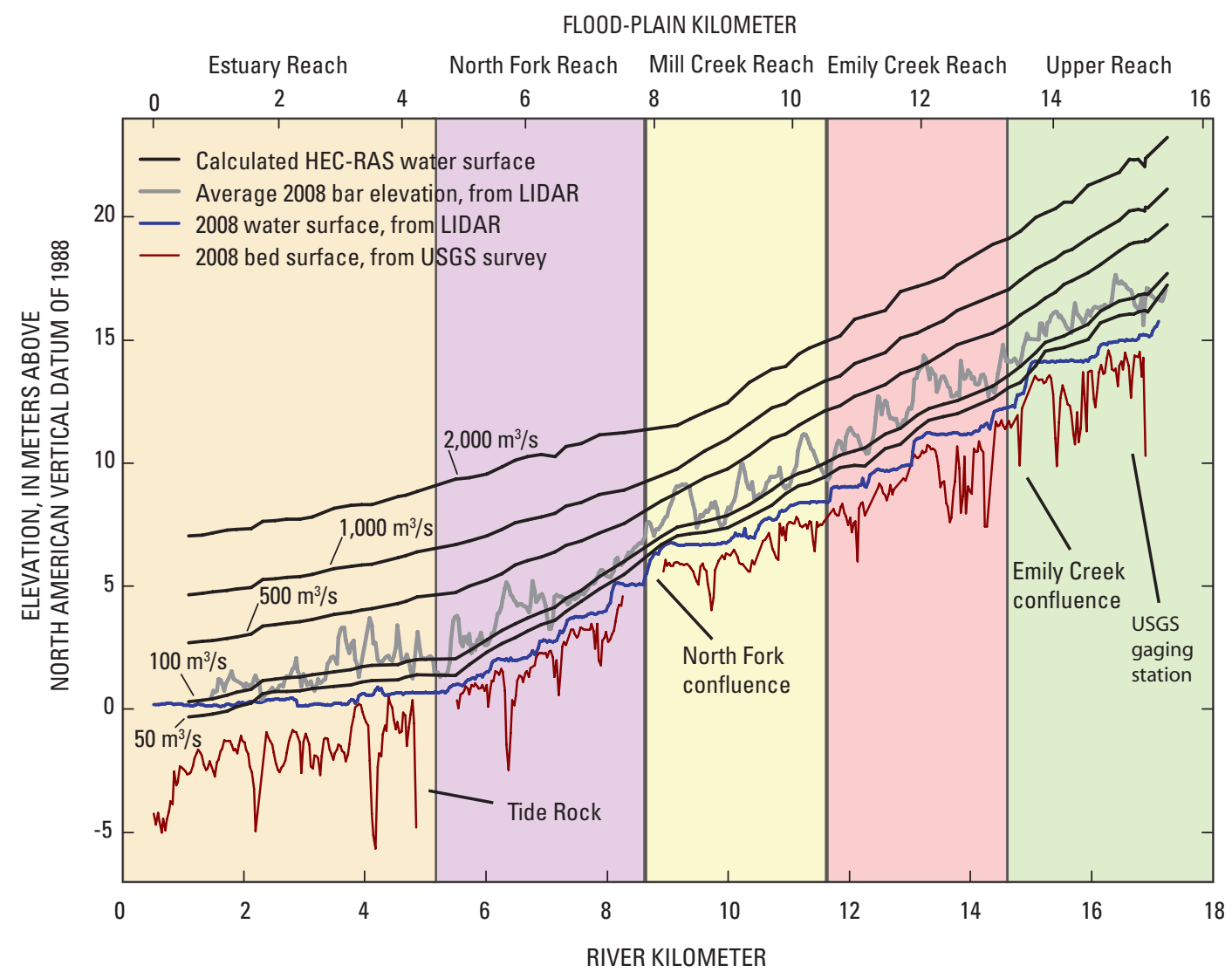

Figure 25. Surveyed channel thalweg in 2008 (USGS survey), water-surface (from LIDAR topography, discharge approximately 7.8 cubic meters per second), bar surfaces (from LIDAR topography), and water-surface profiles as calculated from HEC-RAS for flows between 50 and 2,000 cubic meters per second for the lower Chetco River, Oregon.

\section{Direct Measurement of Bedload Transport}

Although challenging and subject to many uncertainties, direct measurement of bedload transport can substantially aid estimates of annual fluxes of bed material (Hicks and Gomez, 2003). An ideal situation is to make numerous bedload transport measurements over a range of flows to produce a bedload rating curve relating bedload transport rates to river flow (for example, Emmett, 1980; Wilcock and others, 1996; Pitlick and others, 2008). This process requires multiple measurements, possibly over several years to encompass the necessary range of flows, and is especially difficult for rivers such as the Chetco River in which sediment transporting flows are in response to short duration rainfall events. As a consequence, the purpose of making bedload measurements on the Chetco River was not to develop a bedload transport rating curve but solely to aid in selection of bedload transport equations as described in the following sections. The measurements reported here, however, could be incorporated into a bedload rating curve as part of a sustained measurement program.

\section{Sampling}

Two measurement trips were completed during winter 2008-09. The measurements were made from the bridge crossing the river at the USGS streamflow measurement site at FPkm 15.2, near the upstream boundary of the study reach. The channel here makes a sweeping left bend, with the low flow channel abutting steep bedrock of the valley wall, and the left side formed by an active gravel bar inset against vegetated flood plain. For sampling, an $80 \mathrm{~kg}$ TR-2 bedload sampler with a 30 -cm-wide by $15-\mathrm{cm}$-tall opening was used with a $0.5 \mathrm{~mm}$ mesh collection bag (fig. 26). The TR-2 sampler was designed by the USGS in 1986 to sample coarse sand and gravel near Mount St. Helens after the eruption of 1980 (Childers, 1992), and has size and weight characteristics appropriate for the high flows and coarse sediment loads typical of the Chetco River. The sampler was suspended from the bridge with a truck-mounted hydraulic winch. The nose of the sampler was stabilized by a line running through a wheeled pulley riding a stay line crossing the river about $30 \mathrm{~m}$ upstream, with the free end controlled by personnel on the bridge deck. 

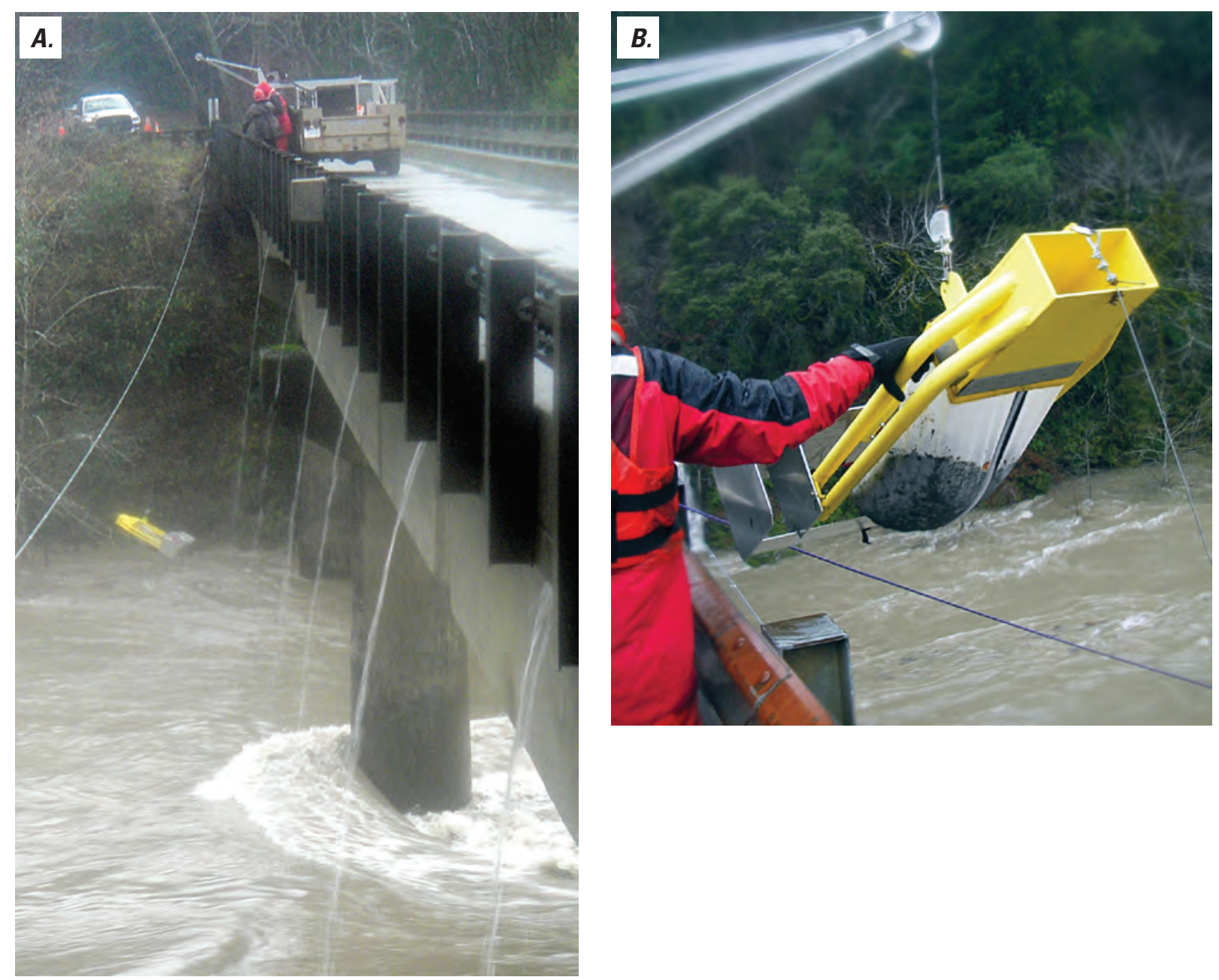

Figure 26. Bedload sampling at USGS streamflow-gaging station, Chetco River near Brookings, Oregon (14400000), December 28, 2008. Streamflow was 1,170 cubic meters per second. (A) View of sampling equipment, including truck and sampler, during deployment; cable in view is for discharge measurements and was not used for bedload sampling. ( $B$ ) TR-2 sampler after sample collection. (Photographs by Jim 0'Connor, U.S. Geological Survey, December 28, 2008.)

Sampling protocols were modified from the single-equalwidth-method prescribed by Edwards and Glysson (1999) to account for time limitations. For each sampling transect, the cross section was sampled by $8-10$ verticals (in contrast to the 20-40 verticals recommended by Edwards and Glysson (1999)) spaced at 4.6-6.1 m apart. The sampler was placed on the bed for 30 seconds for each sample. The intent was to make multiple transects for each measurement, but time and equipment limitations allowed only one complete (or nearly complete) transect for each measurement. The sampler was emptied after most individual vertical measurements, except near the flow edges where little material was collected. Samples were dried, weighed, and sieved by the U.S. Geological Survey Sediment Laboratory in Vancouver, Washington (table 5). Transport rates were calculated by 
Table 5. Summary of bedload measurements for winter 2008-09, Chetco River, Oregon.

[Measurements at U.S. Geological Survey streamflow-gaging station 14400000 with TR-2 sampler; using modified version of single equal-width-increment method of Edwards and Glysson (1999). A bbreviations: kg, kilogram; mm, millimeter; m³/s, cubic meter per second, m, meter; kg/s, kilogram per second]

\begin{tabular}{|c|c|c|c|c|c|c|c|}
\hline $\begin{array}{l}\text { Sample } \\
\text { transect } \\
\text { (date and } \\
\text { start time) }\end{array}$ & $\begin{array}{l}\text { Number of } \\
\text { verticals }\end{array}$ & $\begin{array}{l}\text { Sample } \\
\text { mass } \\
(\mathrm{kg})\end{array}$ & $\begin{array}{l}\text { Median } \\
\text { particle size } \\
(\mathrm{mm})\end{array}$ & $\begin{array}{l}\text { Water } \\
\text { discharge } \\
\left(\mathrm{m}^{3} / \mathrm{s}\right)\end{array}$ & $\begin{array}{l}\text { Channel } \\
\text { width } \\
\text { (m) }\end{array}$ & $\begin{array}{l}\text { Bedload } \\
\text { discharge } \\
(\mathrm{kg} / \mathrm{s})\end{array}$ & Comments \\
\hline $\begin{array}{l}12-28-08 \\
\text { at } 1100\end{array}$ & 10 & 102.4 & 31 & 1,190 & 70 & 78.4 & $\begin{array}{l}\text { Poor sampler contact with channel bed } \\
\text { for some verticals. }\end{array}$ \\
\hline $\begin{array}{l}12-28-08 \\
\text { at } 1400\end{array}$ & 10 & 193.9 & 13 & 1,120 & 70 & 148.4 & $\begin{array}{l}\text { Good sampler contact with channel bed } \\
\text { for most verticals. }\end{array}$ \\
\hline $\begin{array}{l}02-24-09 \\
\text { at } 1123\end{array}$ & 9 & 21.6 & .8 & 290 & 60 & 15.7 & $\begin{array}{l}\text { Sampler support cable failed at vertical } \\
8 \text {; calculation assumes no material } \\
\text { for verticals } 8 \text { and } 9 \text {, so this should } \\
\text { be considered a minimum value. }\end{array}$ \\
\hline
\end{tabular}

$$
Q_{b}=M \times \frac{\left[\frac{W}{(n \times W)}\right]}{T},
$$

where

$\mathrm{Q}_{\mathrm{b}}$ is the bedload transport in kilograms per second;

$M$ is the sample mass in kilograms;

$T$ is the sample time (for each vertical) in seconds;

$W$ is the wetted width in meters;

$\mathrm{n}$ is the number of verticals; and

$W$ is the width of the sampler in meters.

The first measurement trip was December 28-29, 2008, during a wet storm producing high flows along the southern Oregon coast. Flow on the Chetco River increased from about $105 \mathrm{~m}^{3} / \mathrm{s}$ early on December 27 to a peak of $1,200 \mathrm{~m}^{3} / \mathrm{s}$ at 1215 on December 28, before decreasing to about $880 \mathrm{~m}^{3} / \mathrm{s}$ by midnight of December 28. Flow then increased again, peaking even higher at 1215 on December 29 with a discharge of 1,450 m³. $\mathrm{s}$. For comparison, the 2- and 5-year recurrence-interval flows on the Chetco River are 1,060 and $1,425 \mathrm{~m}^{3} / \mathrm{s}$, respectively (fig. 27). During these flows, depths exceeded $12 \mathrm{~m}$ and surface velocities were greater than $3 \mathrm{~m} / \mathrm{s}$. Two measurement transects were completed on December 28. The first, between 1100 and 1310, spanned the peak flow for the day. Because it was difficult to maintain the stability of the sampler in the water and to be certain that it was securely on the channel bed (severe drag on the supporting cable and stay-line prevented detectable slackening of the support cable when the sampler grounded), this measurement is considered inferior to the second measurement of the day, between 1400 and 1606, in which the sampler maintained better position and contact with the bed. An attempted measurement during the high flow of December 29 was unsuccessful because the velocities and flow depths prohibited the sampler from reaching the channel bottom in a controlled manner.

The second measurement trip was on February 24, 2009, in the midst of several days of elevated flow after a late winter frontal system that crossed the Chetco River drainage basin. Flow increased from less than $30 \mathrm{~m}^{3} / \mathrm{s}$ early on February 21 to a peak of $450 \mathrm{~m}^{3} / \mathrm{s}$ at 1800 on February 23 and decreased overnight. During the February 24 sampling between 1123 and 1217, flow was steady at $290 \mathrm{~m}^{3} / \mathrm{s}$ for the entire measurement period (fig. 27). This flow has been exceeded on a mean daily basis for 4.4 percent from October 1, 1969 to March 5, 2009. Sampling proceeded well for this bedload measurement, with much less intense flow than the December 28-29 event, and solid contact with the bed, until the 8th (and penultimate) vertical near the right bank, when the sampler support cable failed, halting completion of the transect. The partial results are reported in table 5 and the calculated transport rate should be considered a minimum value, although the two missing verticals would add negligibly to the total judging from (1) the relative contribution of load from that part of the cross section during the December 28 measurements, (2) the trend of sample masses from this transect, and (3) acoustic Doppler "moving bed" measurements made later in the day (fig. 28). 


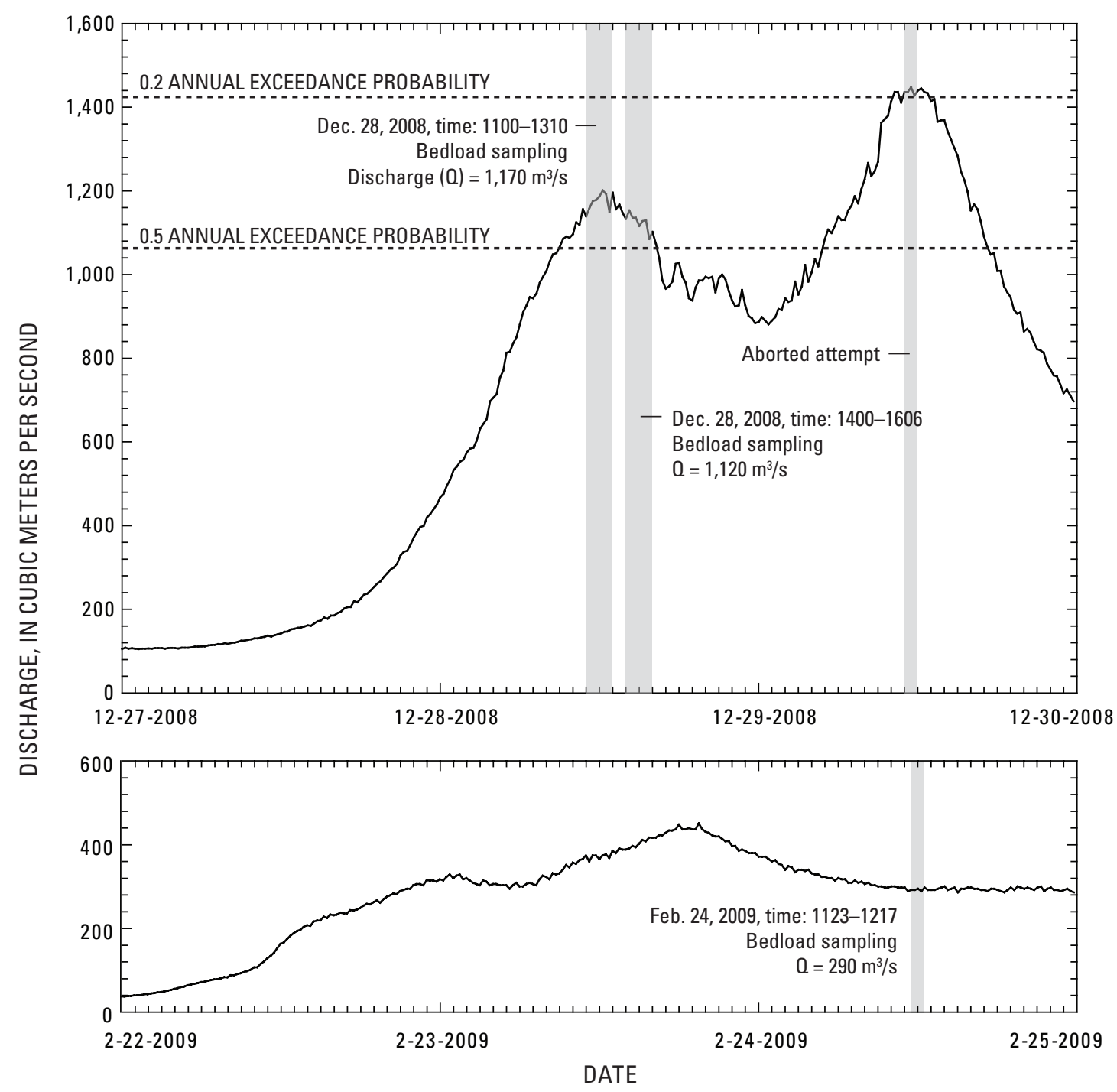

Figure 27. Discharge and sampling periods for bedload measurements on the Chetco River, Oregon. (A) December 29-30, 2008, sampling periods, also showing flow exceedance probabilities as calculated following Bulletin 17 guidelines (Water Resources Council, 1981) from annual peak flows for 1970-2007. (B) February 24-25, 2009, sampling period. 


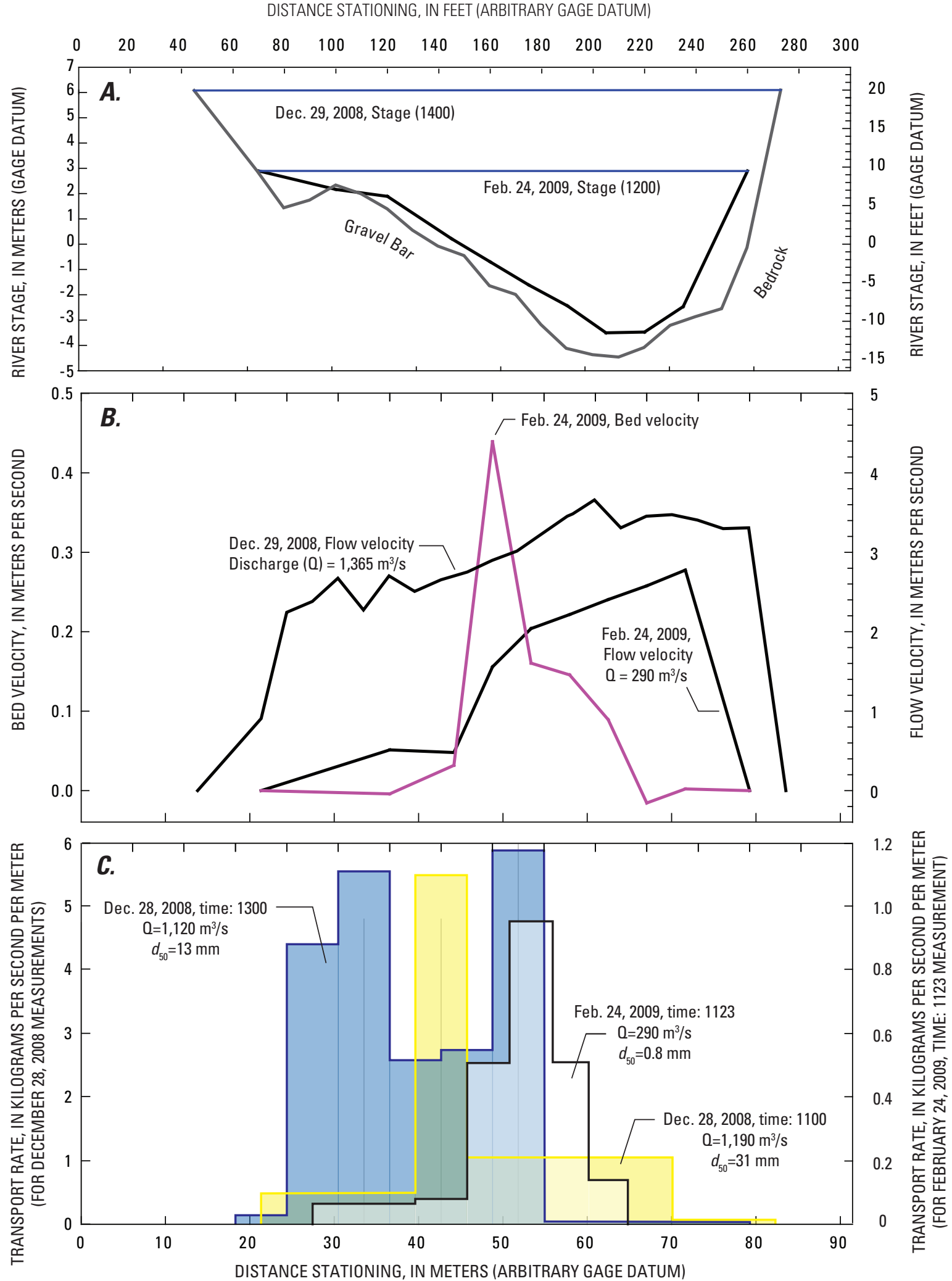

Figure 28. Summary flow and bedload transport data for December 28-30, 2008, and February 24-25, 2009, measurements, Chetco River, Oregon. (A) Channel cross sections, from December 29-30, 2008, and February 24-25. 2009, soundings, with measured stage. (B) Depthaveraged mean bed velocity from December 29, 2008, and February 24, 2009, measurements, and February 24 moving-bed velocity, as measured by acoustic Doppler current profiler. $(C)$ Measured unit bedload transport rates by sampling vertical; several verticals were composited for the December 28, 2008, 1100 measurement, reducing spatial resolution. Most transport for this measurement was between stations 40 and 55 . 


\section{Results and Discussion of Bedload Sampling}

Despite the sampling difficulties and incomplete results, the measurements show high rates of coarse bedload transport at high flows (fig. 28, table 5). The transport rate for the December 281400 measurement, corresponding to a flow slightly exceeding the 2-year recurrence-interval discharge, was nearly $150 \mathrm{~kg} / \mathrm{s}$, with an average unit transport rate of $2.1(\mathrm{~kg} / \mathrm{m}) / \mathrm{s}$. As expected, the transport rate of the lower flow of February 24, 2009, was much less - only $15.7 \mathrm{~kg} / \mathrm{s}$ and a unit transport rate of $0.26(\mathrm{~kg} / \mathrm{m}) / \mathrm{s}$. The transport rate calculated from the December 281400 measurement is higher than nearly all reported examples of high bed load transport rates on western U.S. gravel-bed streams and rivers-which typically range up to about $0.4(\mathrm{~kg} / \mathrm{m}) / \mathrm{s}$ - but is less than the $3.9(\mathrm{~kg} / \mathrm{m}) / \mathrm{s}$ measured for the North Fork Toutle River in a drainage basin tremendously disturbed by the 1980 Mount St. Helens eruption (Pitlick, 1992; Pitlick and others, 2009). The measured transport rate at the highest flow, $1,190 \mathrm{~m}^{3} / \mathrm{s}$, was substantially lower than the rate later in the day at a slightly lower flow, but this discrepancy is due to poor sampler contact with the bed for several measurement verticals. Evident from all measurements, including the "moving bed" Doppler measurement also made on February 24, 2009, is that most bedload transport was over the gravel bar forming the left bank, despite higher velocities in the channel thalweg (fig. 28).

The median particle size of the bedload scaled with water discharge for the December 28, 2008, measurements ranging from 13 to $31 \mathrm{~mm}$, whereas sediment collected during the February 24, 2009, high flow was chiefly sand with a median diameter of $0.8 \mathrm{~mm}$. The $\mathrm{d}_{84}$ for measurements made on December 28, 2008, at 1100 and 1400 were 50 and $60 \mathrm{~mm}$ respectively, slightly finer than the 70 - to $110-\mathrm{mm} \mathrm{d}_{84}$ values for surface and subsurface bed-material samples collected from Fitzhugh bar, 0.5 to $1 \mathrm{~km}$ upstream (fig. 29). Although bedload is typically finer than the surface material and is closer in size to subsurface material (Lisle, 1995), it is possible that the TR-2 sampler, with its 152 - by $305-\mathrm{mm}$ opening, was undersampling the largest clasts. Alternatively, still higher flows may be required to transport the coarsest particles in this reach.

\section{Estimation of Bed-Material Transport Rates Using Established Transport Equations}

Application of bed-material transport formulas are a common means of estimating sediment fluxes in streams (Collins and Dunne, 1989; Gomez, 1991; Hicks and Gomez, 2003). A primary advantage of using bedload transport equations is that the approach can be applied on any stream for which information on flow, channel geometry, and bed-sediment characteristics is available. Moreover, the application of these formulas is typically straightforward and can provide a relatively rapid means of estimating sediment flux across a range of flow scenarios, from individual storm events to decades. For the Chetco River, multiple transport relations for seven locations were applied between FPkm 15.3 and 2.6 for the nearly 40 years of available flow data, enabling assessment of spatial and temporal trends in bed-material transport.

Although several empirical and semiempirical transport equations are available for bedload transport (Gomez and Church, 1989), all actually predict only the transport capacity, defined as the "maximum load a river can carry" (Gilbert and Murphy, 1914, p. 35). For conditions of unlimited bed material available from the bed and banks, a correct relation for transport capacity coupled with accurate descriptions of flow and bed material should result in accurate estimates of bed-material flux. For the Chetco River, the assumption of unlimited supply relative to transport capacity is probably approximately valid because of the voluminous gravel accumulations flanking and underlying the valley bottom within the study area and in the $12 \mathrm{~km}$ upstream of the study area.

Nonetheless, even if river conditions meet this requirement that bed-material transport is a function of flow, channel, and bed texture rather than sediment availability, large uncertainties still arise because bed-material transport is highly variable in time and governed by highly nonlinear relations between local flow and bed-material transportboth of which are difficult to characterize at high resolution (Gomez, 1991; Wilcock and others, 2009). These challenges, in conjunction with the wide variety of field situations and few measurements, in part explain the large number of transport equations available and the variation in their forms and data requirements (Hicks and Gomez, 2003). For this study, we assess and possibly mitigate for these factors by (1) evaluating multiple transport relations for multiple cross sections, (2) checking transport equations against the direct bedload measurements, (3) characterizing flow at individual cross sections using the results from a calibrated one-dimensional flow model, and (4) evaluating the results in the context of other information on sediment flux rates.

\section{Equation Selection and Analysis}

The bedload transport calculations for the Chetco River were implemented by the software package Bedload Assessment in Gravel-bedded Streams (BAGS), a program operating within a Microsoft Excel workbook (Pitlick and others, 2009). Using BAGS enables users to select from six semiempirical transport formulas, which were developed and tested using data from gravel or sandy-gravel streams (Wilcock and others, 2009). Users specify an equation and geometry, flow, and sediment parameters. With this 


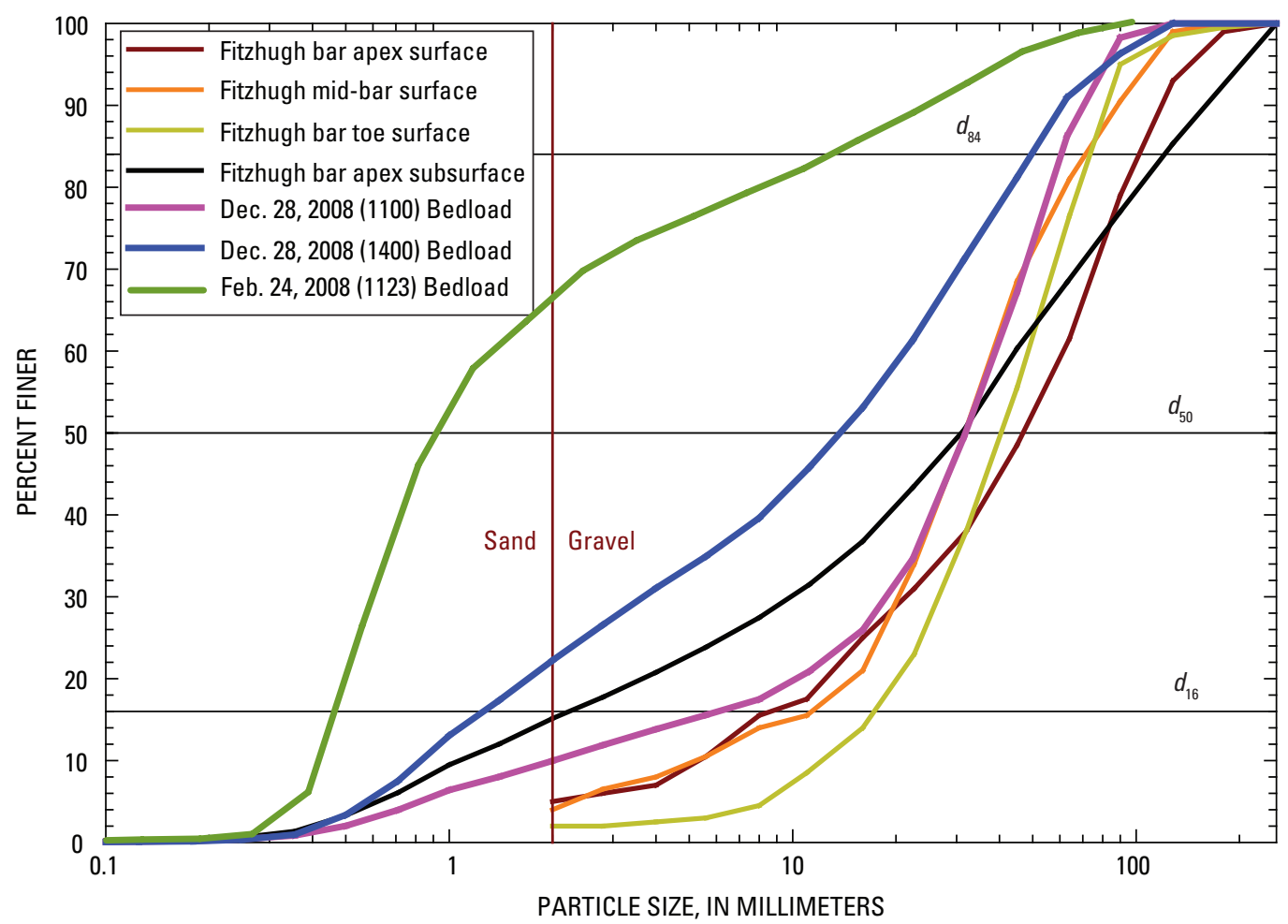

Figure 29. Particle size distributions for sampled bedload and Fitzhugh Bar (flood-plain kilometer 15.5) surface and subsurface measurement, Chetco River, Oregon. Bedload and Fitzhugh Bar subsurface gradations from sieve analysis by U.S. Geological Survey Sediment Laboratory in Vancouver, Washington; surface gradations from Wolman (1954) particle count with measurement template.

information, bed-material transport rates are calculated for a specific flow and cross section geometry.

The bedload transport formulas implemented in BAGS are:

- Parker-Klingeman-McLean, a substrate-based equation (Parker and others, 1982)

- Parker-Klingeman, a substrate-based equation (Parker and Klingeman, 1982)

- Bakke and others, a calibrated equation version of the Parker-Klingeman formula (Bakke and others, 1999)

- Parker, a surface-based equation (Parker, 1990 a,b)

- Wilcock, a two-fraction calibrated model for sand and gravel, (Wilcock, 2001)

- Wilcock and Crowe, a surface based equation (Wilcock and Crowe, 2003)
Although all six formulas are substantively similar and have been successfully applied to gravel-bed rivers, key attributes differentiate the equations, elaborated in Wilcock and others (2009). The substrate-based methods (ParkerKlingeman-McLean and Parker-Klingeman) rely on grain size data from the bed subsurface, and were developed using data collected by Milhous (1973) at Oak Creek, a small gravel-bed stream in the Oregon Coast Range. There are two surface-based methods; the first of which utilizes the Parker (1990 a, b) equation, which was developed from grain-size distributions and transport rates at Oak Creek, whereas the second surface-based method implements the Wilcock and Crowe (2003) equation, which was developed from flume experiments using varying amounts of sand. The two calibrated equations of Bakke and others (1999) and Wilcock (2001) require measurements of bedload transport in order to calibrate reference shear stress, and thus improve the overall transport estimates. In this study, four of the six bedload equations in BAGS were applied to the Chetco River; the two calibrated models of Bakke and others (1999) and Wilcock (2001) equation were not used because of too few direct bedload measurements for reliable calibration. 
For the Chetco River, we first applied the four equations not requiring calibration to a cross section adjacent to the bedload measurement site to enable comparison with the direct bedload measurements collected during winter 2008-09 (fig. 30). Underlying the resulting calculations are the surface and subsurface bed-material size distributions measured near the cross section, channel cross sections from the HEC-RAS model, and a range of simulated streamflows and their associated model-calculated energy-slope $\left(S_{f}\right)$ values. Although all four equations overpredict the measured transport value for the higher quality December 28, 2008, 1400 measurement at a streamflow of $1,120 \mathrm{~m}^{3} / \mathrm{s}$ by a factor of 1.7-3.8, the Parker (1990a, b) and Wilcock and Crowe (2003) surface-bed-composition equations performed better than the substrate-based methods in closely predicting the transport rate measured for the $290 \mathrm{~m}^{3} / \mathrm{s}$ streamflow of February 24, 2009 (fig. 28).

The subsequent analysis was carried forward using only the Parker (1990a, b) and Wilcock and Crowe (2003) bed-material transport relations, which have a similar theoretical framework. The major distinction between the two approaches is in determination of the reference Shields shear stress $\left(\tau_{\text {rsg }}^{*}\right)$; in the Parker $(1990 \mathrm{a}, \mathrm{b})$ equation, $\tau_{\text {rsg }}^{*}$ is assumed to be a constant value of 0.0386 , but in the Wilcock and Crowe (2003) equation, $\tau_{\text {rsg }}^{*}$ varies with the sand content of the surface bed material.

For each of 7 cross sections between FPkm 2.6 and FPkm 15.3, we calculated transport rates for 12 discharges ranging between 15 and 2,000 m³/s, using the model-calculated $S_{f}$ values and nearby measurements of bar-surface particle size (fig. 30, tables 4 and $\underline{6}$ ). Discharges were increased by 14 percent at the North Fork confluence to account for tributary inflow. The results for each discharge produced a relation between discharge $(Q)$ and bed-material transport rate $\left(Q_{s}\right)$, which were fitted by curves to produce a sediment-discharge rating curve. Although many sediment rating curves are fit by power functions (Hicks and Gomez, 2003; Wilcock and others, 2009), this form did not fully characterize the calculated Chetco River bed-material transport rates. As a consequence, we developed continuous ratings by fitting piecewise polynomial functions to the results for each cross section.

In part, the poor fit of power functions resulted from using the energy slope $\left(S_{f}\right)$ instead of a reach-averaged channel slope. The energy slopes calculated by the step-backwater modeling varied substantially with discharge at nearly all cross sections (fig. 30A), reflecting the transition from channel control on slope (mostly because of the pool and riffle structure of the low flow channel) to broader valley-bottom controls at higher discharges. Consequently, the transport rating curves were highly variable, especially at low discharges, but approached more typical power functions at higher discharges as $S_{f}$ approached reach-scale valley slopes (for example, fig. 30B).
Partly as a consequence of the nonsystematic variation of $S_{f}$ with discharge, high transport rates were calculated for some cross sections at very low discharge (commonly where cross sections were located at riffles). In these cases, we assumed no transport at low discharges. The cutoff discharge ranged from 50 to $230 \mathrm{~m}^{3} / \mathrm{s}$ for all but one of the cross sections - flows typically confined to the low flow channel or barely covering low channel-flanking bars and not likely to transport substantial bed material (fig. 25; Mueller and others, 2005). For the cross section at FPkm 8.5, no transport was assumed for flows less than $425-450 \mathrm{~m}^{3} / \mathrm{s}$, depending on the transport relation. Very low transport rates calculated for this cross section were likely the result of relatively coarse bed material at the closest sample location, coupled with low calculated energy gradients (table 6).

The resulting $Q-Q_{s}$ relations served as a basis for calculating annual sediment transport fluxes and their spatial and temporal variation. Annual transport volumes were calculated for each cross section by applying the discharge record of October 1, 1969-September 30, 2008 from the USGS streamflow-gaging station at FPkm 15.3. Typically, annual transport volumes are calculated using mean daily values (for example, Collins and Dunne, 1989), but because of the combination of the highly nonlinear transport rates and the rapid flow changes on the Chetco River during transport events, annual bed-material transport volumes determined from mean daily values are likely to underestimate true values. Therefore, annual bed-material transport volumes were based on the higher resolution unit discharge values. For the Chetco River, unit flow values for the study period were recorded every 15 minutes after 2006 and every 30 minutes before 2006, but are only electronically archived for the post-1988 period.

For the 1988 through 2008 water years, transport rates were calculated for each cross section using the 15-minute and 30-minute unit flow data, summing total transport for each day. To extend the record back through water year 1970 and to fill more recent periods when unit flow data were not available (unit flow data are not available for all of 1993 and parts of several other years), relations for each cross section were developed between daily transport volumes calculated from the unit flow measurements and mean daily flow for all days of predicted transport. For the cross-section at the USGS streamflow-gaging station (FPkm 15.3), the relations for both the Parker (1990a,b) and Wilcock-Crowe (2003) equations revealed negligible daily transport when daily mean flow was less than $85 \mathrm{~m}^{3} / \mathrm{s}$, (which is within the range of low-flow thresholds at nearby cross-sections determined from the $Q-Q_{S}$ relations based solely on unit value data; table 6). The regressions had regression correlation coefficients ranging from 0.968 to 0.998 , and were applied to all days to permit calculations for the entire record of October 1, 1969September 30, 2008. For the USGS streamflow-gaging station, daily transport 1970-2008 was calculated by: 


$$
\begin{gathered}
Q_{s, d P}=\left\{\begin{array}{c}
0, \quad Q_{d m f} \leq 85 \\
-1.982 \times 10^{-2}\left(Q_{d m f}^{3}\right)+62.19 \times\left(Q_{d m f}^{2}\right)-17,747 \times\left(Q_{d m f}\right)+1,428,000, \quad Q_{d m f}>85
\end{array},\right. \\
Q_{s, d W C}=\left\{\begin{array}{c}
0, \quad Q_{d m f} \leq 85 \\
-2.418 \times 10^{-2}\left(Q_{d m f}^{3}\right)+57.75 \times\left(Q_{d m f}^{2}\right)-7,676 \times\left(Q_{d m f}\right)+342,500, \quad Q_{d m f}>85
\end{array}\right.
\end{gathered}
$$

where

$Q_{s, d p}$ is the daily bed-material transport (in $\mathrm{kg}$ ) at the USGS Chetco River streamflow-gaging station (FPkm 15.3), determined from regression between daily mean flows and daily transport calculated from the Parker $(1990 \mathrm{a}, \mathrm{b})$ transport formula applied to unit flow values.

$\mathrm{Q}_{\mathrm{s}, \mathrm{d} W \mathrm{WC}}$ is the daily bed-material transport (in $\mathrm{kg}$ ) at the USGS Chetco River streamflow-gaging station (FPkm 15.3), determined from regression between daily mean flows and daily transport calculated from the Wilcock-Crowe (2003) transport formula applied to unit flow values.

$Q_{d m f}$ is the daily mean flow (in $\mathrm{m}^{3} / \mathrm{s}$ ) for the USGS Chetco River gaging station (FPkm 15.3).

Annual transport volumes were calculated by summing daily transport and applying a bulk density of 2.1 metric tons per cubic meter.

$$
v=\frac{m}{(1-n) \rho}
$$

where

$\mathrm{m}$ is mass in kilograms.

$\checkmark$ is volume in cubic meters.

$\mathrm{n}$ is in-situ porosity of bed-material sediment. An in-situ porosity of 0.21 was applied based on a range of porosity data collected by Milhous (2001) as presented in Bunte and Abt (2001).

$\rho$ is particle density. A standard particle density of $2,650 \mathrm{~kg} / \mathrm{m}^{3}$ was applied. 


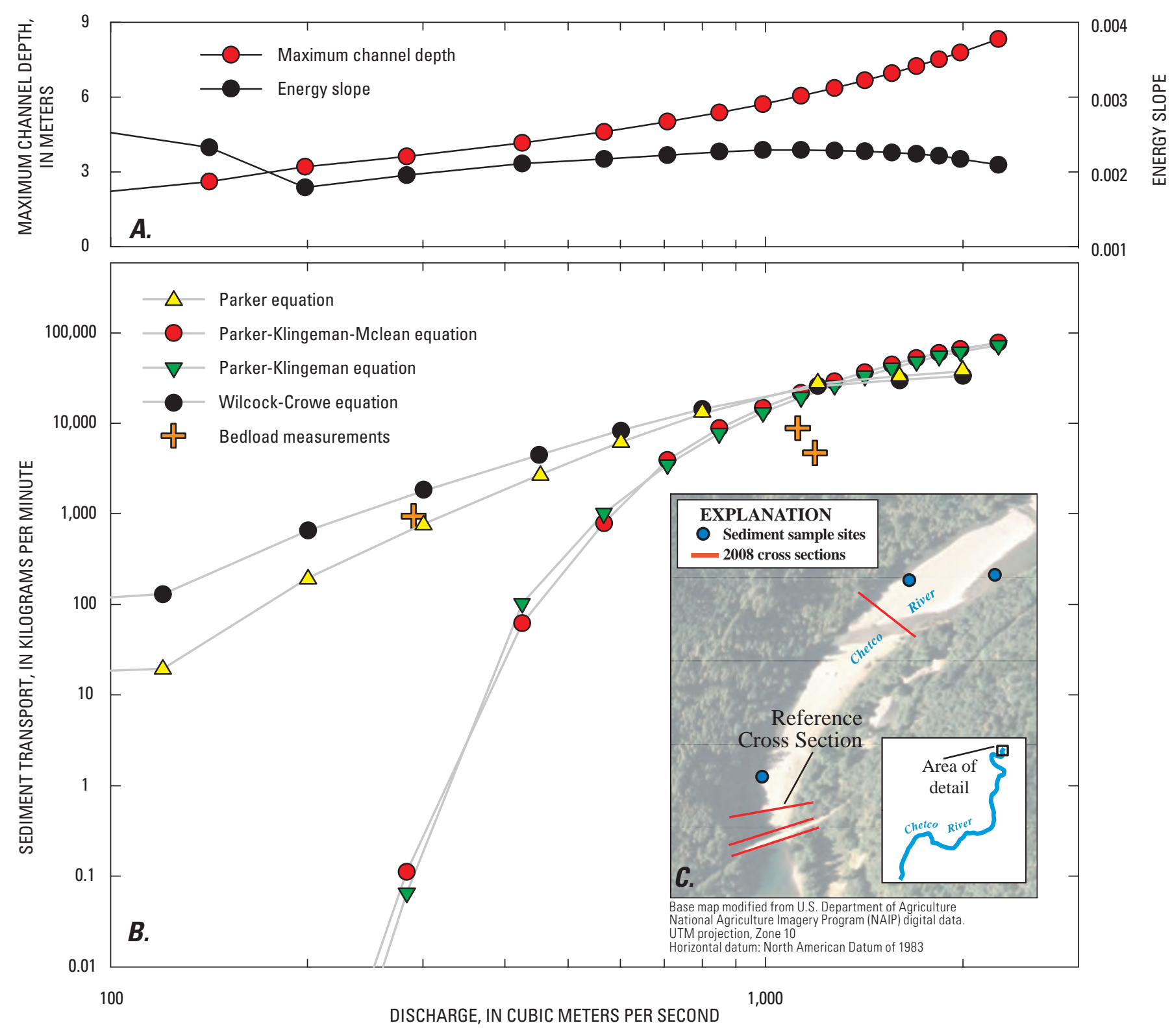

Figure 30. Streamflow hydraulics, calculated and measured bed-material transport, and location map for vicinity of measurement site near flood-plain kilometer 15.3 on Chetco River, Oregon. $(A)$ Modeled flow depth and energy slope for reference cross section at flood-plain kilometer 15.3. $(B)$ Calculated bed-material transport rates at reference cross section at flood-plain kilometer 15.3 for four bed-material transport equations described in text. Also shown are measured bedload transport rates for three measurements made from bridge at flood-plain kilometer 15.24. (C) Location of streamflow-model cross sections, bed-material transport calculations (reference cross section), the bridge from which the bedload measurements were made (which is also the location of the USGS streamflow-gaging station), and location of sediment samples from which grain-size measurements were averaged for calculating bedload transport rates. 


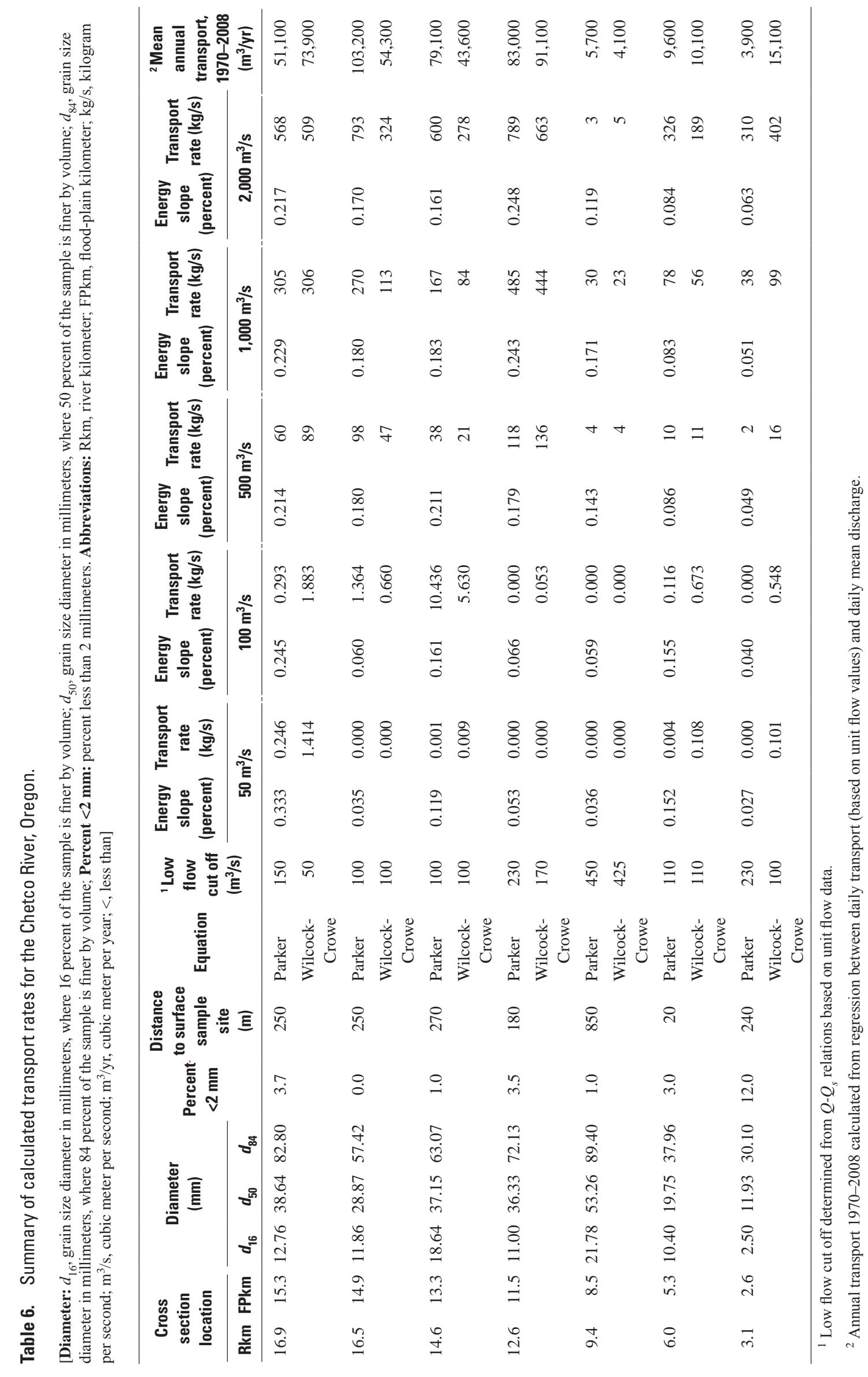




\section{Results and Discussion of Bed-Material Transport Equation Calculations}

Application of the Parker (1990a, b) and Wilcock and Crowe (2003) bed-material transport equations for seven cross sections over 39 years indicates considerable spatial and temporal variability in predicted annual transport volumes (figs. 31 and 32). On the basis of the overall consistency in predicted transport capacity for the cross sections in the Upper and Emily Creek reaches (fig. 31) and the agreement between measured and predicted transport rates (fig. 30), the results for the cross section at FPkm 15.3 were determined to be representative of the volume of bed-material entering the study reach. For this "reference" cross section (fig. 30C), predictions of bed-material influx into the reach range from less than 3,000 $\mathrm{m}^{3} / \mathrm{yr}$ for some dry years such as 1977 and 2001, to more than 150,000 m³/yr for the wet years of 1982 and 1997 (fig. 32). The mean annual volume for the 1970-2008 period for this cross section is $51,100 \mathrm{~m}^{3} / \mathrm{yr}$ as calculated by the Parker (1990a, b) relation, and 73,900 $\mathrm{m}^{3} / \mathrm{yr}$ based on the Wilcock and Crowe (2003) equation (table 6). These values are closely bracketed by a 43,600 to 103,200 m³/yr range encompassed by the predictions of mean annual transport for all four of the analyzed cross sections in the Upper and Emily Creek reaches.

For each of the seven analyzed cross sections, the calculated range of annual bed-material transport averaged over the 39-year analysis period ranged from 3,900 m³/yr at FPkm 2.6 to $103,200 \mathrm{~m}^{3} / \mathrm{yr}$ at FPkm 14.9 for the Parker (1990a, b) equation, and 4,100 $\mathrm{m}^{3} / \mathrm{yr}$ at FPkm 8.5 to 91,100 $\mathrm{m}^{3} / \mathrm{yr}$ at FPkm 11.5 for the Wilcock and Crowe (2003) equation (fig. 31). The section-to-section spatial variability of mean annual transport rates along the channel probably is not indicative of actual conditions because of

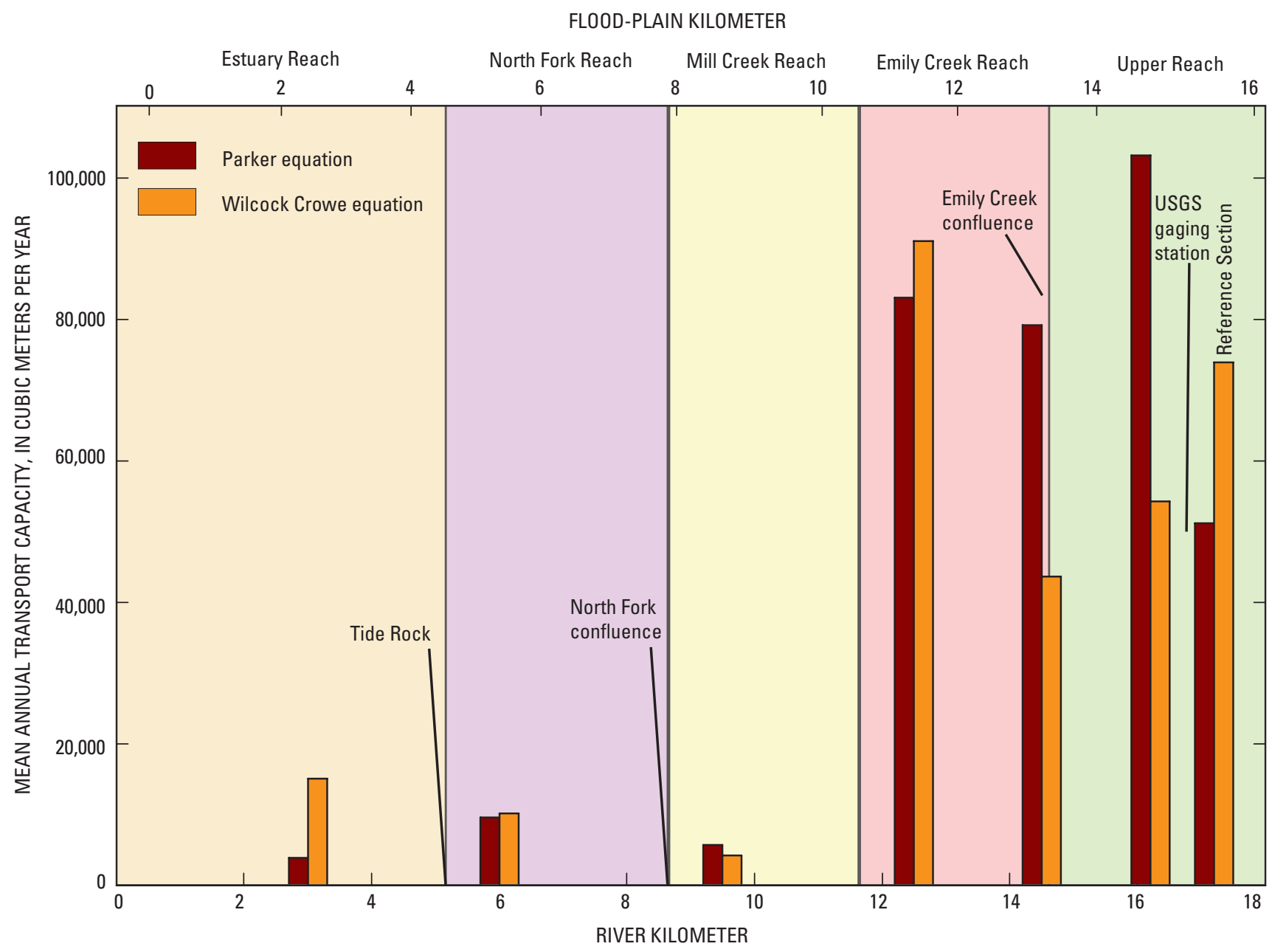

Figure 31. Mean annual calculated bed-material transport capacity for seven cross sections along the lower Chetco River, Oregon, for water years 1970-2008. Calculations based on Parker (1990a, b) and Wilcock and Crowe (2003) transport equations. Hydraulics at each cross section from one-dimensional step-backwater hydraulic model for entire study reach. 


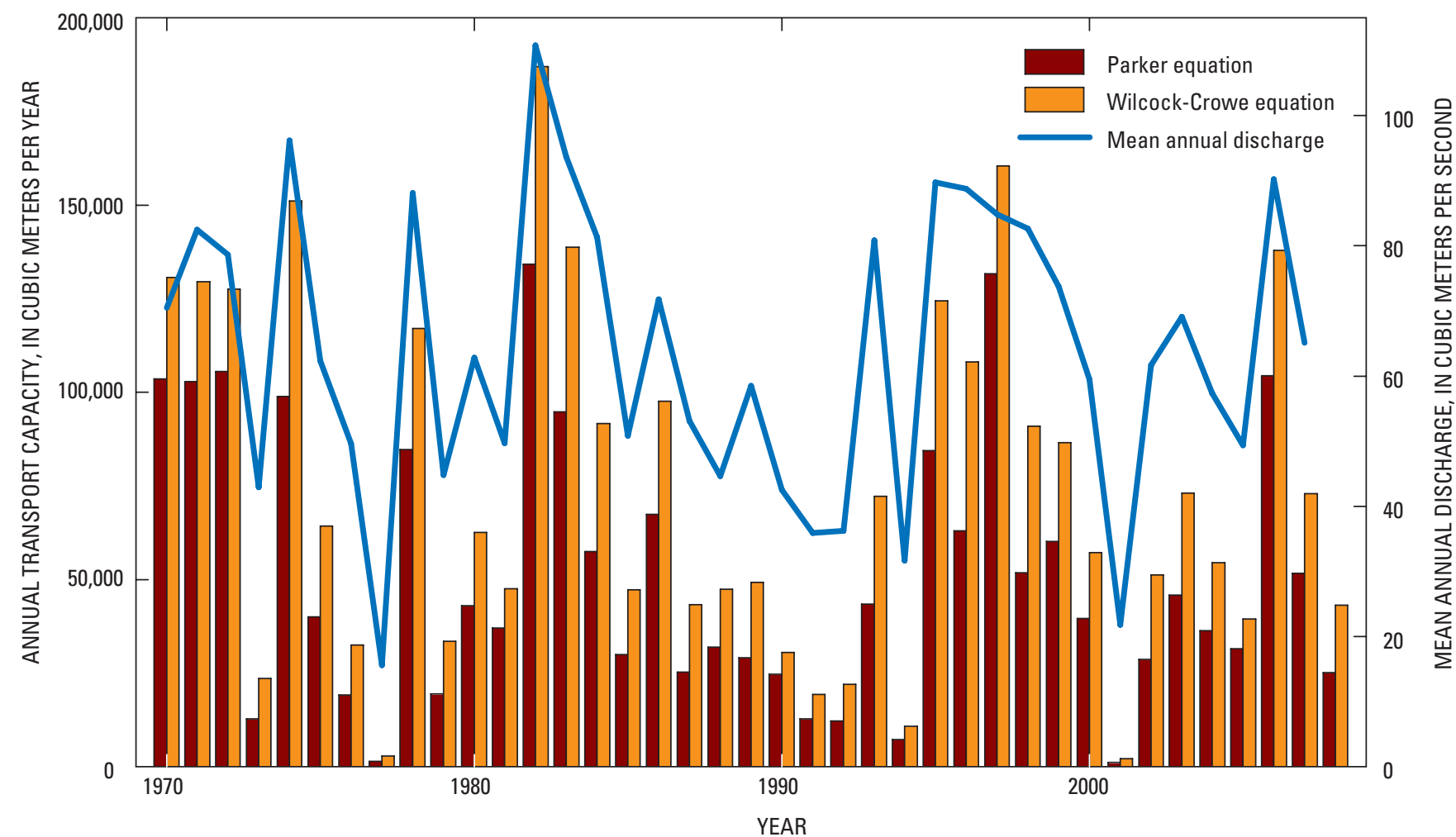

Figure 32. Annual transport capacity and mean annual discharge at USGS streamflow-gaging station, Chetco River near Brookings, Oregon (14400000). Annual bed-material transport capacity computed for reference cross section at flood-plain kilometer 15.3 for water years 1970-2008 on basis of the Parker (1990a, b) and Wilcock and Crowe (2003) transport relations.

(1) differences in the suitability of particular cross sections for bed-material transport calculations because of factors such as flow obstructions and along cross section variations in shear stress, (2) poor characterization of local surface particle-size distributions, particularly because some analyzed cross sections were as much as $850 \mathrm{~m}$ away from the nearest sediment sampling location, and (3) differences in the accuracy of the hydraulic modeling for each cross section, particularly in regards to calculated values of $S_{f}$, which is a critical flow parameter controlling transport rates (Wilcock and others, 2009). Nevertheless, the general trends evident in figure 31-transport capacities of 40,000 to $100,000 \mathrm{~m}^{3} / \mathrm{yr}$ in the Upper and Emily Creek Reaches, diminishing downstream to less than 10,000 m³/yr in the Mill Creek Reach—probably closely indicate overall transport conditions. This pattern is also consistent with geomorphic evidence of historical sedimentation in the lower Mill Creek and North Fork reaches.
The annual variability in predicted bed-material transport capacity is also high (fig. 32), but this is attributable to the nonlinear relation between bed-material transport and flow coupled with the high year-to-year flow variability. For the reference cross section at FPkm 15.3, the annual calculated bed-material volumes range from $1,067 \mathrm{~m}^{3} / \mathrm{yr}$ in the particularly dry year of 2001, as calculated by the Parker (1990a, b) relation to $160,500 \mathrm{~m}^{3} / \mathrm{yr}$ in 1997 , as calculated by the Wilcock and Crowe (2003) equation. The distribution of predicted annual transport volumes is negatively skewed, meaning that most years—about 60 percent-have transport rates less than the mean value. The 2002 water year record highlights the temporal variability within a single year; for this year the total bed-material transport predicted by the Parker (1990a, b) equation is $28,600 \mathrm{~m}^{3} / \mathrm{s}$, but one-half of this volume was predicted to have been transported in a 6-day period encompassing less than 2 percent of the year (fig. 33). 

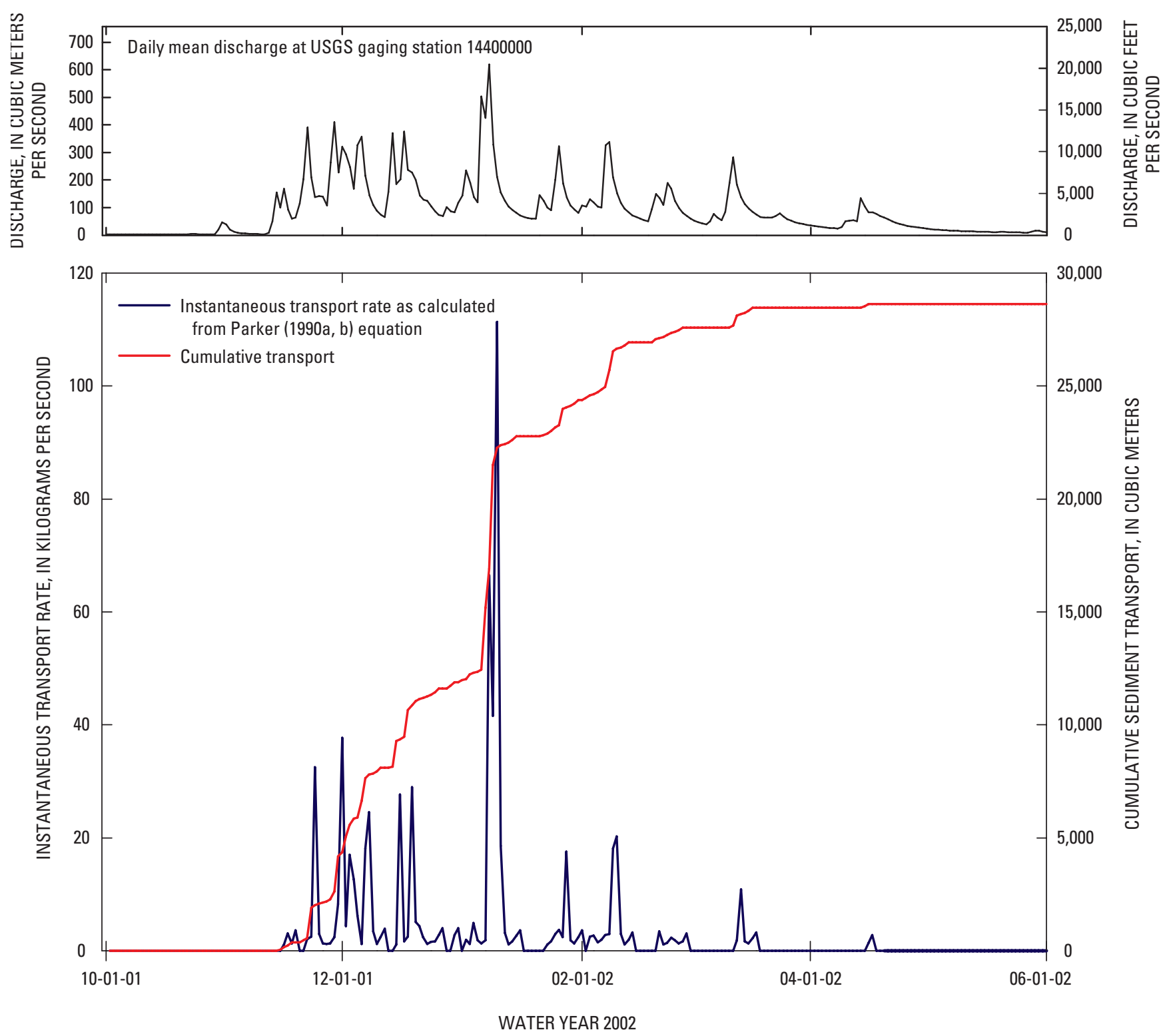

Figure 33. Discharge and calculated bed-material transport for water year 2002 at reference cross section at flood-plain kilometer 15.3, Chetco River, Oregon. 
The Parker (1990a, b) and Wilcock and Crowe (2003) relations generally produce total annual volume estimates that agree to within a factor of 2 for most analyzed cross sections. Differences in predicted transport capacities between the two equations chiefly are because of the sand content of the surface bed material, with the Wilcock and Crowe (2003) relation predicting higher transport rates at cross sections where the sand content is higher, such as for the downstream-most site at FPkm 2.6. For cross sections where the surface samples had little sand, such as cross sections at FPkm 11.5, 8.5, and 5.3, the equations agree to within 10 percent (table 6 ).

Quantitative assessment of the uncertainty of the transport values derived from application of these bedmaterial capacity equations is challenging, especially for situations of few actual measurements (Pitlick and others, 2009). The two direct bedload discharge measurements support selection of the Wilcock and Crowe (2003) and Parker (1990a, b) equations for calculating transport capacity, and the underlying assumption that bed-material transport is indeed a function of streamflow rather than supply. Measurements are lacking, however, to test these equations and assumptions for other areas in the study reach. Because of the semiempirical nature of the equations, uncertainty and errors arise from channel geometry, flow, and sediment texture characterizations. However, a range of these parameters is part of the calculated transport rates for each of the cross sections, and the resulting range of mean annual transport volumes of 51,120-103,200 m³/yr (as calculated by the Parker equation [1990 a, b]) for the four cross sections in the Upper and Emily Creek reaches transport relation provides an indication of the effects of such uncertainty as a result of characterization of local conditions. Systematic analysis of the effects of surface bed-material size on calculated transport rates for the reference cross section at FPkm 15.3 shows that a plus or minus 10 percent variation in the surface grain-size distribution results in 20-35 percent difference in predicted transport rates, indicating that transport capacity is highly sensitive to surface bed-sediment texture.

One independent check of the overall reasonableness of these predicted values is consideration of the predicted transport volumes relative to bar area. For water year 2005, the Parker (1990 a, b) and Wilcock and Crowe (2003) equations applied to the reference cross section predict 31,500 and $39,500 \mathrm{~m}^{3}$ entering the study area, respectively, volumes that translate to seemingly reasonable values of $15-20 \mathrm{~cm}$ of deposition on all the bare bars (which generally correspond to the low elevation bar surfaces) as mapped in the study reach from aerial photographs taken in summer 2005.

The primary means by which uncertainty in the transport equations could be reduced is by more direct bedload measurements. Additional measurements would allow further checking of the equations used in this analysis or enabling use of the calibrated transport equations of Bakke and others (1999) and Wilcock (2001). If a sufficient number of measurements were available over a wide range of flows, a site-specific empirical equation relating bed-material transport to flow could supplant the application of the equations and allow for more rigorous assessments of uncertainty.

\section{Estimation of Bed-Material Flux by Assessment of Channel Change}

An independent approach to assessing the transport rates of bed material is to exploit the intrinsic relation between rates of channel change in alluvial rivers and rates of sediment transport. This type of "morphology-based" approach (Popov, 1962; Martin and Church, 1995) relates volumetric change within a reach to assumptions regarding storage, annual transport lengths, or independent boundary conditions to provide annual estimates of bed-material flux. Morphology-based approaches to estimating sediment budgets have been applied to numerous gravel-bed rivers throughout the world, including many rivers in similar environments as the Chetco River (Collins and Dunne, 1989; Martin and Church, 1995; McLean and Church, 1999; Ham and Church, 2000; Gaeuman and others, 2003; Martin and Ham, 2005; Surian and Cisotto, 2007). In proper settings, this approach has the advantage of (1) being based on actual measurements of observed channel change, (2) being potentially applied for multiple periods and in the absence of flow data, and (3) integrating multiple transport events in determining bed-material fluxes, thereby avoiding the uncertainties in predicting transport from applying strongly nonlinear transport relations to highly variable flows.

\section{Morphologic Analysis}

Estimates of bed-material transport rates require volumetric estimates of changes in bed material for specific periods. For the Chetco River, most bed material is stored in the bars flanking the low-flow channel, so this analysis focused on estimating changes in bar volume. Estimates of volumetric change are best acquired from repeat high-resolution topographic surveys (Martin and Church, 1995; McLean and Church, 1999), but in the absence of such surveys, they are commonly obtained by mapping planview changes between sequential sets of aerial photographs and estimating the thickness of bed material involved in the mapped changes (Collins and Dunne, 1989; Gaeuman and others, 2003). Short analysis periods are preferable to reduce the negative bias in calculated volumetric change introduced by possible repeated erosion and deposition at the same location by multiple events. Consequently, the ideal situation is to calculate volumetric changes after each transporting flow (Lindsay and Ashmore, 2002), but the more typical circumstance is to rely on aerial photograph sequences spanning periods of less than 5 years. A potentially favorable 
situation for future analyses, made possible recently, is the opportunity to accurately determine volumetric changes by repeat LIDAR topographic surveys using the survey in 2008 as a starting point.

For the Chetco River study area, we applied this approach using sequences of aerial photographs and the LIDAR topographic survey of 2008, which together span five time intervals: 1939-43, 1962-65, 1995-2000, 2000-2005, and 2005-08. This analysis was based on the maps of the active channel areas described previously. For each period, we overlaid the maps of active channel features to create three polygon classes (fig. 34): erosion, deposition or no-volumetric-change. Erosion polygons were assigned to areas where a bar or flood-plain feature mapped on the first photograph set became a water feature on the second photograph set of the analysis pair. Likewise, deposition polygons were those areas that changed from water to bar (in cases water became flood plain). Areas that did not change between land and water were classified as no-volumetric-change.

Because this approach relies on the accurate mapping of depositional and erosional areas, several steps were taken to reduce mapping errors and georeferencing and rectification uncertainties. These steps included reclassifying some features on the active-channel maps to avert erroneous designations and transitions, such as classifying small disconnected water bodies as deposition because they were water filled on one photograph but dry on the next. We also eliminated all small areas (mostly less than $10 \mathrm{~m}^{2}$, but as large as $200 \mathrm{~m}^{2}$ ) that possibly resulted from imprecise registration or digitization of features that seemingly had not changed. These areas, however, cumulatively represent only a small percentage of the total depositional and erosional areas; for example, for the period between 1939 and 1943, the total area excluded by these uncertain polygons was less than 2 percent of total area of change. Each of the polygons remaining after this process was inspected at 1:3,000 to verify assigned classifications.

As for the assessment of temporal trends in bar area, different discharges (and stages) between photograph sets in analysis pairs were accounted for by adjusting the net area of erosion or deposition by the estimated difference in bar area as a result of the difference in discharge (fig. 7). For certain year pairs, such as 2005 and 2008, for which the difference in discharge is small, this adjustment is very small. But for analysis periods such as 1939-43 and 1995-2000, this adjustment is large relative to the area of net erosion or deposition (fig. 35, table 7).
1962

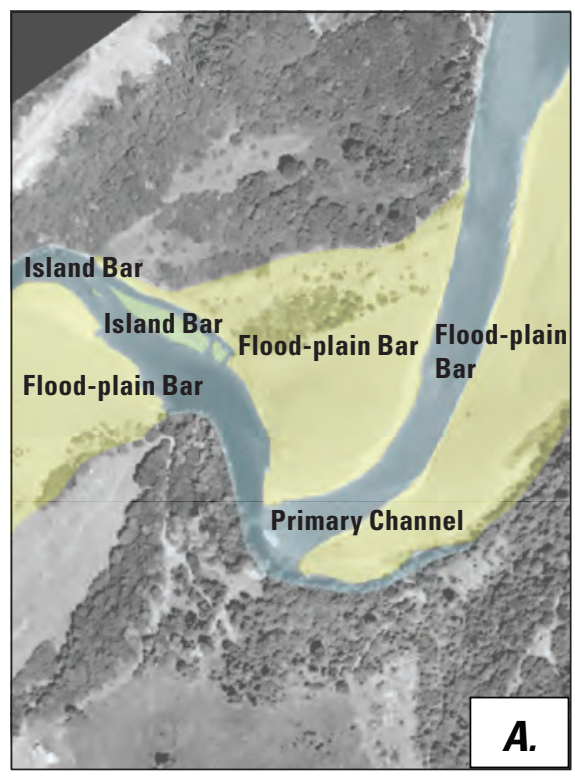

1965

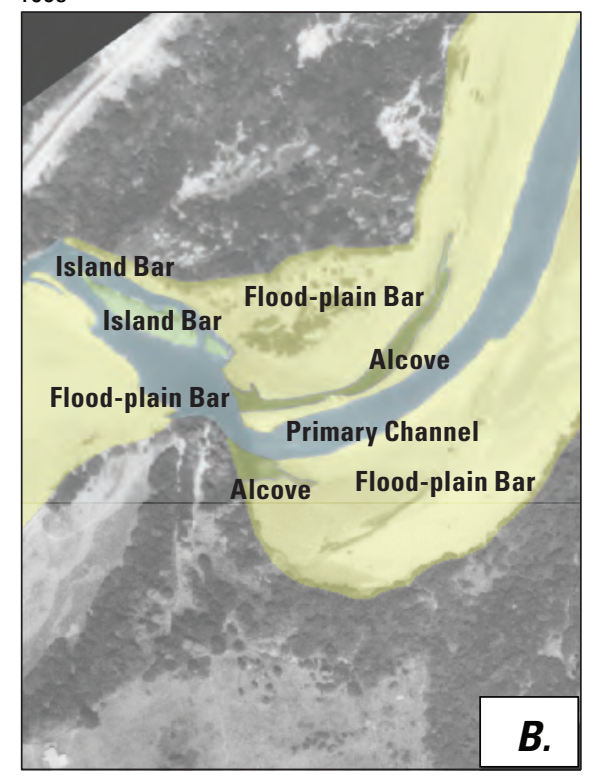

Morphologic change, 1962-1965

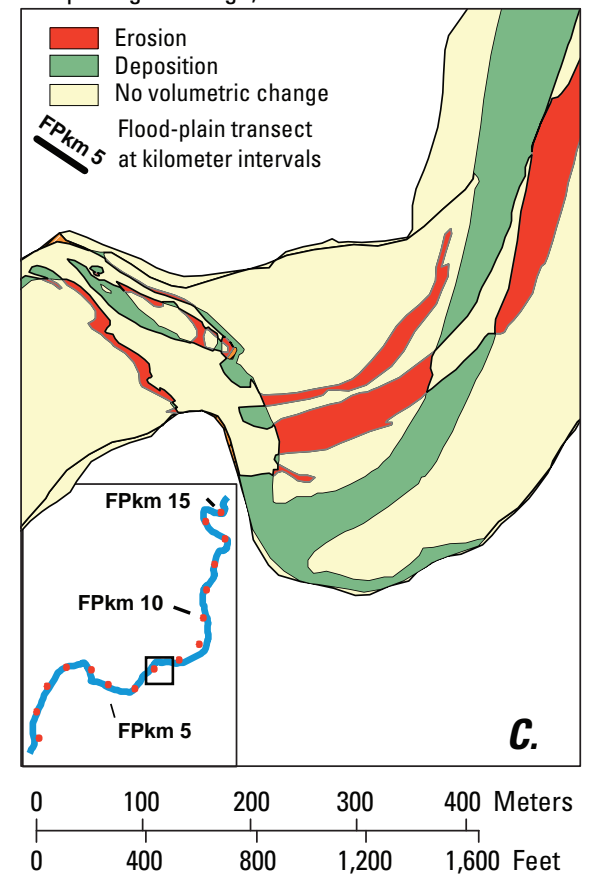

Figure 34. Example of erosion and deposition classification for morphologic analysis near flood-plain kilometer 7, Chetco River, Oregon. (A) Channel and bar mapping for 1962. (B) Channel and bar mapping for 1965. (C) Erosion, deposition, and no-volumetricchange classifications for 1962-65. 

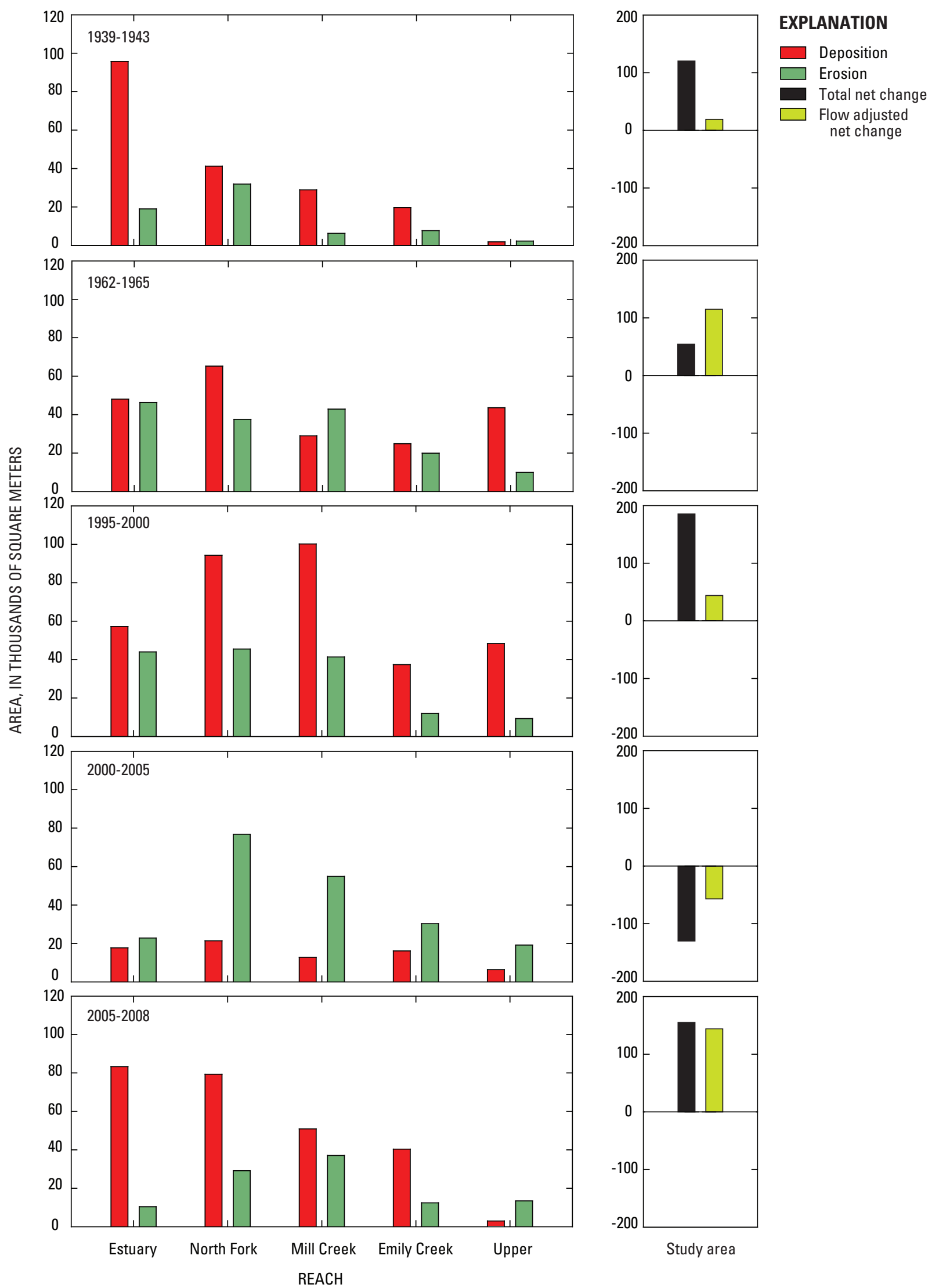

Figure 35. Areas of bed-material deposition and erosion volumes for selected periods in the Chetco River, Oregon. Individual reach measurements not adjusted for difference in flow stage. For each period, the total net change for the study reach was adjusted for flow differences between photograph sets (fig. 7) to determine "flow-adjusted net change" to use in calculating net bed-material influx to the study reach. 
Table 7. Summary of morphology-based sediment-transport-volume estimates, Chetco River, Oregon.

[A bbreviations: $\mathrm{m}^{2}$, square meter; $\mathrm{m}^{3}$, cubic meter; $\mathrm{m}^{3} / \mathrm{yr}$, cubic meter per year; -, no data]

\begin{tabular}{|c|c|c|c|c|c|}
\hline & \multicolumn{5}{|c|}{ Analysis period } \\
\hline Number of years & 4 & 3 & 5 & 5 & 3 \\
\hline Area of eroded bar $\left(\mathrm{m}^{2}\right)$ & 67,000 & 157,000 & 152,000 & 204,000 & 102,000 \\
\hline New bar area $\left(\mathrm{m}^{2}\right)$ & 187,000 & 211,000 & 337,000 & 74,000 & 257,000 \\
\hline Net measured change in bar area $\left(\mathrm{m}^{2}\right)$ & 120,000 & 54,000 & 185,000 & $-130,000$ & 155,000 \\
\hline \multicolumn{6}{|c|}{ Scenario 1: Erosion and deposition, where bar thickness in each reach is average of all bars } \\
\hline Volume of erosion $\left(\mathrm{m}^{3}\right)$ & 183,000 & 443,000 & 421,000 & 560,000 & 283,000 \\
\hline Volume of deposition $\left(\mathrm{m}^{3}\right)$ & 538,000 & 598,000 & 942,000 & 214,000 & 723,000 \\
\hline Net change in bed-material $\left(\mathrm{m}^{3}\right)$ & 355,000 & 155,000 & 521,000 & $-346,000$ & 440,000 \\
\hline \multicolumn{6}{|c|}{ Scenario 2: Erosion and deposition, where bar thickness in each reach is average of all low bars } \\
\hline Volume of erosion $\left(\mathrm{m}^{3}\right)$ & 116,000 & 282,000 & 268,000 & 338,000 & 171,000 \\
\hline Volume of deposition $\left(\mathrm{m}^{3}\right)$ & 361,000 & 375,000 & 581,000 & 133,000 & 462,000 \\
\hline Net change in bed-material $\left(\mathrm{m}^{3}\right)$ & 245,000 & 93,000 & 313,000 & $-205,000$ & 291,000 \\
\hline Flow-adjusted net change in bed-material $\left(\mathrm{m}^{3}\right)$ & 56,000 & 204,000 & 75,000 & $-85,000$ & 273,000 \\
\hline Annual net balance ${ }^{3}\left(\mathrm{~m}^{3} / \mathrm{yr}\right)$ & 61,000 & 31,000 & 63,000 & $-41,000$ & 97,000 \\
\hline Flow-adjusted annual net balance ${ }^{3}\left(\mathrm{~m}^{3} / \mathrm{yr}\right)$ & 14,000 & 68,000 & 15,000 & $-17,000$ & 91,000 \\
\hline \multicolumn{6}{|c|}{ Scenario 3: Erosion calculated using reach average thickness of all bars; deposition calculated using reach average thickness of low bars } \\
\hline $\begin{array}{l}\text { Summary Ranges: Flow-adjusted annual net } \\
\text { balances }\left(\mathrm{m}^{3}\right)\end{array}$ & $\begin{array}{r}-12,000 \text { to } \\
14,000\end{array}$ & $\begin{array}{r}-27,000 \text { to } \\
111,000\end{array}$ & $\begin{array}{c}-29,000 \text { to } \\
25,000\end{array}$ & $\begin{array}{r}-49,000 \text { to } \\
-17,000\end{array}$ & $\begin{array}{r}51,000 \text { to } \\
137,000\end{array}$ \\
\hline
\end{tabular}


Table 7. Summary of morphology-based sediment transport-volume-estimates, Chetco River, Oregon.-Continued

[A bbreviations: $\mathrm{m}^{2}$, square meter; $\mathrm{m}^{3}$, cubic meter; $\mathrm{m}^{3} / \mathrm{yr}$, cubic meter per year; -, no data]

\begin{tabular}{|c|c|c|c|c|c|}
\hline & \multicolumn{5}{|c|}{ Analysis period } \\
\hline \multicolumn{6}{|c|}{ Summary comparisons } \\
\hline Total volume $\left(\mathrm{m}^{3}\right)$ removed due to gravel mining ${ }^{1}$ & - & - & 160,000 & 310,000 & 185,000 \\
\hline $\begin{array}{l}\text { Total bed-material }\left(\mathrm{m}^{3}\right) \text { influx as calculated by transport } \\
\text { equations }{ }^{2}\end{array}$ & - & - & $\begin{array}{r}390,000 \text { to } \\
530,000\end{array}$ & $\begin{array}{r}190,000 \text { to } \\
270,000\end{array}$ & $\begin{array}{r}200,000 \text { to } \\
270,000\end{array}$ \\
\hline $\begin{array}{l}\text { Average annual lower Chetco River influx from bedload } \\
\text { transport equations }{ }^{4}\left(\mathrm{~m}^{3} / \mathrm{yr}\right)\end{array}$ & - & - & $\begin{array}{l}78,000 \text { to } \\
106,000\end{array}$ & $\begin{array}{r}38,000 \text { to } \\
54,000\end{array}$ & $\begin{array}{r}67,000 \text { to } \\
90,000\end{array}$ \\
\hline $\begin{array}{l}\text { Annual lower Chetco River bed-material influx as } \\
\text { calculated from range of flow-adjusted morphologic } \\
\text { estimates, accounting for gravel extraction volumes, } \\
\text { and assuming no bed-material transport out the lower } \\
\text { river }\left(\mathrm{m}^{3} / \mathrm{yr}\right)\end{array}$ & $\begin{array}{c}5-12,000 \text { to } \\
14,000\end{array}$ & $\begin{array}{c}5-27,000 \text { to } \\
111,000\end{array}$ & $\begin{array}{l}3,000 \text { to } \\
52,000\end{array}$ & $\begin{array}{r}13,000 \text { to } \\
45,000\end{array}$ & $\begin{array}{r}113,000 \text { to } \\
197,000\end{array}$ \\
\hline
\end{tabular}

More difficult to infer from the aerial photograph pairs is the thickness of bed material involved in areas of erosion and deposition, a critical parameter for estimating volumes. The approach was to designate characteristic bar thicknesses for each reach and then multiply by erosional and depositional areas to obtain corresponding volumes. An upper limit for characteristic bar thickness was determined from measurements of average bar elevation above the channel thalweg, measured by GIS analysis of the channel and LIDAR topographic measurements for 543 orthogonals spaced at 30-m intervals along the channel centerline and stratified by reach (fig. 36). Calculated in this manner, average bar height in 2008 ranged from $2.4 \mathrm{~m}$ in the North Fork Reach to $3.7 \mathrm{~m}$ for the Emily Creek Reach.

To determine a lower bound, and one that probably reflects deposit thickness for newly formed bars, we used the same analysis but evaluated elevations only from bars created between 2005 and 2008 (fig. 36), resulting in estimates of "new bar" average thicknesses between 1.5 and $2.3 \mathrm{~m}$ (relative to thalweg) depending on reach. Implicit in using these new-bar values for earlier analysis periods is that the relation between channel thalweg elevation and bar height is similar for all periods. As shown from the channel change analysis, however, this assumption probably is not valid for certain periods, and the channel lowering after the late 1970s (without substantial coincident bar lowering) may result in volume overestimates for earlier periods, especially for 1939-43 and 1962-65, which predate channel incision. Also difficult to infer from aerial photographs is the thickness of deposition or scour on surfaces not changing status during an observation period, including gravel bars and areas within the low-flow channel. These volumes are not considered by our analysis, but could be evaluated in future analyses with additional LIDAR topography or high resolution topographic surveys. 
FLOOD-PLAIN KILOMETER

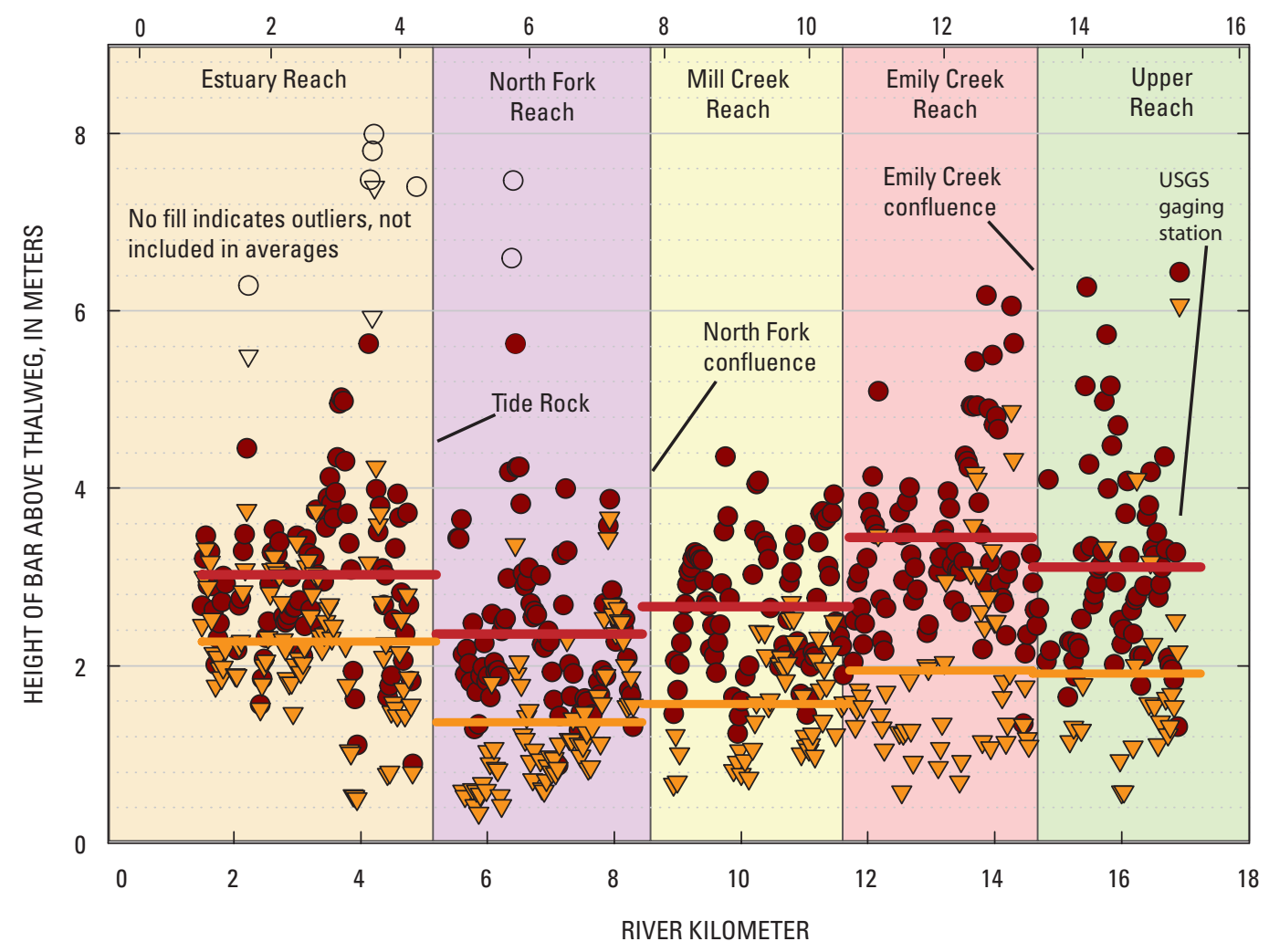

\section{EXPLANATION}

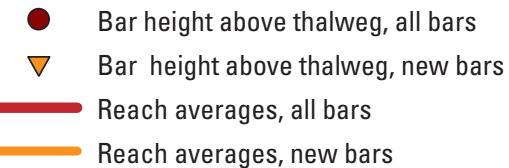

Figure 36. Bar thickness values used to calculate erosion and deposition volumes from changes in bar area in the Chetco River, Oregon. Values determined by difference of average bar elevation and thalweg elevation at 30-m intervals along the flood-plain centerline, and averaged for each reach. "All bars" include all bars mapped from 2008 LIDAR topography. "New bars" are bars that formed between 2005 and 2008, are typically lower, and are inferred to represent the thickness of new deposits. 


\section{Assessment of Sediment Volumes from Morphologic Analysis}

On the basis of three depositional and erosional thickness scenarios, we calculated areas and volumes of erosion and deposition for each of the five periods and for each of the five reaches (fig. 35, table 7). The three scenarios involved multiplying the areas of erosion and deposition by (1) reachaverage values for average bar thickness, (2) reach-average values for average new-bar thickness, and (3) what we determined as the most realistic scenario of calculating erosional volumes by multiplying the area of erosion by the average thickness of all bars but using the average thickness of the new bars for calculating depositional volumes. This latter scenario is certainly most appropriate for the 2005-08 period, because the value for the average thickness of new bars was obtained specifically for this period. The analysis shows that for all scenarios, measured deposition and erosion areas and volumes as determined from changes in bar area are larger in the downstream reaches (fig. 35, table 7). The analysis for this period also indicates that for most periods and reaches, this measurement approach shows more deposition than erosion. The periods of greatest positive net change, after accounting for differences in flow, were 1962-65 and 2005-08, both of which spanned major floods. The relatively dry 2000-2005 period is the only period for which every reach apparently lost bed-material volume, even after accounting for the higher flow on the 2005 aerial photographs.

Estimating actual transport rates requires additional assumptions. The simplest situation and the one applied in this study is to assume no gravel transport from the river to the ocean, and to consider the net changes to represent bedmaterial influx rates for the entire lower Chetco River. This approach has been applied to several of the British Columbia studies, in which bed-material fines downstream and the channels transition from gravel to sand bed (Martin and Church, 1995; McLean and Church, 1999; Ham and Church, 2000). This assumption may not apply perfectly to the Chetco River because of the historical presence of isolated gravel bars downstream to FPkm 1. Nevertheless, the few bars in the lower $3 \mathrm{~km}$, the downstream reduction in bed-material grain size (fig. 22), and the 80- to 90-percent decrease in transport capacity (fig. 31) predicted by the transport equations for conditions in 2008 indicate that the flux of gravel-size bed material exiting the study reach is a small fraction of that entering the study reach. Accordingly, the net volume accumulated in the study reach is a minimum indication of bed-material flux at the upstream end of the study reach. A more complete assessment includes the volume removed by gravel extraction (Martin and Church, 1995), thereby implicitly assuming that the mining volumes have been replenished without substantially affecting bar and channel boundaries. This assumption is approximately correct for the Chetco River where recent gravel extraction has been by bar skimming at locations away from the low channel, and repeat surveys show substantial replenishment most years (Ted Freeman, Freeman Rock Inc. and Robert Elayer, Tidewater Contractors Inc., written commun., 2008). Therefore, for the summary calculation of lower Chetco River bed-material influx from the morphologic approach, we have added the reported volumes of mined gravel for 1995-2000, 2000-2005, and 2005-08 (table 7).

Total volumetric changes and flux estimates are best assessed for the more recent periods for which thickness estimates are most valid and periods when the most reliable estimates of the volume of gravel extracted by mining are available. For the $2005-08$, the total calculated net volume change ranges from 179,000 to $440,000 \mathrm{~m}^{3}$ for the three thickness scenarios (table 7). The low end of this range is from our preferred scenario of using average thickness of all bars to calculate erosional volumes but only the thickness of new bars to determine depositional volumes, and gives an annual net volume of $59,000 \mathrm{~m}^{3} / \mathrm{yr}$. Adjusting this value for the difference in discharge in the source imagery for the 2005 and 2008 mapping lowers the average bed-material sediment balance to about $51,000 \mathrm{~m}^{3} / \mathrm{yr}$. Accounting for the $62,000 \mathrm{~m}^{3} / \mathrm{yr}$ removed by gravel mining during 2005-07 (the LIDAR topography of 2008 was acquired before that year's gravel mining) results in an estimated total gravel influx into the lower Chetco River of $113,000 \mathrm{~m}^{3} / \mathrm{yr}$ for the 2005-08 analysis period. This value is probably best considered a minimum value as a consequence of (1) the negative biases inherent in the method, especially for periods spanning multiple transport events (Martin and Church, 1995), (2) the assumption that little bed-material leaves the river, and (3) our selection of a thickness scenario that minimizes positive volumes; although incomplete replenishment of mined areas would bias this value positively. Similar calculations for the other two analysis periods with gravel extraction data indicate annual bed-material influxes ranging from $3,000 \mathrm{~m}^{3} / \mathrm{yr}$ during 1995-2000 up to the $45,000 \mathrm{~m}^{3} / \mathrm{yr}$ measured for $2000-05$. For the earlier periods for which no reliable gravel extraction information is available, annual influx rates, considering only the changes in bar area, are small for 1939-43 (12,000 to $\left.14,000 \mathrm{~m}^{3} / \mathrm{yr}\right)$ and possibly large for $1962-65(27,000$ to $111,000 \mathrm{~m}^{3} / \mathrm{yr}$ ), but the wide range resulting from the various thickness scenarios and the undetermined volume of removed gravel makes these values highly uncertain.

The high influx values for 2005-08 compared to the lower values calculated for 2000-05 correspond with overall high and low flow for those periods (fig. 2). Additionally, the values of annual influx, considering the range of thickness scenarios, correspond within a factor of 3 to those values predicted by the bedload transport equations for these two periods. For 1995-2000, however, the morphologic method predicts substantially smaller influxes than the transport equations. 
The spatial variations in areas of erosion and deposition are consistent with the overall geomorphology (ig. 35). The Upper Reach has had only small net changes in sediment accumulation volumes, and this narrow section apparently has little dynamic storage. We infer that the gravel bars within this reach have morphologies in approximate equilibrium between deposition and erosion, with entrainment approximately balanced by deposition during each transporting flow. More dynamic storage has been accommodated by the wider and lower gradient reaches downstream, particularly the Mill Creek, North Fork, and Estuary reaches. For the Estuary Reach in particular, there has been bar growth during the analysis periods, though this observation is counter to the overall trend for this reach during the entire historical period (figs. 9 and $\underline{10})$.

Although the morphologic analysis as applied here shows the main areas of deposition and offers broad constraints on deposition and erosional volumes which can in turn provide estimates of total bed-material influxes, the multiple assumptions and uncertainties reduce precision and accuracy. The main factors hindering robust estimates are (1) the multiple year periods between photograph sets, (2) the usage of planview change as a means of estimating volumetric changes and the resulting uncertainty due to poor knowledge of the thickness of eroded and deposited areas, and (3) the substantial effects of flow stage in determining areas of erosion and deposition. For the Chetco River, these issues could be overcome by a sustained program of repeated high-resolution topographic and bathymetric surveys. More accurate morphometric estimates of sediment accumulation and erosion could be made from such surveys, for which the LIDAR topography of 2008 could serve as high-quality starting point.

\section{Bed-Material Sediment Budget for the Lower Chetco River}

Consideration of all these bed-material analyses allows for an approximate sediment budget broadly consistent with many of the study observations (fig. 37). As calculated from the transport capacity equations, the average bed-material influx into the upstream end of the study reach for the 39-year period of 1970-2008 was probably in the range of 40,000 to $100,000 \mathrm{~m}^{3} / \mathrm{yr}$. Approximately 5-30 percent of this influx is probably lost to particle attrition and breakdown, and is carried to the Pacific Ocean or

\section{Upper Chetco River Watershed}

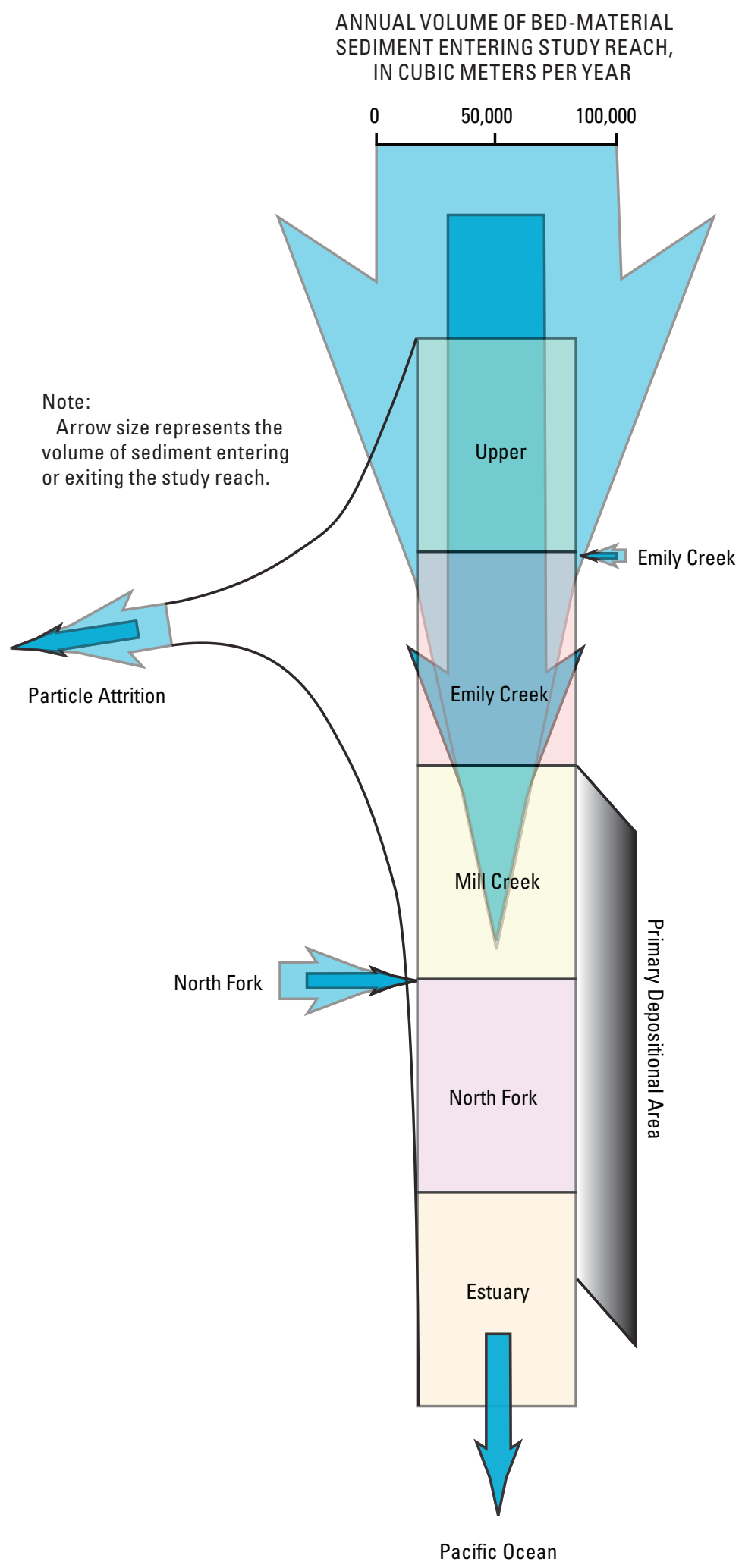

Figure 37. Sediment budget for the lower Chetco River, Oregon. Arrow widths are proportional to annual flux; ranges indicate estimated uncertainty. 
overbank areas by suspended load transport. The volume lost to bed-material attrition is approximately balanced by bed material supplied by tributaries to the lower Chetco River. The transport capacity calculations, channel mapping, and morphologic analyses indicate that most of the bed-material influx has been accumulating in depositional areas within the Mill Creek, North Fork, and Estuary reaches, with perhaps little bed-material sediment exiting the lower river. Net deposition in these reaches approximately matches or slightly exceeds the $59,000 \mathrm{~m}^{3} / \mathrm{yr}$ extracted for aggregate during 2000-2008, but was almost certainly exceeded by the 1976-80 rate of 140,000 $\mathrm{m}^{3} / \mathrm{yr}$ (Marquess and Associates, 1980). The substantial downstream fining and transport capacity equations indicate that most bed-material is likely retained in the lower Chetco River, with little transport, especially of gravel, to the Pacific Ocean.

\section{Comparison with Sediment Yield from Regional Drainage Basins}

Although there has been little previous work on Chetco River sediment transport, geologic analyses and studies of other drainage basins allow for comparisons and evaluation of the reasonableness of the results obtained in this study. The key focus of this study was bed-material influx into the study reach because this is a central issue to understanding overall sediment conditions. From a wide range of considerations, including geologic uplift rates, hillslope sediment production, and actual bed-material measurement programs, estimates for bed-material production were determined to range from 26 to $610\left(\mathrm{~m}^{3} / \mathrm{km}^{2}\right) / \mathrm{yr}$ for several northern California and southern
Oregon coastal drainage basins, with most values being between 40 and $180 \mathrm{~m}^{3} / \mathrm{km}^{2} / \mathrm{yr}$ (table 8). This range translates to $28,000-126,000 \mathrm{~m}^{3} / \mathrm{yr}$ for the $702 \mathrm{~km}^{2}$ contributing area at the upstream end of the Chetco River study reach, encompassing the $40,000-100,000 \mathrm{~m}^{3} / \mathrm{yr}$ predicted by the transport capacity equations and many of the period influx rates indicated by the morphologic analyses (table 7).

\section{Summary of Bed-Material Observations and Analyses}

These analyses of bed material, transport measurements and calculations, and deposition and erosion patterns support the following observations and conclusions regarding sediment in the Chetco River.

The geologic and geomorphic environment of the lower Chetco River is of long-term bed-material accumulation in response to Holocene sea level rise. The present locus of sedimentation (and consequent channel dynamism) is in the area of the North Fork confluence. Recent and ongoing uplift in conjunction with active hillslope erosion processes supply abundant coarse detritus to the channel from much of the drainage basin.

The alluvial valley bottom, bed-sediment textures, armoring ratios, and close agreement between transport relations for bed-material transport indicate a balance between sediment supply and transport capacity at the upstream end of the study reach. Hence, Chetco River bed-material transport into the lower Chetco River is probably limited by transport capacity, rather than sediment supply.

Table 8. Sources for estimates of bedload production rates for coastal drainage basins in northern California and southern Oregon.

[Where applicable, bedload was assumed to be 20 percent of total load. Sediment production rates for this study were scaled to the contributing area at U.S. Geological Survey streamflow-gaging station 14400000, drainage area, $702 \mathrm{~km}^{2}$. A bbreviations: $\mathrm{km}^{2}$, square kilometer; $\left(\mathrm{m}^{3} / \mathrm{km}^{2}\right) / \mathrm{yr}$, cubic meter per square kilometer per year]

\begin{tabular}{|c|c|c|c|c|}
\hline Source & Area of study & $\begin{array}{c}\text { Period } \\
\text { described }\end{array}$ & Method & $\begin{array}{c}\text { Bedload production } \\
\text { rates } \\
{\left[\left(\mathrm{m}^{3} / \mathrm{km}^{2}\right) / \mathrm{yr}\right]}\end{array}$ \\
\hline Kelsey and Bockheim, 1994 & $\begin{array}{l}\text { Southern Oregon Coast, } \\
\text { including Chetco Bay }\end{array}$ & Holocene & $\begin{array}{l}\text { Uplift rate, assuming } \\
\text { equilibrium }\end{array}$ & $140-180$ \\
\hline $\begin{array}{l}\text { E.G. Andrews, U.S. } \\
\text { Geological Survey, } \\
\text { written commun., } 2008\end{array}$ & Northern California Rivers & 1950-2006 & Bedload equation & $26-610$ \\
\hline Raines and Kelsey, 1991 & Grouse Creek, California & 1960-1989 & Landslide volume analysis & 130 \\
\hline Russell, 1994 & Pistol River, Oregon & 1940-1991 & Landslide volume analysis & 80-110 \\
\hline MFG, Inc., 2006 & Smith River, Oregon & 1932-2003 & Calibrated bedload equation & 40 \\
\hline
\end{tabular}


Applying established transport equations for multiple cross sections at the upstream end of the reach gives likely mean annual bed-material transport rates into the lower Chetco River of approximately $40,000-100,000 \mathrm{~m}^{3} / \mathrm{yr}$ for water years 1970-2008, with the reference cross section at the upstream end of the study reach giving a narrower range of 51,100 to 73,900 $\mathrm{m}^{3} / \mathrm{yr}$ (fig. 31). On a per unit area, the influx values for the Chetco River are similar to those values from nearby coastal drainage basins (table 8). Because of year-to-year flow variability, predicted influx of bed-material ranges from less than $3,000 \mathrm{~m}^{3}$ in dry years to greater than $150,000 \mathrm{~m}^{3}$ for wet years with large floods such as 1982 and 1997 (fig. 32).

Transport capacity, as predicted by the transport equations, diminishes substantially downstream, from values approaching the influx rates in the Upper and Emily Creek reaches to less than 10,000 $\mathrm{m}^{3} / \mathrm{yr}$ for the North Fork and Estuary reaches (fig. 31). The decreased transport capacity of these downstream reaches is consistent with these reaches being long-term areas of sedimentation as indicated by active channel migration and bar deposition (iggs. 12 and $\underline{13}$ ).

The morphologic approach to estimating bed-material influx into the study reach gives a much wider range of results, with annual reach-scale net volume changes reaching as much as $200,000 \mathrm{~m}^{3} / \mathrm{yr}$ for the $2005-08$ period. For this period, this rate of bed-sediment influx is about twice that predicted by the transport relation equations. For the other two periods when the methods can be compared (1995-2000 and 2000-05), the morphologic approach gives influx rates equivalent, or less than, that predicted by the bed-material transport relations (table 7). The assumptions and uncertainties intrinsic to the morphologic approach when based on historical aerial photographs reduce the utility of the morphologic analyses as applied for the Chetco River. But this approach could be valuable and much more accurate if based on annually collected high-resolution topographic data.

Analysis of downstream fining and particle attrition shows that approximately 5-30 percent of the bed-material volume is worn down and transported out of the reach through particle breakage and attrition. The volume lost through attrition is approximately balanced by bed-material input from tributaries entering the study area.

The predicted downstream decrease in transport capacity, the small bed-sediment particle sizes in the downstream bars, and the rough congruence between the net volume changes determined from the morphologic method with the predicted sediment influx into the reach indicate that, in the absence of gravel extraction, most bed-material sediment entering into the lower Chetco River remains in the study area, with most probably stored in the Mill Creek, North Fork, and Estuary reaches.

Comprehensive measurements of particle size at bars along the study area shows armoring ratios and surface particle size increase, between the Upper and North Fork reaches (fig. 22). This downstream increase in surface coarsening may indicate that sediment supply in the North Fork and Estuary reaches is less than flow capacity.

The best estimates of mean annual bed-material influx from this study $-40,000-100,000 \mathrm{~m}^{3} / \mathrm{yr}$ - are of similar magnitude or slightly exceed the volume of gravel mined for the 1993-2008 period (fig. 6). For low flow years such as 2001, gravel extraction almost certainly exceeded supply. For high-flow years such as 2006, bed-material influx likely exceeded the volume mined. The voluminous gravel mining in the late 1970s (Marquess and Associates, 1980) probably exceeded replenishment rates by at least a factor of 3 .

\section{Summary}

The analysis of the lower 16 kilometers of the gravel-bed Chetco River and its flood plain focused on understanding bed-material transport and its relation to channel and flood-plain morphology. The main study components were (1) detailed mapping and surveying of the valley bottom to document spatial and temporal changes to the channel and flanking bars and flood plains and (2) quantitative investigation of the flux of bed material into and through the study reach. These study components have resulted in a mutually consistent and coherent understanding of the recent history of the active channel and how observed changes may relate to the influx and removal of bed sediment.

\section{Primary Findings}

The Chetco River is a wandering gravel-bed river flanked by abundant and large gravel bars formed of coarse bedmaterial sediment. The upper reaches of the study area are primarily transport zones, with bar positions fixed by valley geometry and the active bars mainly providing transient storage of bed material. The lower river has been aggrading in response to Holocene sea level rise. The Mill Creek and North Fork reaches, between flood-plain kilometers (FPkm) 5 and 10 , have historically been the primary area of this aggradation, with consequent active sedimentation and channel migration. Sediment transport capacity is limited in this reach and most net sediment influx into the study area probably accumulates here. A small amount of fine gravel is transported into the Estuary Reach. It is plausible that little gravel-sized bed sediment exits the Chetco River naturally.

The repeat surveys and map analyses indicate an overall reduction in bar area and local decreases in sinuosity, mainly between 1965 and 1995. Some loss of bar area is due to erosion and some has resulted from vegetation colonization and transition to vegetated and developed flood-plain surfaces. 
Repeat topographic and bathymetric surveys indicate channel incision for large parts of the study reach, with some areas of the North Fork, Mill Creek and Emily reaches incising as much as $2 \mathrm{~m}$. The specific gage analysis at the upstream end of the study reach indicates that recent incision may have followed aggradation culminating in the late 1970s. These observations are consistent with a reduction of sediment supply relative to transport capacity after at least the channel surveys of 1977. Also consistent with this sediment imbalance is the trend of bed coarsening between FPkms 15.3 and 7.7 and the greater degree of armoring for the bars at FPkm 6 and 3 compared to a measurement at the upstream end of the reach.

Multiple and independent analyses, supported by direct measurements of bedload during winter 2008-09, indicate that the mean annual flux of bed material into the study reach is approximately 40,000-100,000 m³/yr after 1970 . The year-to-year flux, however, varies tremendously, with some years probably having little or no bed-material entering the study reach, but for some high-flow years, such as 1982 and 1997, as much as 190,000 $\mathrm{m}^{3} / \mathrm{yr}$ of bed-material enters the reach. For comparison, the estimated annual volume of gravel extracted from the lower Chetco River for commercial aggregate has ranged from 5,000 to $90,000 \mathrm{~m}^{3}$ and averaged about 59,000 $\mathrm{m}^{3} / \mathrm{yr}$ between 2000 and 2008. Mined volumes, however, probably exceeded $140,000 \mathrm{~m}^{3} / \mathrm{yr}$ for several years in the late 1970s, greatly surpassing likely replenishment rates.

The historical planform and vertical changes to the lower Chetco River, which almost certainly exist because of a reduced sediment supply relative to transport capacity, have likely resulted from a combination of (1) bed-sediment removal and (2) transient effects as the river has adjusted to the probable large volume of sediment brought in by the flood of 1964. Fully disentangling these factors is not possible with the information available.

\section{Implications Regarding Possible Future Trends and Monitoring Strategies}

For a gravel-bed river such as the lower Chetco River, the physical character of the active channel is chiefly the result of bed-material transport processes. At the broad scale, the balance between bed-material transport capacity and sediment supply controls channel morphology. Details of channel conditions depend, however, on various factors including the history of flow and sediment transport, the time lags involved in eroding and depositing sediment, and other local and drainage-basin-scale disturbances that might directly or indirectly affect the channel.

Despite these complexities, if gravel removal exceeds bed-material influx, decreased bar areas and channel incision probably will ensue, similar to the conditions of the late 1970s and 1980s. Such changes likely will be in conjunction with bed coarsening and possibly greater armoring of bar surfaces. Another probable outcome of a sediment deficit would be reduced migration rates, because bar deposition is a major cause of channel migration. Without gravel extraction, aggradation and enhanced channel migration is likely, probably first in the historical sedimentation area of the Mill Creek and North Fork reaches. Because of the low transport capacity in these middle reaches, effects of enhanced sediment supply would probably take longer to affect the Estuary Reach. The time scales of changes depend foremost on sediment influx. A large influx associated with a flood like the one in 1964 could reverse most historical changes during the event. In contrast, the effects of sustained periods of excess transport capacity relative to sediment influx are likely to be manifest over years and decades, and possibly at diminishing rates as the channel and bars coarsen.

Because the sediment balance is a controlling factor, a key aspect of understanding possible effects of various management scenarios on the lower Chetco River is accurate knowledge of the volume of the influx of bed material. For the Chetco River, the bed-material capacity equations applied to the flow record provide seemingly reasonable estimates of bed-material influx to the lower river. This situation offers the opportunity, as long as continuous streamflow measurements are available, to provide annual (or even higher resolution) predictions of the volume of bed-material influx that could be used to guide management actions. Such analyses would be enhanced by a sustained bed-material measurement program, ideally involving at least one or two bedload transport measurements per year, to evaluate the reliability of the transport equations and ultimately develop a site specific bedload transport rating curve.

Another key for improving predictions of channel conditions and documenting effects of management actions is understanding the fate and effects of bed-material sediment entering the reach. Repeat high-resolution topographic and bathymetric surveys of the entire active channel will (1) document the rates at which sediment is moving through the system, (2) allow identification of trends in vertical and planform channel behavior, and (3) provide independent assessment of the sediment influx and transport. Such surveys would ideally be supplemented by periodic bed-material sediment sampling for evaluating bed texture trends. Besides providing for direct and systematic monitoring of the active channel and enhancing understanding of key transport processes, this knowledge may be important for determining relevant management time-scales by providing information on how long it may take the effects of management actions to have desired or detectable outcomes. In contrast, reach-scale interrelations between sediment supply and channel and flood-plain characteristics limit the utility of site-specific topographic surveys for predicting and monitoring conditions in a manner responsive to typical management requirements. 
From these considerations, an efficient and credible monitoring program would focus mainly on system-wide assessments of sediment influx and channel change. Sediment influx would probably be most reliably evaluated by annual analysis of the streamflow record, ideally supplemented by continued bedload transport measurements in order to improve the accuracy of the influx predictions and to confirm that the capacity-based equations remain appropriate. Continued channel-change assessments could be efficiently based on the LIDAR topographic and estuary and channel surveys from 2008. Repeat high-resolution surveys at 1-year intervals would enable an independent check of the influx estimates as well as allow monitoring of trends in channel and floodplain conditions. These types of surveys could replace the site specific surveys with little or no loss of information relevant to trend monitoring. Even at lesser intervals, such surveys would probably provide trends and data useful for evaluating planform and vertical changes in the active channel. Monitoring of bedsediment texture and vegetation could be less frequent (for example, 5-10 years) and would allow evaluation of how these habitat attributes are changing with overall channel condition.

\section{Acknowledgments}

This study was guided by the State of Oregon Technical Team for instream gravel mining, chaired by Judy Linton of the Portland District of the U.S. Army Corps of Engineers, and including representatives from Oregon Department of State Lands, National Oceanic and Atmospheric Administration Fisheries, U.S. Fish and Wildlife Service, Oregon Department of Fish and Wildlife, Oregon Department of Environmental Quality, Oregon Coastal Management Program, and area gravel-mining companies. Surveying and bedload measurements were provided by the Central Point Field Office of the USGS Oregon Water Science Center under the leadership of Marc Stewart with guidance and analysis from Richard Kittelson and Roy Wellman of the Portland Field Office. John Risley of the USGS Oregon Water Science Center assisted with extending the streamflow record and Michelle Adams assisted with field measurements. Information on past gravel mining and access to measurement sites were provided by Tidewater Contractors Inc., South Coast Lumber Inc., and Freeman Rock Inc.; in particular Ted Freeman, Robert Elayer, Bill Yocum, Fred Arnold, and Virgil Frazer were supportive. Ian Madin of the Oregon Department of Geology and Mineral Resources expedited transfer of LIDAR topography for our use. Bedload transport modeling was facilitated by provision of and assistance with the Bedload Assessment for Gravel-bed Streams (BAGS) software by John Pitlick, Yantao Cui, and Peter Wilcock. Robyn Darbyshire, U.S. Forest Service, provided assistance with vegetation identification. Mackenzie Keith of the USGS Oregon Water Science Center provided valuable assistance with manuscript preparation. The report was reviewed by Erich Mueller (University of Colorado), Mary Ann Madej (USGS), and William Langer (USGS).

\section{References Cited}

American Society of Civil Engineers, 1999, Topographic surveying - Technical engineering and design guides as adapted from the U.S. Army Corps of Engineers, no. 29: American Society of Civil Engineers, 95 p.

Bakke, P.D., Basdekas, P.O., Dawdy, D.R., and Klingeman, P.C., 1999, Calibrated Parker-Klingeman model for gravel transport: Journal of Hydraulic Engineering, v. 125, p. 657-660.

Bowling, L.C., Storck, Pascal, and Lettenmaier, D.P., 2000, Hydrologic effects of logging in Western Washington, United States: Water Resources Research, v. 36, no. 11, p. 3223-3240.

Buffington, J.M., and Montgomery, D.R., 1999, Effects of sediment supply on surface textures of gravel-bed rivers: Water Resources Research, v. 35, no. 11, p. 3523-3530.

Bunte, Kristin, and Abt, S.R., 2001, Sampling surface and subsurface particle-size distributions in wadable gravel and cobble-bed streams for analyses in sediment transport, hydraulics, and stream-bed monitoring: U.S. Department of Agriculture, Forest Service, Rocky Mountain Research Station, General Technical Report RMRS-GTR-74, 428 p.

Burgette, R.J., Weldon II, R.J., and Schmidt, D.A., 2009, Interseismic uplift rates for western Oregon and alongstrike variation in locking on the Cascadia subduction zone: Journal of Geophysical Research, v. 114, p. B01408. doi:10.1029/2008JB005679.

Chetco Watershed Council, 1995, Chetco River assessment: Chetco Watershed Council, 28 p.

Childers, Dallas, 1992, Field comparison of four pressuredifference bedload samplers in high-energy flows: U.S. Geological Survey Water-Resources Investigations Report 92-4068, 59 p.

Church, Michael, 1983, Pattern of instability in a wandering gravel bed channel, in Collinson, J.D., and Lewis, J., eds., Modern and ancient fluvial systems: International Association of Sedimentologists Special Publication 6, p. 169-180.

Church, Michael, 1988, Floods in cold climates, in Baker, V.R., Kochel, R.C., and Patton, P.C., eds., Flood geomorphology: New York, John Wiley and Sons, p. 205-229.

Church, Michael, McLean, D.G., and Wolcott, D.F., 1987, River bed gravels: sampling and analysis, in Thorne, C.R., Bathurst, J.C., and Hey, R.D., eds., Sediment transport in gravel-bed rivers: Chichester, John Wiley and Sons, p. 43-88. 
Collins, B.D., and Dunne, Thomas, 1989, Gravel transport, gravel harvesting, and channel-bed degradation in rivers draining the southern Olympic mountains, Washington, U.S.A.: Environmental Geology, v. 13, no. 3, p. 213-224.

Dietrich, W.E., Kirchner, J.W., Ikeda, Hiroshi, and Iseya, Fujiko, 1989, Sediment supply and the development of the coarse surface later in gravel-bedded rivers: Nature, v. 340, no. 6230, p. 215-217.

Edwards, T.K., and Glysson, G.D., 1999, Field methods for measurement of fluvial sediment: U.S. Geological Survey Techniques of Water-Resources Investigations, book 3, chap. C2, 89 p., accessed July 19, 2009, at http://pubs.usgs. gov/twri/twri3-c2/.

Emmett, W.W., 1980, A field calibration of the sedimenttrapping characteristics of the Helley-Smith bedload sampler: U.S. Geological Survey Professional Paper 1139, $44 \mathrm{p}$.

Gaeuman, D.A., Schmidt, J.C., and Wilcock, P.R., 2003, Evaluation of inchannel gravel storage with morphologybased gravel budgets developed from planimetric data: Journal of Geophysical Research, v. 108, no. F1, p. 6001, doi:10.1029/2002JF000002.

Gilbert, G.K., and Murphy, E.C., 1914, The transportation of debris by running water: U.S. Geological Survey Professional Paper 86, p. 263.

Gomez, Basil, 1991, Bedload transport: Earth-Science Reviews, v. 31, no. 2, p. 89-132.

Gomez, Basil, and Church, Michael, 1989, An assessment of bed load sediment transport formulas for gravel bed rivers: Water Resources Research, v. 25, p. 1161-1186.

Gurnell, A.M., 1997, Channel change on the River Dee meanders, 1946-1992, from the analysis of air photographs: Regulated Rivers: Research and Management, v. 13, p. 13-26.

Ham, D.G., and Church, Michael, 2000, Bed-material transport estimated from channel morphodynamicsChilliwack River, British Columbia: Earth Surface Processes and Landforms, v. 25, p. 1123-1142.

Harden, D.R., 1995, A comparison of flood-producing storms and their impacts in northwestern California, in Nolan, K.M., Kelsey, H.M., and Marron, D.C., eds., Geomorphic processes and aquatic habitat in the Redwood Creek basin, northwestern California: U.S. Geological Survey Professional Paper 1454, p. D1-D9.

Hickey, J.J., 1969, Variations in low-water streambed elevations at selected stream-gaging stations in northwestern California: U.S. Geological Survey Water-Supply Paper 1879-E, 33 p.
Hicks, D.M., and Gomez, B., 2003, Sediment transport, in Kondolf, G.M. and Piegay, H., eds., Tools in fluvial geomorphology: Chichester, John Wiley and Sons, p. 425-461.

Hoey, T.B., and Ferguson, R.I., 1994, Numerical simulation of downstream fining by selective transport in gravel-bed rivers-Model development and illustration: Water Resources Research, v. 30, p. 2251-2260.

Hughes, M.L., McDowell, P.F., and Marcus, W.A., 2005 [2006], Accuracy assessment of georectified aerial photographs-Implications for measuring lateral channel movement in GIS: Geomorphology, v. 74, p. 1-16.

Jones, J.A., and Grant, G.E., 1996, Long-term stormflow responses to clearcutting and roads in small and large basins, western Cascades, Oregon: Water Resources Research, v. 32, no. 4, p. 959-974.

Jones, J.A., and Grant, G.E., 2001, Comment on "Peak flow responses to clear-cutting and roads in small and large basins, western Cascades, Oregon" by Jones, J.A., and Grant, G.E.: Water Resources Research, v. 37, no. 1, p. 179-180.

Kelsey, H.M., 1980, A sediment budget and an analysis of geomorphic process in the Van Duzen River basin, north coastal California, 1941-1975-Summary: Geological Society of American bulletin, v. 91, no. 4, p. 190-195.

Kelsey, H.M., and Bockheim, J.G., 1994, Coastal landscape evolution as a function of eustasy and surface uplift rate, Cascadia margin, southern Oregon: Geological Society of American Bulletin 106, p. 840-854.

Kelsey, H.M., Coghlan, Mike, Pitlick, John, and Best, David, 1995, Geomorphic analysis of streamside landslides in the Redwood Creek basin, northwestern California, in Nolan, K.M., Kelsey, H.M., and Marron, D.C., eds., Geomorphic processes and aquatic habitat in the Redwood Creek basin, northwestern California: U.S. Geological Survey Professional Paper 1454, p. J1-J12.

Kelsey, H.M., Engebretson, D.C., Mitchell, C.E., and Ticknor, R.L., 1994, Topographic form of the Coast Ranges of the Cascadia margin in relation to coastal uplift rates and plate subduction: Journal of Geophysical Research, v. 99, no. B6 p.12245-12255.

Klingeman, P.C., 1973, Indications of streambed degradation in the Willamette Valley: WRRI-21, Water Resources Research Institute Report WRRI-21, Corvallis, Department of Civil Engineering, Oregon State University, 99 p.

Klingeman, P.C., 1993, Chetco River, Oregon-Hydrologic/ hydraulic/morphologic analyses of navigability: Report to Oregon Department of Justice, $47 \mathrm{p}$. 
Kodama, Yoshinori, 1994, Downstream changes in the lithology and grain size of fluvial gravels, the Watarase River, Japan; evidence of the role of abrasion in downstream fining: Journal of Sedimentary Research, v. 64, p. 68-75.

Komar, P.D., 1997, The Pacific Northwest coast—Living with the shores of Oregon and Washington: Durham, North Carolina, Duke University Press, 195 p.

Kondolf, G.M., 1994, Geomorphic and environmental effects of instream gravel mining: Landscape and Urban Planning, v. 28, no. 2-3, p. 225-243.

Kondolf, G.M., 1997, Hungry water-Effects of dams and gravel mining on river channels: Environmental Management, v. 21, no. 4, p. 533-551.

Kondolf, G.M., Lisle, T.E., and Wolman, G.M., 2003, Bed sediment measurement, in Kondolf, G.M., and Piegay, H., eds., Tools in fluvial geomorphology: Chichester, John Wiley and Sons, p. 347-395.

Kulm., L.D., and Byrne, J.V., 1966, Sediment response to hydrography in an Oregon estuary: Marine Geology, v. 4, p. 85-118.

Lindsay, J.B., and Ashmore, P.E., 2002, The effects of survey frequency on estimates of scour and fill in a braided river model: Earth Surface Processes and Landforms, v. 27, p. 27-43.

Lisle, T.E., 1981, Recovery of aggraded stream channels at gauging stations in northern California and southern Oregon, erosion and sediment transport in Pacific Rim steeplands, in Davies, T.R.H., and Pearce, A.J., eds., International Association of Hydrological Sciences: AISH Publication 132, p. 189-211.

Lisle, T.E., 1995, Particle size variations between bed load and bed material in natural gravel bed channels: Water Resources Research, v. 31, no. 4, p. 1107-1118.

Lisle, T.E., Nelson, J.M., Pitlick, John, Madej, M.A., and Barkett, B.L., 2000, Variability of bed mobility in natural, gravel-bed channels and adjustments to sediment load at local and reach scales: Water Resources Research, v. 36, no. 12, p. 3743-3755.

MFG, Inc., Graham Matherws and Associates, and Alice Berg and Associates, 2006, Assessment of the lower Smith River: Report prepared for County of Del Norte, Crescent City, California, $41 \mathrm{p}$.

Mackin, J.H., 1948, Concept of the graded river: Geological Society of America Bulletin, v. 59, p. 463-512.
Madej, M.A., 1995, Changes in channel-stored sediment, Redwood Creek, northwestern California, 1947 to 1980, in Nolan, K.M., Kelsey, H.M., and Marron, D.C., eds., Geomorphic processes and aquatic habitat in the Redwood Creek basin, northwestern California: U.S. Geological Survey Professional Paper 1454, p. O1-O27.

Maguire, Mike, 2001, Chetco River watershed assessment: Gold Beach, Oregon, Chetco River Watershed Council by the South Coast Watershed Council, 106 p.

Marquess and Associates, Inc., 1980, Chectco River survey and permit analysis: Medford, Oregon, Marquess and Associates, Inc., 12 p.

Martin, Y.E., and Church, Michael, 1995, Bed-material transport estimated from channel surveys-Vedder River, British Columbia: Earth Surface Processes and Landforms, v. 20, p. 347-361.

Martin, Y.E., and Ham, D.G., 2005, Testing bedload transport formulae using morphologic transport estimates and field data-lower Fraser River, British Columbia: Earth Surface Processes and Landforms, v. 30, p. 1265-1282.

McLean, D.G., and Church, Michael, 1999, Sediment transport along lower Fraser River 2-Estimates based on the long-term gravel budget: Water Resources Research, v. 35, no. 8, p. 2549-2559.

Merwade, V.M., Maidment, D.R., and Hodges, B.R., 2005, Geospatial representation of river channels: ASCE Journal of Hydrologic Engineering, v. 10, no. 3, p. 243-251.

Milhous, R.T., 1973. Sediment transport in a gravel-bottomed stream: Corvallis, Oregon State University, Ph.D. dissertation, $232 \mathrm{p}$.

Milhous, R.T., 2001, Specific weight and median size of the bed material of gravel and cobble bed rivers, in Proceedings of the Seventh Federal Interagency Sedimentation Conference, March 25-29, 2001, Reno, Nevada: Subcommittee on Sedimentation, Federal Interagency Committee on Water Resources, p. III-70-77.

Mount, N.J., and Louis, John, 2005, Estimation and propagation of error in the measurement of river channel movement from aerial imagery: Earth Surface Processes and Landforms, v. 30, no. 5, p. 635-643.

Mueller, E.R., Pitlick, John, and Nelson, J.M., 2005, Variation in the reference Shields stress for bed load transport in gravel-bed streams and rivers: Water Resources Research, v. 41, 10 p., W04006, doi: 10.1029/2004WR003692.

O’Connor, J.E., Jones, M.A., and Haluska, T.L., 2003, Flood plain and channel dynamics of the Quinault and Queets Rivers, Washington, USA: Geomorphology, v. 51, p. 31-59. 
O’Connor, J.E., Wallick, J.R., Sobieszczyk, Steven, Cannon, Charles, and Anderson, S.W., 2009, Preliminary assessment of vertical stability and grave transport along the Umpqua River, southwestern Oregon: U.S. Geological Survey Open-File Report 2009-1010, 46 p.

Oregon Department of Geology and Mineral Industries, 2009: Lidar collection and mapping-Oregon Lidar Consortium, accessed July 19, 2009, at http://www.oregongeology.org/ sub/projects/olc/default.htm.

Oregon Department of State Lands, 1972, An inventory of filled lands in the Chetco River: Salem, Oregon, Advisory Committee's Engineering Staff for the Advisory Committee to the State Land Board, 15 p.

Orr, E.L., Orr, W.N., and Baldwin, E.M., 1992, Geology of Oregon, 4th ed.: Dubuque, Iowa, Kendall/Hunt Publishing, 254 p.

Paola, Chris, Parker, Gary, Seal, Rebecca, Sinha, S.K., Southard, J.B., and Wilcock, P.R., 1992, Downstream fining by selective deposition in a laboratory flume: Science, v. 258, no. 5089, p. 1757-1760.

Parker, Gary, 1990a, Surface-based bedload transport relation for gravel rivers: Journal of Hydraulic Research, v. 28, no. 4, p. 417-436.

Parker, Gary, 1990b, The ACRONYM series of PASCAL programs for computing bedload transport in gravel rivers: St. Anthony Falls Laboratory, University of Minnesota, External Memorandum M-220, 124 p.

Parker, Gary, and Klingeman, P.C., 1982, On why gravel bed streams are paved: Water Resources Research, v. 18, no. 5, p. 1409-1423.

Parker, Gary, Klingeman, P.C., and McLean, D.G., 1982, Bedload and size distribution in paved gravel-bed streams: Journal of the Hydraulics Division, Proceedings of the American Society of Civil Engineers, v. 109, no. HY4, p. 54-571.

Peterson, C.D., Scheidegger, P.D., and Komar, P.D., 1982, Sand-dispersal patterns in an active-margin estuary of the northwestern United States as indicated by sand composition, texture and bedforms: Marine Geology, v. 50, p. 77-96.

Pitlick, John, 1992, Flow resistance under conditions of intense gravel transport: Water Resources Research, v. 28, no. 3, p. 891-903.

Pitlick, John, Cui, Y.T., and Wilcock, P.R., 2009, Manual for Computing Bed Load Transport Using BAGS (Bedload Assessment for Gravel-bed Streams) Software: Fort Collins, Colorado, U.S. Department of Agriculture, Forest Service, Rocky Mountain Research Station, General Technical Report RMRS-GTR-223, 45 p.
Pitlick, John, Mueller, E.R., Segura, Catalina, Cress, Robert, and Torizzo, Margaret, 2008, Relation between flow, surface-layer armoring and sediment transport in gravel-bed rivers: Earth Surface Processes and Landforms, v. 33, p. 1192-1209.

Plumley, W.J., 1948, Black Hills terrace gravels-A study in sediment transport: Journal of Geology, v. 56, p. 526-577.

Popov, I.V., 1962, A sediment balance of river reaches and its use for the characteristics of the channel process: Soviet Hydrology, v. 3, p. 249-266.

Raines, M.A., and Kelsey, H.M., 1991, Sediment budget for the Grouse Creek basin, Humboldt County, California: Eureka, Calif., Six Rivers National Forest, U.S. Department of Agriculture, 110 p., accessed August 1, 2009, at http:// www.waterboards.ca.gov/water issues/programs/tmdl/ records/region 1/2003/ref1719.pdf.

Ramp, Len, 1975, Geology and mineral resources of the upper Chetco drainage area, Oregon, including the Kalmiopsis Wilderness and Big Craggies Botanical areas: Oregon Department of Geology and Mineral Industries Bulletin 88, $47 \mathrm{p}$.

Ratti, F.D., and Kraeg, R.A., 1979, Natural resources of the Chetco River estuary: Oregon Department of Fish and Wildlife for Oregon Land Conservation and Development Commission, Estuary inventory report, v. 2, no. 9, accessed July 24, 2009, at http://ir.library.oregonstate.edu/jspui/ handle/1957/3183.

Reid, L.M., and Dunne, Thomas, 1996, Rapid evaluation of sediment budgets: Reiskirchen, Germany, Catena Verlag GMBH, 164 p.

Reid, L.M., and Dunne, Thomas, 2003, Sediment budgets as an organizing framework in fluvial geomorphology, in Kondolf, M., and Piégay, H., eds., Tools in fluvial geomorpholgy: Chichester, John Wiley and Sons, p. 463-500.

Rice, K.C., 1999, Trace-element concentrations in streambed sediment across the conterminous United States: Environmental Science and Technology, v. 33, p. 2499-2504.

Ricks, C.L., 1995, Effects of channelization on sediment distribution and aquatic habitat at the mouth of Redwood Creek, northwestern California, in Nolan, K.M., Kelsey, H.M., and Marron, D.C., eds., Geomorphic processes and aquatic habitat in the Redwood Creek basin, northwestern California: U.S. Geological Survey Professional Paper 1454, p. Q1-Q17.

Russell, P.P., 1994, Sediment production and delivery in Pistol River, Oregon and its effects on pool morphology: Corvallis, Oregon State University, MS thesis, 111 p., 29 figs. 
Schmidt, J.C., and Wilcock, P.R., 2008, Metrics for assessing the downstream impacts of dams: Water Resources Research, v. 44, 19 p., W04404, doi: 10.1029/2006WR005092.

Schumm, S.A., and Stevens, M.A., 1973, Abrasion in place-A mechanism for rounding and size reduction of coarse sediments in rivers: Geology, v. 1, p. 37-40.

Shaw, John, and Kellerhals, Rolf, 1982, The composition of recent alluvial gravels in Alberta river beds: Alberta Research Council Bulletin 41, p. 151.

Slotta, L.S., and Tang, S.S., 1976, Chetco River tidal hydrodynamics and associated marina flushing-Final Report: Corvallis, Ocean Engineering Programs, School of Engineering, Oregon State University, Oregon Sea Grant publication, ORESU-T, 76-005, p. 55, accessed July 24, 2009, at http://nsgl.gso.uri.edu/oresu/oresut76005.pdf.

Smelser, M.G., and Schmidt, J.C., 1998, An assessment methodology for determining historical changes in mountain streams: U.S. Department of Agriculture, Forest Service, General Technical Report RMRS-GTR-6, 29 p.

Soil Conservation Service, 1979, Flood hazard study, Chetco River, Curry County Oregon: Portland, Oregon, U.S. Department of Agriculture, $29 \mathrm{p}$.

Stewart, J.H., and LaMarche, V.C., 1967, Erosion and deposition produced by the flood of December 1964, on Coffee Creek, Trinity County, California: U.S. Geological Survey Professional Paper 422-K, 22 p.

Surian, Nicola, and Cisotto, Alberto, 2007, Channel adjustments, bedload transport and sediment sources in a gravel-bed river, Brenta River, Italy: Earth Surface Processes and Landforms, v. 32, p.1641-1656.

U.S. Army Corps of Engineers, 1893, Annual report of the Chief of Engineers, United States Army, to the Secretary of War, for the year 1893 [Part IV]: Washington, U.S. Government Printing Office, 3544 p.

U.S. Army Corps of Engineers, 1939, Chetco River, Oregon-Entrance to Tide Rock-June 20-July 14, 1939 [bathymetric survey]: Portland, Oregon, U.S. Engineer Office, 2 sheets, scale 1:3000.

U.S. Army Corps of Engineers, 2006, HEC-RAS River Analysis System, user's manual, version 4.0 Beta: Davis, California, U.S. Army Corps of Engineers, Institute for Water Resources, Hydrologic Engineering Center, 420 p.

U.S. Environmental Protection Agency, 1999, Van Duzen River and Yager Creek total maximum daily load for sediment: U.S. Environmental Protection Agency Region IX, 65 p., accessed August 1, 2009 at http://www. epa.gov/region09/water/tmdl/vanduzen/vanduzen.pdf.
U.S. Forest Service, 2008, Rogue River national forest data library-Geographic information systems: Washington, DC, U.S. Forest Service, accessed February 26, 2009, at http:// www.fs.fed.us/r6/data-library/gis/rogue-river/index.shtml.

U.S. Forest Service and Bureau of Land Management, 2004, Biscuit fire recovery project, Final environmental impact statement: Medford, Oregon, U.S. Department of Agriculture, Forest Service and U.S. Department of Interior, Bureau of Land Management, [variously paged], accessed July 24, 2009, at http://www.fs.fed.us/r6/rogue-siskiyou/ biscuit-fire/feis.shtml.

U.S. Geological Survey, 2009, Chetco River sediment transport study: U.S. Geological Survey web page, accessed July 19, 2009, at http://or.water.usgs.gov/chetco/.

U.S. Water Resources Council, 1981, Guidelines for determining flood flow frequency, Bulletin 17B of the Hydrology Committee: Washington, D.C., U.S. Government Printing Office [variously paged].

Waananen, A.O., Harris, P.P., and Williams, R.C., 1971, Floods of December 1964 and January 1965 in the Far Western States: U.S. Geological Survey Water Supply Paper 1866-A, 265 p.

Wemple, B.C., Jones, J.A., and Grant, G.E., 1996, Channel network extension by logging roads in two basins, western Cascades, Oregon: Water Resources Bulletin, v. 32, no. 6, p. 1195-1207.

Wilcock, P.R., 2001, Toward a practical method for estimating sediment-transport rates in gravel-bed rivers: Earth Surface Processes and Landforms, v. 26, no. 13, p. 1395-1408.

Wilcock, P.R., Barta, A.F., Shea, C.C., Kondolf, G.M., Matthes, W.V.G., and Pitlick, John, 1996, Observation of flow and sediment transport entrainment on large gravel-bed river: Water Resources Research, v. 32, p. 2897-2909.

Wilcock, P.R., and Crowe, J.C., 2003, Surface-based transport model for mixed-size sediment: Journal of Hydraulic Engineering, American Society of Civil Engineers, v. 129, p. $120-128$.

Wilcock, P.R., Pitlick, John, and Cui, Y.T., 2009, Sediment transport primer-Estimating bed-material transport in gravel-bed rivers: Fort Collins, Colorado, U.S. Department of Agriculture, Forest Service, Rocky Mountain Research Station, General Technical Report RMRS-GTR-226, 78 p.

Wolman, M.G., 1954, A method for sampling coarse river-bed material: American Geophysical Union Transactions: v. 35, p. 951-956. 
Publishing support provided by the U.S. Geological Survey

Publishing Network, Tacoma Publishing Service Center

For more information concerning the research in this report, contact the Director, Oregon Water Science Center

U.S. Geological Survey

2130 SW 5th Avenue

Portland, Oregon 97201

http://or.water.usgs.gov 
